\title{
An Assessment of Flywheel High Power Energy Storage Technology for Hybrid Vehicles
}

\author{
December 2011
}

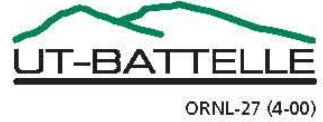




\section{DOCUMENT AVAILABILITY}

Reports produced after January 1, 1996, are generally available free via the U.S. Department of Energy (DOE) Information Bridge.

Web site http://www.osti.gov/bridge

Reports produced before January 1, 1996, may be purchased by members of the public from the following source.

National Technical Information Service

5285 Port Royal Road

Springfield, VA 22161

Telephone 703-605-6000 (1-800-553-6847)

TDD 703-487-4639

Fax 703-605-6900

E-mail info@ntis.fedworld.gov

Web site http://www.ntis.gov/support/ordernowabout.htm

Reports are available to DOE employees, DOE contractors, Energy Technology Data Exchange (ETDE) representatives, and International Nuclear Information System (INIS) representatives from the following source.

Office of Scientific and Technical Information

P.O. Box 62

Oak Ridge, TN 37831

Telephone 865-576-8401

Fax 865-576-5728

E-mail reports@adonis.osti.gov

Web site http://www.osti.gov/contact.html

This report was prepared as an account of work sponsored by an agency of the United States Government. Neither the United States Government nor any agency thereof, nor any of their employees, makes any warranty, express or implied, or assumes any legal liability or responsibility for the accuracy, completeness, or usefulness of any information, apparatus, product, or process disclosed, or represents that its use would not infringe privately owned rights. Reference herein to any specific commercial product, process, or service by trade name, trademark, manufacturer, or otherwise, does not necessarily constitute or imply its endorsement, recommendation, or favoring by the United States Government or any agency thereof. The views and opinions of authors expressed herein do not necessarily state or reflect those of the United States Government or any agency thereof. 
Materials Science and Technology Division

\title{
An Assessment of \\ Flywheel High Power Energy Storage Technology for Hybrid Vehicles
}

\author{
James G. R. Hansen \\ David U. O'Kain * \\ * David U. O'Kain is retired from ORNL and is participating \\ in this assessment as a consultant to ORNL
}

December 2011

\author{
Prepared for \\ Vehicle Technologies Program, \\ Office of Energy Efficiency and Renewable Energy, \\ Department of Energy \\ Prepared by \\ OAK RIDGE NATIONAL LABORATORY \\ Oak Ridge, Tennessee 37831-6285 \\ managed by \\ UT-BATTELLE, LLC \\ for the \\ U.S. DEPARTMENT OF ENERGY \\ under contract DE-AC05-00OR22725
}


This page intentionally left blank. 


\section{TABLE OF CONTENTS}

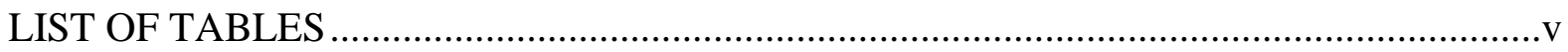

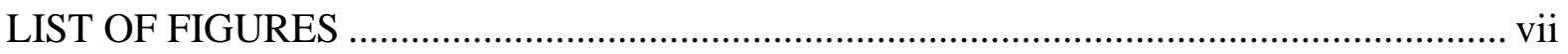

LIST OF ABBREVIATIONS AND ACRONYMS ...................................................... ix

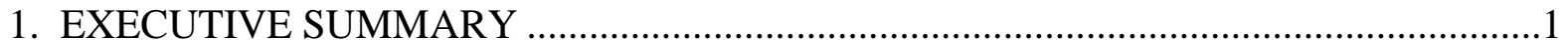

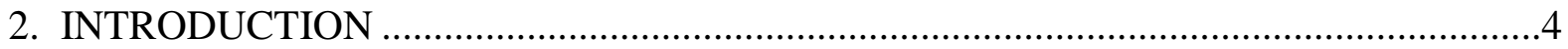

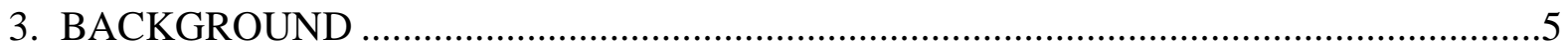

3.1 Flywheel High Power Energy Storage for Hybrid Vehicles ..................................... 5

3.2 Hybrid Electric Versus All-Mechanical Flywheel System Implementation ................. 6

3.3 Energy Stored and Delivered ........................................................................ 7

3.4 Flywheel Stresses and Materials ...................................................................... 9

4. STATE OF THE ART IN FLYWHEEL HIGH POWER ENERGY STORAGE.............13

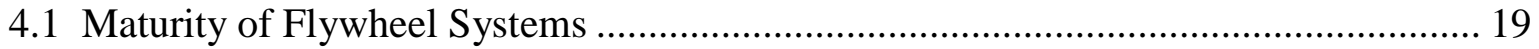

4.2 Flywheel System Performance Parameters .......................................................... 22

4.3 Flywheel Systems Compared to Batteries and Ultracapacitors ............................... 27

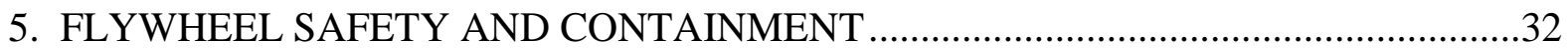

5.1 Composite Rotors Have Different Failure Characteristics ...................................... 32

5.2 Design Approaches To Reduce Flywheel Risk ...................................................... 33

5.3 Flywheel Standard for Safe and Reliable Operation for Space Applications ............. 36

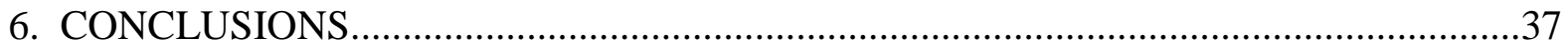

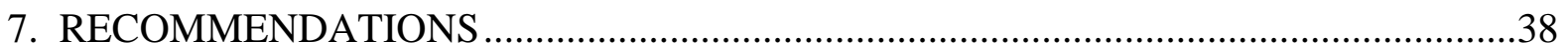

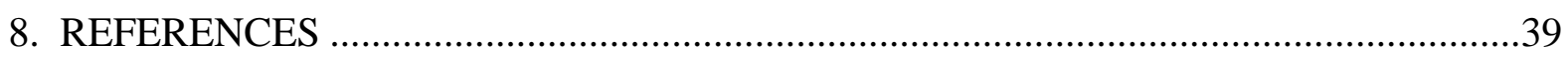

APPENDIX A - SUMMARY INFORMATION PROVIDED BY DEVELOPERS OF FLYWHEEL ENERGY STORAGE SYSTEMS ...................................................... A-1

APPENDIX B - FIA ENVIRONMENTALLY SUSTAINABLE MOTOR SPORT

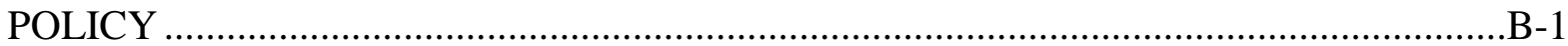

APPENDIX C - HOOP STRESS IN A THIN ROTATING RING ...................................

APPENDIX D - THICK RIGHT CIRCULAR CYLINDER RIMS AND ROTORS WITH

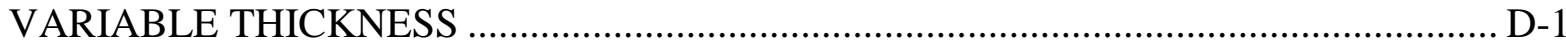

APPENDIX E - EVALUATION OF THE ENERGY STORAGE REQUIREMENT FOR A LIGHT DUTY VEHICLE ................................................................................... E-1 
This page intentionally left blank. 


\section{LIST OF TABLES}

Table 2-1. Flywheel requirements ..................................................................... 4

Table 3-1. Max specific energies for thin ring flywheels made of different materials........... 10

Table 4-1. Nominal weight and specific power for non-energy storage components of Toyota

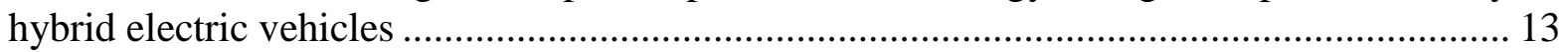

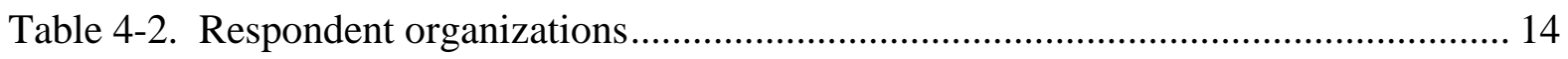

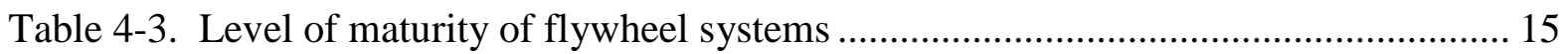

Table 4-4. Performance summary of flywheels for hybrid vehicle applications ................. 17

Table 4-5. Flywheels compared with USABC Power Assist HEV Battery Goals ................ 30

Table 4-6. Flywheels compared with USABC Plug-in HEV Battery Goals ........................ 30

Table 4-7. Flywheels compared with USABC Goals for Advanced Batteries for EVs ......... 31

Table 4-8. Flywheels compared with FreedomCar ultracapacitor end-of-life requirements.. 31 
This page intentionally left blank. 


\section{LIST OF FIGURES}

Figure 3-1. Comparison of typical hybrid electric and mechanical energy storage and power

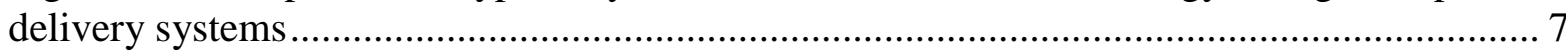

Figure 3-2. Delivered energy versus speed ratio .................................................... 8

Figure 3-3. Idealized flywheel - rotating thin ring with wall thickness t ........................... 9

Figure 3-4. Flywheel rim specific energy vs radius ratio and velocity............................. 11

Figure 3-5. Flywheel rim energy density vs radius ratio and velocity.............................. 12

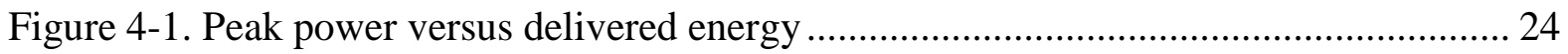

Figure 4-2. Specific power versus specific energy ......................................................... 25

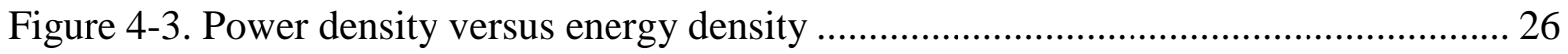


This page intentionally left blank. 


\section{LIST OF ABBREVIATIONS AND ACRONYMS}

$\mathrm{AC}$

AFRL

AIAA

ANSI

BEV

CCM

CFT

CRADA

CVT

DARPA

DC

DOE

DOT

EV

FHSPV

FIA

FMECA

HEV

ICE

IGBT

ISS

g

J

KERS

LLNL

$\mathrm{kW}$

$\mathrm{kWh}$

LEESS

MLC

MTBF

NEV

OEM

ORNL

PAHEV

PHEV

PM

PNGV

RPM (rpm)

SPU

UPS

USABC

UT-CEM

$\mathrm{VA}$
Alternating Current

Air Force Research Laboratory

American Institute of Aeronautics and Astronautics

American National Standards Institute

Battery Electric Vehicle

Centre for Concepts in Mechatronics

Clutched Flywheel Transmission

Cooperative Research and Development Agreement

Continuously Variable Transmission

Defense Advanced Research Projects Agency

Direct Current

U.S. Department of Energy

U.S. Department of Transportation

Electric Vehicle

Flywheel Hybrid System for Premium Vehicles

Fédération Internationale de l'Automobile

Failure Mode Effects and Criticality Analysis

Hybrid Electric Vehicle

Internal Combustion Engine

Insulated Gate Bipolar Transistor

International Space Station

Acceleration of gravity, $9.81 \mathrm{~m} / \mathrm{s}^{2}$

Joules

Kinetic Energy Recovery System

Lawrence Livermore National Laboratory

Kilowatts

Kilowatt-hours

Lower Energy-Energy Storage System

Magnetically Loaded Composite

Mean Time Between Failures

Neighborhood Electric Vehicle

Original Equipment Manufacturer

Oak Ridge National Laboratory

Power Assist Hybrid Electric Vehicle

Plug-In Hybrid Electric Vehicle

Permanent Magnet

Partnership for a New Generation of Vehicles

Revolutions per Minute

Surge Power Unit

Uninterruptible Power Supply

United States Advanced Battery Consortium LLC

University of Texas - Center for Electromechanics

Volt-Amperes 
VCC

$\mathrm{W} / \mathrm{kg}$

$\mathrm{W} / \mathrm{L}$

$\mathrm{Wh} / \mathrm{kg}$

$\mathrm{Wh} / \mathrm{L}$
Volvo Car Corporation

Watts per Kilogram

Watts per Liter

Watt-Hours per Kilogram

Watt-Hours per Liter 


\section{EXECUTIVE SUMMARY}

Hybrid vehicle technology is a well-conceived method of improving the efficiency and quality of operation of light-duty and heavy-duty vehicles. The hybrid approach often involves replacing today's internal combustion engine (ICE) with hybrid electric vehicle (HEV) propulsion systems consisting of a smaller primary power source, an electrical powertrain, and some form of energy storage. Instead of an electrical powertrain, it is also possible to use a mechanical powertrain which includes either a continuously variable transmission (CVT) or another gearing system. The purpose of this assessment is to determine the state of the art of advanced flywheel high power energy storage systems to meet system needs for high power energy storage and energy/power management.

To meet requirements for hybrid powertrains, advanced high power energy storage and conversion technologies are needed. These technologies should address issues of high power energy storage, energy/power management, and auxiliary power. Advanced flywheel high power energy storage systems are one possible way to meet high power energy storage and energy/power conversion needs.

The Fédération Internationale de l'Automobile (FIA), the governing body for world motor sport and the federation of the world's leading motoring organizations, in October 2009 strongly endorsed flywheels. Regarding hybrid vehicles, FIA stated that "Technology such as flywheels reducing dependence on batteries and concentrating on ICE load shift proves to be the most promising way forward." FIA singled out flywheels in their endorsement.

The Department of Energy (DOE) tasked Oak Ridge National Laboratory (ORNL) to assess the state-of-the-art of flywheel high power energy storage for hybrid vehicles. The tasking came from the DOE Vehicle Technologies Program within the DOE Office of Energy Efficiency and Renewable Energy.

The primary tool used in the flywheel technology assessment was a questionnaire entitled "Flywheel Energy Storage System Specifications". The questionnaire was sent to organizations that produce complete flywheel systems, rather than producers of system components. Suggested minimum flywheel requirements for both light-duty and heavy-duty hybrid applications of interest to DOE are given below (same as Table 2-1 in main body of this report).

\begin{tabular}{|c|c|c|c|}
\hline Vehicle Application & $\begin{array}{c}\text { Delivered Energy } \\
\text { (kWh) }\end{array}$ & $\begin{array}{c}\text { Delivered Energy } \\
\text { (MJ) }\end{array}$ & $\begin{array}{c}\text { Peak Power } \\
\text { (kW) }\end{array}$ \\
\hline Light-duty & 0.3 to 0.5 & $1.08-1.80$ & 25 to 40 \\
\hline Heavy-duty & 2 & 7.2 & 150 to 200 \\
\hline
\end{tabular}

Light-duty vehicle applications pertain to the family vehicle and heavy-duty vehicle applications may be Class 3-6 medium duty trucks (such as delivery vans) or Class 6-7 trucks and buses (either standard city bus or transit bus).

Flywheels seem to be especially well suited to hybrid powertrains. Flywheels can effectively assist the hybrid powertrain in meeting high peak power requirements for hybrid vehicle 
acceleration. During regenerative braking, high power levels can be absorbed by the flywheel system at efficiencies far superior to those attainable by batteries.

Maturity of flywheel technology has evolved considerably in recent years. The most extensive experience operating flywheel high power energy storage systems in heavy-duty hybrid vehicles is in Europe. In Germany L-3 Communications Magnet-Motor GmbH (L-3 MM) has developed an impressive experience base in the development and operation of flywheel systems for heavyduty hybrid vehicles. L-3 MM flywheel systems have been in operation since 1988 on a total of 17 hybrid electric buses. Each of 12 buses has experienced 60,000 hours of operation or the equivalent of 1,000,000 speed cycles each. That total experience constitutes a considerable history of and testament to safe use of flywheels on heavy-duty hybrid vehicles. Three systems have been demonstrated and tested on vehicles of a city train or tram. In the Netherlands, The Centre for Concepts in Mechatronics (CCM) reported testing of Alpha and Beta models of a flywheel system for heavy-duty hybrid application with an improved safety Gamma model yet to be tested. CCM flywheel technology was furthered in a European technology development program. In the UK, Parry People Movers' steel flywheel systems are paired with a mere 2.3 liter automobile engine to drive railcars efficiently. In the USA, the University of Texas Center for Electromechanics has demonstrated a flywheel system on a hybrid bus, and Tribology Systems, Inc. reports prototype flywheel systems in customers' beta testing.

The most mature uses of flywheel technology in light-duty vehicles have occurred in Europe in a number of racing venues and also in road car advanced evaluations. Williams Hybrid Power Limited (WHP), Flybrid Systems LLP, and Ricardo UK Ltd (Ricardo), all in the United Kingdom, have developed flywheel units for Formula 1. The WHP system uses the more familiar electrical powertrain with motors and generators, rather than a mechanical powertrain. In another racing venue, the Nurburgring Long Distance Championship, Porsche had significant success in the 2010 season racing its 911 GT3 R hybrid racer with a hybrid powertrain using a WHP flywheel powered by regen braking that delivers $25 \%$ increased fuel economy over the standard racing ICE. At full charge the WHS flywheel delivered a total of $120 \mathrm{~kW}$ (160 hp) for about 6 to 8 seconds to electric motors/generators on the front axle. In January of 2011 Porsche unveiled its new 918 RSR flywheel hybrid racer based on the 911 GT3 R developments.

The Flybrid flywheel system uses a mechanical powertrain. Surge power from a Flybrid flywheel KERS supplemented an ICE to power the Hope Racing LMP1 car in June 2011 and become the first hybrid car to compete in the LeMans 24-hour race. The Flybrid system employing a clutched flywheel transmission (CFT) in its mechanical powertrain provided an extra $97 \mathrm{~kW}(130 \mathrm{hp})$ from the $38 \mathrm{lb}(17.2 \mathrm{~kg})$ system, including the CFT. A Flybrid flywheel provides energy storage for the new Jaguar XF developed in the United Kingdom Flywheel Hybrid System for Premium Vehicles (FHSPV) project. The Flybrid 60,000 rpm flywheel in the $143 \mathrm{lb}(64.9 \mathrm{~kg})$ flywheel system, including the CVT, delivers up to $0.117 \mathrm{kWh}$ of energy. Volvo Car Corporation (VCC) is currently evaluating Flybrid flywheel energy storage in a mechanical powertrain employing a $13.2 \mathrm{lb}$ flywheel with a diameter of $7.87 \mathrm{in}$. running at over $60,000 \mathrm{rpm}$ to provides the rear axle with an additional $60 \mathrm{~kW}(80.4 \mathrm{hp})$ to dramatically improve acceleration. Volvo says that the flywheel system can be used in a much larger volume of their cars than top-of-the-line [hybrid] technology such as plug-in. A 20\% fuel economy improvement is expected for both the Jaguar and Volvo applications. 
The Ricardo Kinergy flywheel concept features a flywheel in a hermetically-sealed vacuum/containment vessel using magnetic gearing to couple the flywheel to a transmission. This eliminates need for a vacuum pump and a vacuum seal on the output rotating shaft. The magnetic gearing eliminates high speed gear tooth wear and associated vibration. A magnetic gear ratio of up to 10:1 means that the output shaft operating in air is running at up to 10 times lower angular speed than the flywheel. The FLYBUS project is evaluating the Ricardo Kinergy flywheel for a heavy-duty hybrid on an Optare Solo bus. The flywheel is magnetically coupled to a Torotrak CVT that is coupled to the standard power take-off unit on the bus's Allison automatic transmission. The hardware to be delivered at the end of 2011 is to improve fuel economy by $8 \%$, and further projections to $21 \%$ are feasible. FLYBUS will demonstrate the potential to retro-fit the current fleet of 500,000 buses in Europe, at a fraction of the cost of a conventional battery hybrid. The KinerStor project that applies the Kinergy flywheel to lightduty hybrids has potential for $30 \%$ fuel savings with equivalent $\mathrm{CO}_{2}$ reductions at an on-cost of $\$ 1,660(£ 1,000)$.

Flywheel performance parameters are expressed in this report in terms of peak power versus delivered energy, specific power versus specific energy, and power density versus energy density using the values reported by flywheel developers. One concludes from the comparison between the performance of flywheels and batteries, that the most effective utilization of flywheels is in providing high power while providing just enough energy storage to accomplish the power assist mission effectively. Flywheels meet or exceed the power related goals (discharge power, regenerative power, specific power, power density, weight and volume) for HEV and EV batteries and ultracapacitors.

By far the greatest technical challenge facing the developer of vehicular flywheel systems is the issue of safety and containment. Flywheel safety issues must be addressed during the design and testing phases to ensure that production flywheel systems can be used with adequately low risk. The PNGV program pointed out the desirability to establish designs and operating procedures such that full rotor burst failure modes are absolutely avoided. Flywheel developers must work to reduce both the probability of and consequences from the various failure modes.

There have been some significant demonstrations to address flywheel safety. Magnet-Motor $\mathrm{GmbH}$ (L-3 MM) evaluated their heavy-duty flywheels in $6 \mathrm{~g}$ and $15 \mathrm{~g}$ shock tests that were successfully demonstrated. Relative to light-duty flywheels, a Flybrid flywheel for racing was subjected to a $>20 \mathrm{~g}$ deceleration in a Formula One crash test facility at the Cranfield Impact Centre while running at full speed of $64,500 \mathrm{rpm}$, and the flywheel was undamaged and still spinning after the test. 


\section{INTRODUCTION}

The Department of Energy (DOE) tasked Oak Ridge National Laboratory (ORNL) to assess the state-of-the-art of flywheel high power energy storage for hybrid vehicles. The tasking came from the DOE Vehicle Technologies Program under the auspices of the DOE Office of Energy Efficiency and Renewable Energy. The objective of the assessment is to determine if flywheels are an appropriate and mature technology for potential use as high power energy storage and energy power management in hybrid vehicles.

As part of the task, a questionnaire entitled "Flywheel Energy Storage System Specifications" was sent to organizations that produce complete flywheel systems, i.e. not to producers of system components. Specification information requested in the questionnaire is similar to that documented in the report An Assessment of Flywheel Energy Storage Technology for Hybrid and Electric Vehicles, prepared by Abacus Technology Corporation in July 1996 for DOE (Reference 1). Instructions for completing the questionnaire asked respondents not to include proprietary or business sensitive information in their responses, because of open publication of this report. Flywheel Energy Storage System Specifications from the respondents are included in Appendix A. We wish to thank participants for providing specifications for their flywheel systems.

Flywheel minimum requirements suggested in the questionnaire for both light-duty and heavyduty hybrid applications of interest to DOE are given in Table 2-1. Multiple flywheel developers' goals for delivered power and energy are different than the DOE suggested values in Table 2-1. Their power level is typically higher and their amount of delivered energy is typically lower. Appendix E includes an evaluation of the energy storage requirements for a light-duty hybrid vehicle. A recommendation is made there to consider revising the specifications such that the target delivered energy level for a flywheel for a light duty vehicle is somewhat less than the $0.3-0.5 \mathrm{kWh}$ in Table 2-1.

Table 2-1. Flywheel requirements

\begin{tabular}{|c|c|c|c|}
\hline Vehicle Application & $\begin{array}{c}\text { Delivered Energy } \\
\text { (kWh) }\end{array}$ & $\begin{array}{c}\text { Delivered Energy } \\
\text { (MJ) }\end{array}$ & $\begin{array}{c}\text { Peak Power } \\
\text { (kW) }\end{array}$ \\
\hline Light-duty & 0.3 to 0.5 & $1.08-1.80$ & 25 to 40 \\
\hline Heavy-duty & 2 & 7.2 & 150 to 200 \\
\hline
\end{tabular}

Light-duty vehicle applications pertain to the family vehicle and heavy-duty vehicle applications may be Class 3-6 medium duty trucks (such as delivery vans) or Class 6-7 trucks and busses (either standard city bus or transit bus).

These values of peak power and delivered energy are later shown in blue as a reference on Figure 4-1, which plots peak power versus delivered energy for flywheel systems reported by respondents to the questionnaire. 


\section{BACKGROUND}

The Fédération Internationale de l'Automobile (FIA) is the governing body for world motor sport and the federation of the world's leading motoring organizations. The FIA in October 2009 strongly endorsed flywheels, when the FIA Commission issued the FIA Environmentally Sustainable Motor Sport Policy (Reference 2) including the following:

"Energy recovery technologies should be promoted through motor sport. The best method of integrating the various levels of hybridisation, ensuring equivalency, and promoting their qualities, is in an efficiency-based formula as described in point one. Although many automobile manufacturers are developing hybrids, there is a strong opinion that they do not represent a cost effective means of reducing fuel consumption and $\mathrm{CO}_{2}$ emissions, but are increasingly demanded by the market place. Energy Recovery Systems technology, however, is fundamental to the future of the automobile, including these hybrids. Motor sport can make a useful contribution to development and marketing. Technology such as flywheels reducing dependence on batteries and concentrating on ICE load shift proves to be the most promising way forward."

The above ringing endorsement for flywheels has "the goal of fundamentally changing the technology basis of racing, and contributing to the development of the road car of the future." Appendix B comprises the entire FIA policy statement.

\subsection{Flywheel High Power Energy Storage for Hybrid Vehicles}

Hybrid technology is a well-conceived method of improving the efficiency and quality of operation of vehicles. DOE realized this fact and sponsored further hybrid development. Program goals have been to improve vehicle efficiency and decrease emissions through advancement of hybrid technology. The hybrid approach generally involves replacing today's internal combustion engines with hybrid electric vehicle (HEV) propulsion systems consisting of a smaller primary power source and an electrical powertrain incorporating energy storage. Various studies have predicted substantial fuel economy increases ranging from 50 to over $200 \%$.

Advanced flywheel high power energy storage systems are one possible way to meet high power energy storage and energy/power conversion needs. Other competitive methods involve advanced batteries, ultracapacitors, and hydro-pneumatic energy storage. The purpose of this assessment is to assist companies developing hybrid vehicles in their consideration of using advanced flywheel high power energy storage systems to meet system needs for high power energy storage and energy/power management.

Flywheels seem to be especially well suited to hybrid powertrains. Flywheels can effectively assist the hybrid powertrain with meeting the significant peak power requirements for heavy vehicles. During acceleration and hill climbing in a typical urban driving cycle, flywheels can provide to the vehicle the relatively high power levels required for relatively short durations. During regenerative braking, high power levels can be absorbed by the flywheel system at efficiencies far superior to those attainable by batteries alone. When the power required to 
propel the vehicle is less than the power produced by the primary power source, the excess energy can be stored in the flywheel for later use. This load leveling capability provided by flywheel systems is an asset to energy/power conversion and management.

A flywheel high power energy storage system can be an excellent load leveler for hybrid vehicles. The load leveler should have a relatively high ratio of both power to energy and specific power to specific energy. To illustrate the capability of flywheel systems to meet this requirement, lines of power to energy ratios have been included in Figure 4-1 and Figure 4-2 later in this report.

A rather unique attribute of flywheel systems is the ability to decouple their energy and power capacities. The energy stored and delivered by a flywheel depends primarily upon the flywheel rotor, while the power stored and delivered is primarily dependent on the design and ratings of the motor/generator and associated power electronics in the electrical powertrain or for the case of a mechanical powertrain in the design of the flywheel system's CVT. This decoupling capability available to the flywheel system designer is a major benefit of flywheels for applications involving high power, which is the case for hybrid powertrains.

\subsection{Hybrid Electric Versus All-Mechanical Flywheel System Implementation}

Flywheel systems for hybrid vehicles can be implemented with either an electrical or a mechanical powertrain. The hybrid electric system must convert the energy from mechanical to electrical and then back to mechanical. This energy conversion requires a motor/generator attached to the flywheel and an additional motor/generator which is mechanically attached to the transmission or to the driveshaft of the vehicle. For the hybrid electric system, the flow of energy to and from the flywheel is in the form of electrical energy. For the mechanical powertrain the flywheel is coupled to the drive wheels via a continuously variable mechanical transmission, and in this case energy to and from the flywheel is in the form of mechanical energy. Finally a combination of the hybrid electric and mechanical systems is possible.

The mechanical powertrain offers a number of attractive features. It is simple, compact, and relatively lightweight; it does not require motors, generators, power electronics, high voltage, or high current. However, at this stage of development, the mechanical powertrain does have technical questions related to rotating vacuum seal technology, efficiency, and reliability. The all mechanical system has the inherent advantage that the form of the energy is always mechanical, and there is no energy loss associated with conversion of energy from mechanical to electrical (possibly also to chemical for batteries and back to electrical) and back to mechanical. Therefore round trip efficiency of energy recovered during regenerative braking has the potential to be higher for the hybrid mechanical powertrain than for the hybrid electrical powertrain. A comparison of the hybrid electrical powertrain and the hybrid mechanical powertrain systems is shown in Figure 3-1.

The majority of respondents to the questionnaire to be discussed in Section 4 proposed flywheels in hybrid electric architectures. Three respondents, Flybrid, HyKinesys, and Ricardo, proposed all-mechanical systems. 
Electrical Powertrain

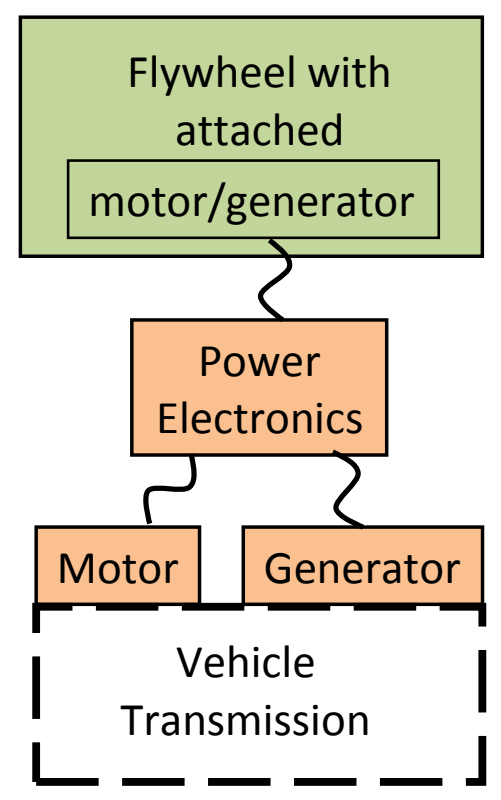

Mechanical Powertrain

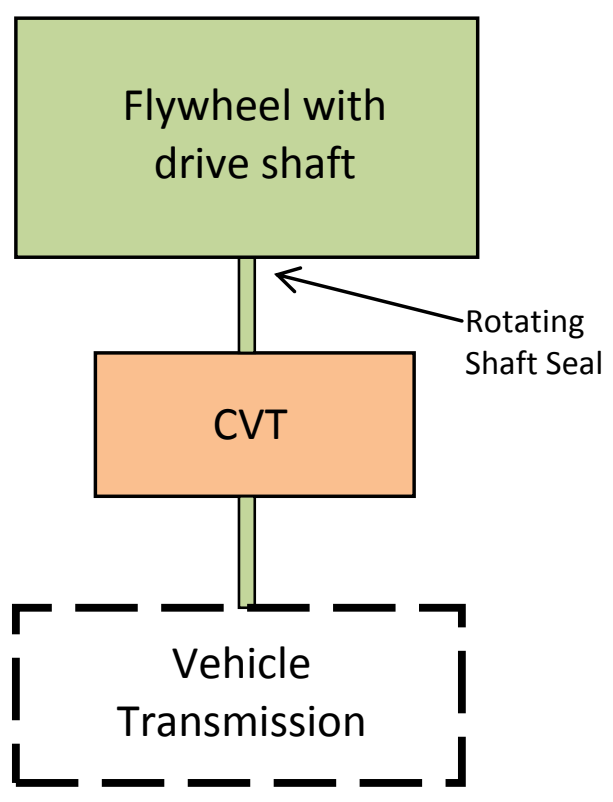

Figure 3-1. Comparison of typical hybrid electric and mechanical energy storage and power delivery systems .

\subsection{Energy Stored and Delivered}

A very brief discussion of the mechanics of rotating mechanical systems is in order. A more detailed discussion is given in a European Community study on storage technologies for intermittent renewable energies (Reference 3) and in a Sandia National Laboratories study on energy storage systems for stationary applications (Reference 4). The kinetic energy, $\mathrm{E}_{\mathrm{k}}$, stored in the flywheel rotor is given by:

$$
\mathrm{E}_{\mathrm{k}}=1 / 2 \mathrm{I} \omega^{2}
$$

where: $\mathrm{I}$ is the polar moment inertia of the rotor and $\omega$ is its angular velocity.

Flywheel stored (gross) energy and flywheel delivered (net) energy can be expressed by setting limits on angular velocity in equation (1).

$$
\begin{gathered}
\mathrm{E}_{\text {stored }}=1 / 2 \mathrm{I} \omega_{\max }{ }^{2} \\
\mathrm{E}_{\text {delivered }}=\mathrm{E}_{\text {stored }}-\mathrm{E}_{\min }=1 / 2 \mathrm{I}\left(\omega_{\max }{ }^{2}-\omega_{\min }{ }^{2}\right)
\end{gathered}
$$

where: $\omega_{\max }$ and $\omega_{\min }$ are the maximum and minimum operating speed limits.

Equation (3) divided by equation (2) is plotted in Figure 3-2, where delivered energy is expressed as a value between 0 and 1 times the stored energy. 


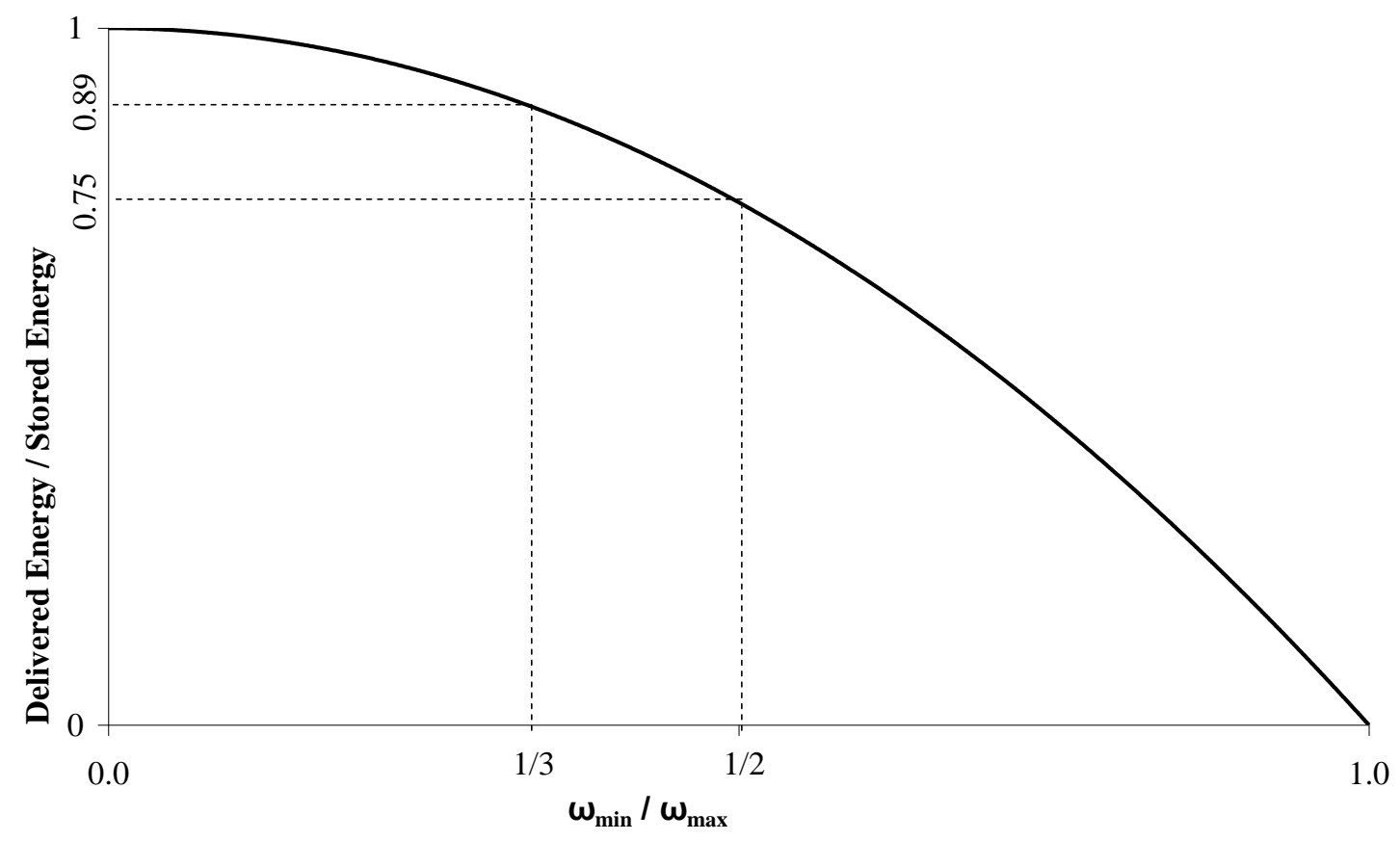

Figure 3-2. Delivered energy versus speed ratio.

Most of the energy is stored at high speed, because of the $\omega^{2}$ term in the kinetic energy expression in equation (1). Thus, one immediately sees diminishing returns for operating to lower and lower speeds. The lower limit on operating speed also affects the cyclic fatigue life of the rotor, the efficiency of power electronics associated with a motor/generator in a hybrid electric flywheel system, and the operation of a CVT in a flywheel system utilizing a mechanical powertrain.

Multiple authors (References 3,4) have stated that useful stored energy occurs for an operational speed ratio of $\omega_{\min } / \omega_{\max }=1 / 3$ for a stationary flywheel application. Many times for vehicular applications the operational speed ratio is quoted more conservatively as $\omega_{\min } / \omega_{\max }=1 / 2$. Figure 3-2 shows that when operating to practical lower limits of $1 / 3$ and $1 / 2$ of maximum speed that respectively $89 \%$ and $75 \%$ of the stored energy is delivered.

Flywheel high speed operation also affects the system power in a positive manner. Power for rotating systems is given by:

$$
\mathrm{P}=\mathrm{T} \omega
$$

where: $\mathrm{T}$ is the drive system torque and $\omega$ is the angular velocity.

For a hybrid electric flywheel system the torque is applied by the motor/generator, and for a flywheel system utilizing a mechanical powertrain the torque is applied by the flywheel system's CVT. For the hybrid electric flywheel system the motor/generator torque limits the minimum operating speed as can be seen in equation (4). As speed $\omega$ is reduced, the drive system torque must increase to maintain a constant mechanical power, making very low speed operation more difficult and impractical. 
High strength flywheel rotors constructed of fiber reinforced composite materials allow flywheels to be run at high angular velocity, $\omega$, allowing kinetic energy requirements to be met with a flywheel with a lower inertia and translating into a lower weight flywheel rotor.

\subsection{Flywheel Stresses and Materials}

A discussion of the effect of fiber properties upon flywheel stored energy is needed to quantitatively demonstrate the benefits of composite materials. To simplify the analysis, an idealized flywheel will be considered in which all of the mass in the rim is concentrated in a thin ring of radius r, as seen in Figure 3-3.

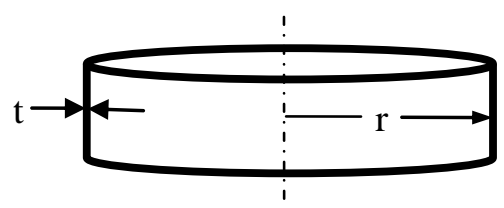

Figure 3-3. Idealized flywheel - rotating thin ring with wall thickness $t$.

The polar moment of inertial equation then becomes

$$
\mathrm{I}=\mathrm{m} \mathrm{r}^{2}
$$

where: $\mathrm{m}$ is the total mass of the idealized zero thickness rim.

Substituting equation (5) into equation (1) gives

$$
\mathrm{E}_{\mathrm{k}}=1 / 2 \mathrm{~m} \mathrm{r}^{2} \omega^{2}
$$

For the idealized flywheel with all mass at radius $r$, the hoop stress in the ring as derived in Appendix $\mathrm{C}$ is

$$
\sigma=\rho r^{2} \omega^{2}
$$

where: $\rho$ is the density of the ring material.

Solving for $\mathrm{r}^{2} \omega^{2}$ in equation (7) and substituting into equation (6) yields

$$
\mathrm{E}_{\mathrm{k}}=1 / 2 \mathrm{~m} \sigma / \rho
$$

The specific kinetic energy, defined as kinetic energy per unit mass, is maximized for maximum $\sigma$, so

$$
\mathrm{E}_{\max } / \mathrm{m}=1 / 2 \sigma_{\max } / \rho
$$

showing that to maximize kinetic energy the constituent material needs to have high strength and low density. 
Table 3-1 evaluates equation (9) for a number of different flywheel rim materials on an equivalent mass basis by setting the rim mass equal to $1 \mathrm{~kg}$. Strengths for metal rims are tensile yield strengths for 1-in. thick metal stock. The advantage that composite materials have over metals is readily apparent. The highest performing all composite rim can store nearly an order of magnitude more energy than a metal rim of the same total mass. Carbon-fiber-reinforced composites significantly outperform glass-fiber-reinforced composites. For all of the composites considered in the table the fiber volume fraction was $65 \%$ and the fiber strength translation was taken as $75 \%$. Thus there was a $51.3 \%$ knockdown factor for the composite strength as compared to the fiber strength.

\section{Table 3-1. Max specific energies for thin ring flywheels made of different materials}

\begin{tabular}{|c|c|c|c|c|}
\hline Flywheel rim material & $\begin{array}{c}\text { Density } \\
\rho \\
\left(\mathrm{g} / \mathrm{cm}^{3}\right)\end{array}$ & $\begin{array}{c}\text { Tensile } \\
\text { strength }{ }^{1} \\
\sigma_{\max } \\
(\mathrm{MPa})\end{array}$ & $\begin{array}{l}\text { Maximum specific } \\
\text { kinetic energy } \\
\text { for } 1 \mathrm{~kg} \text { mass ring } \\
1 / 2 \sigma_{\max } / \rho \\
(\mathrm{Wh} / \mathrm{kg})\end{array}$ & $\begin{array}{c}\text { Maximum } \\
\text { peripheral } \\
\text { velocity or } \\
\text { tip speed } \\
(\mathrm{m} / \mathrm{s})\end{array}$ \\
\hline \multicolumn{5}{|l|}{ All metal thin ring } \\
\hline Aluminum 7075 T651 2 & 2.80 & 469 & 23.3 & 409 \\
\hline Titanium Ti-6Al-4V, STA ${ }^{3}$ & 4.43 & 965 & 30.3 & 467 \\
\hline Steel 4340, QT ${ }^{4}$ & 7.70 & 1500 & 27.1 & 441 \\
\hline \multicolumn{5}{|c|}{ All composite thin ring (all fiber volume fractions $65 \% \& \rho_{\text {epoxy }}=1.28 \mathrm{~g} / \mathrm{cm}^{3}$ ) } \\
\hline E-glass / epoxy & 2.15 & 1679 & 108 & 884 \\
\hline S-glass / epoxy & 2.07 & 2235 & 150 & 1038 \\
\hline AS4 carbon / epoxy & 1.61 & 2111 & 182 & 1145 \\
\hline IM7 carbon / epoxy & 1.61 & 2589 & 224 & 1270 \\
\hline IM9 carbon / epoxy & 1.62 & 2993 & 257 & 1360 \\
\hline
\end{tabular}

Notes:

1. Tensile strengths for metals are at yield, because if metal yields the rotor can become unbalanced.

Tensile strengths for composites are at ultimate.

2. Heat treatment: T651

Plate thickness 0.500 - 1.000 in., A-Basis strength (Reference 5)

3. Heat treatment: Solution treat $1 \mathrm{hr}$. @ $1700^{\circ} \mathrm{F}$, water quench, age $3 \mathrm{hr}$. at $1000^{\circ} \mathrm{F}$, air cool

Plate thickness $0.751-1.000$ in., S-Basis strength (Reference 5)

4. Heat treatment: Quench in molten salt, temper so $90 \%$ martensite at center

Forged plate thickness 1.13 in. from equivalent round $/ 1.5=1.7$ in./1.5=1.13 in., S-Basis strength

(Reference 5)

Energies in Table 3-1 are specific values and must be multiplied by the rim mass to determine the total energy stored. For instance, the maximum kinetic energy in an idealized $10 \mathrm{~kg} \mathrm{rim}$ made of IM9/epoxy is $2570 \mathrm{Wh}$. Thus one can see why composite rotors are prized for vehicular applications. The maximum specific kinetic energy shown in the table is achieved at the limit of the strength of the material; the maximum useable specific kinetic energy is less than the values 
shown in the table. It is necessary to leave a stress margin to ensure reliable and safe operation. Localized stresses, such as the joint between the hub and the rim, must also be considered.

It should be noted that the stored energy for the idealized thin ring flywheel is independent of the rim radius. This can be seen by substituting $\mathrm{v}^{2}$ for $\mathrm{r}^{2} \omega^{2}$ in equation (6):

$$
\mathrm{E}_{\mathrm{k}}=1 / 2 \mathrm{~m} \mathrm{v}^{2}
$$

It is now evident that $E_{k}$ is a function of the velocity at the rim outer radius, $v$, which is often called the peripheral velocity or tip speed. The terms peripheral velocity and tip speed are used interchangeably in this assessment. In a similar manner the hoop stress in equation (7) is also seen to be a function of velocity squared. Thus the overspeed failure of a rotor is a function of excessive rim peripheral velocity rather than angular velocity $\omega$. The maximum peripheral velocity, $v=(\sigma / \rho)^{1 / 2}$, calculated by setting the hoop stress in equation (7) equal to the material tensile strength is shown in the right most column in Table 3-1.

We have been considering an idealized rotor with all of the mass concentrated at radius $r$, which is a good approximation for a thin rim. For a thick rim or a rotor with variable thickness the rotor stress field is more complex, as explained in Appendix D. Selection of the shape of the flywheel rim is a tradeoff between high specific energy and high energy density. Using the term radius ratio as the ratio of rim inner radius to rim outer radius, $R_{i n} / R_{\text {out }}$, the formula for the specific energy of a thick rim is:

$$
\text { Specific Energy }=\text { Rim Energy/Rim Mass }=\left(v^{2} / 4\right)\left[1+\left(R_{\text {in }} / R_{\text {out }}\right)^{2}\right] .
$$

as shown in Figure 3-4.

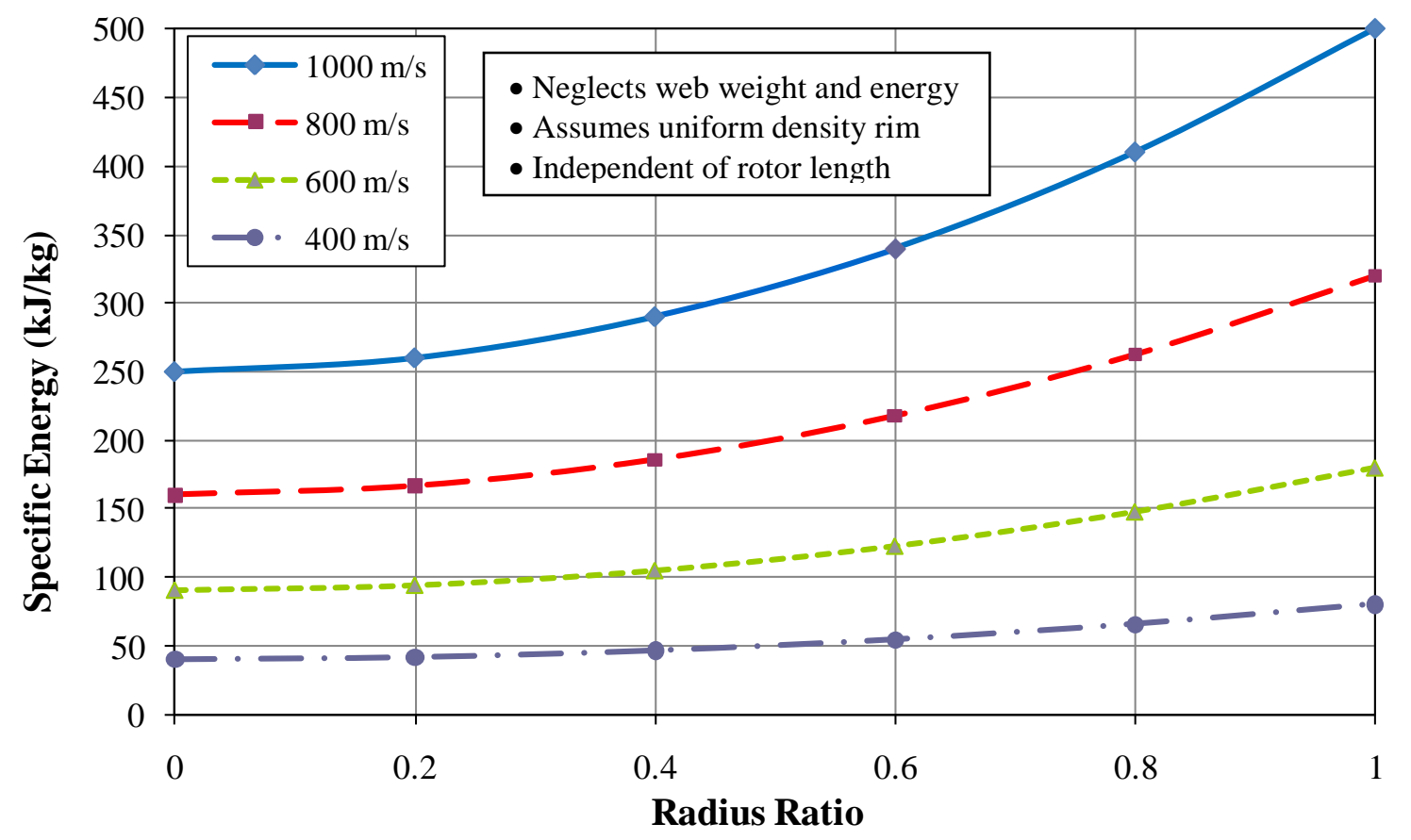

Figure 3-4. Flywheel rim specific energy vs radius ratio and velocity. 
This means that the maximum achievable specific energy is reduced due to the need to maintain a reasonable small volume for the flywheel. For example, selecting a radius ratio of 0.8 will reduce the maximum specific energy to about $82 \%$ of the thin ring maximum specific energy.

Notice that the thin ring maximum specific energy $\left(R_{\text {in }} / R_{\text {out }} \sim 1\right)$ is twice the uniform disk maximum specific energy $\left(R_{\text {in }} / R_{\text {out }}=0\right)$.

The formula for the energy density of the rim is:

$$
\text { Energy Density }=\text { Rim Energy/Rim Enclosed Volume }=\left(\rho v^{2} / 4\right)\left[1-\left(R_{\mathrm{in}} / \mathrm{R}_{\mathrm{out}}\right)^{4}\right] .
$$

The energy density for a rotor made of a typical carbon/epoxy composite material of density $1.604 \mathrm{~g} / \mathrm{cm}^{3}$ is plotted in Figure 3-5.

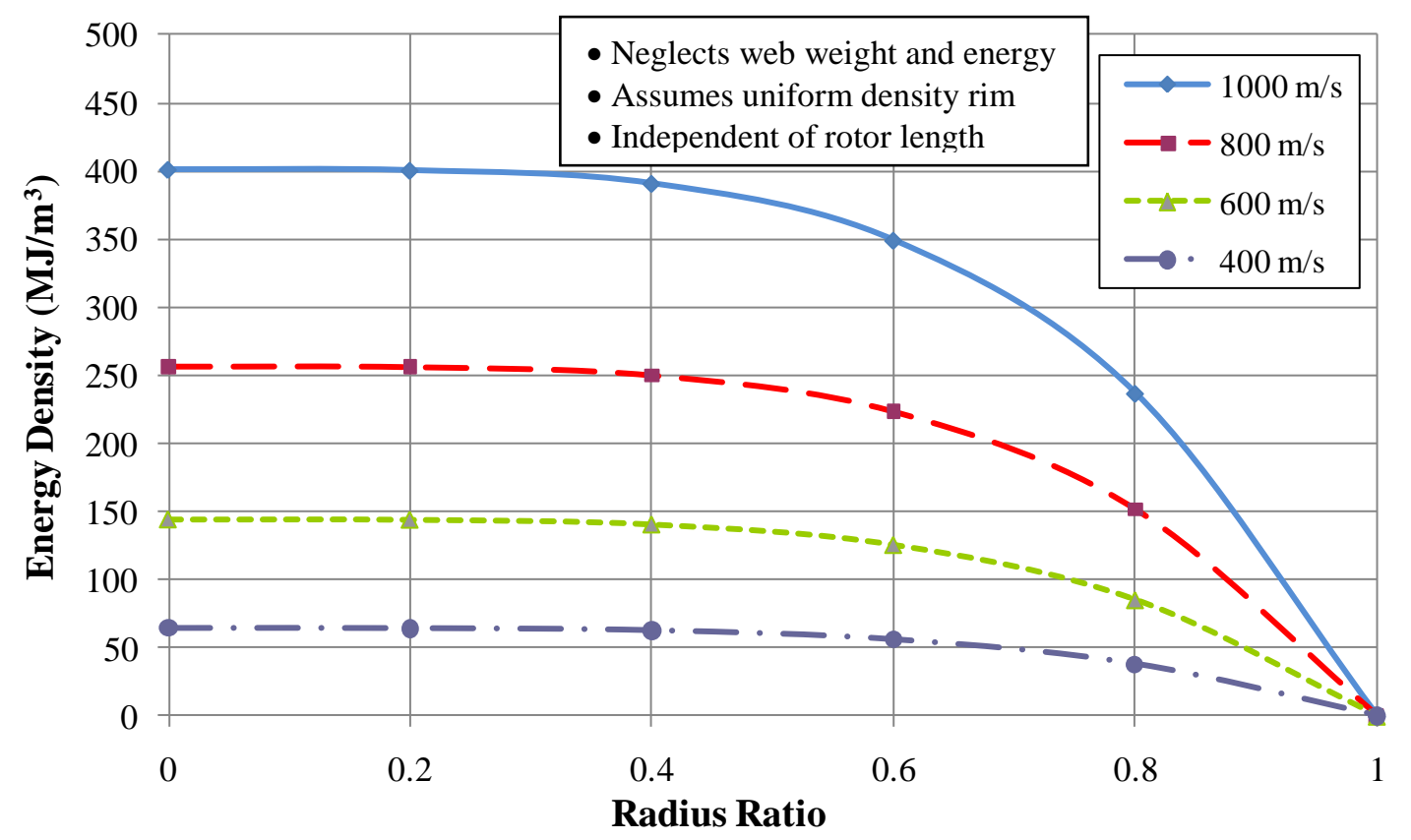

Figure 3-5. Flywheel rim energy density vs radius ratio and velocity.

(for a typical carbon/epoxy composite rotor)

It can be seen that the the energy density changes rapidly going from a radius ratio of 1 to a radius ratio of 0.8 .

The optimum configuration for a metal rotor is called the "constant stress profile" which is a specially shaped, tapered disk with no central hole. This configuration is used for metal turbine wheels. Even when the best constant stress profile shape is used for the design of a metal flywheel, the superior useable specific kinetic energy of composite materials makes them the logical choice for vehicular applications. 


\section{STATE OF THE ART IN FLYWHEEL HIGH POWER ENERGY STORAGE}

The state of the art and maturity of flywheel high power energy storage systems applicable to hybrid vehicles are discussed here primarily for the benefit of hybrid powertrain developers considering flywheels. An attempt was made to locate and involve all companies and organizations developing complete flywheel systems applicable to hybrids.

The primary tool used in the flywheel technology assessment was a questionnaire entitled "Flywheel Energy Storage System Specifications". Completed questionnaires are included in Appendix A. Detailed instructions for completing the questionnaire are included within an instructional questionnaire at the very end of Appendix A. Note that the footnote to the questionnaire states that

"The flywheel system is defined here as including the energy storage rotor, the motor/generator, the bearings, and the containment. Power electronics weight, volume and cost are not considered, in order to allow a more direct comparison with published chemical battery data."

Power electronics were not considered in the Abacus Technology Corporation's flywheel assessment prepared for DOE in 1996 (Reference 1), so to be consistent with that previous evaluation power electronics were also excluded for each design in this current assessment. However, in order to compare the mechanical powertrains with electrical powertrains, we have looked at the weight and specific power of the non-energy storage components that have been used by Toyota Motor Company in their commercial hybrid cars that utilize batteries for energy storage. As shown in Table 4-1, the Toyota hybrid electric powertrain uses a motor, generator, and power conversion unit, and the technology for these products has been improved as newer configurations have been developed. Data in Table 4-1 are from reports of ORNL projects (References 6,7,8) in which hybrid electric powertrains of commercial vehicles utilizing batteries for energy storage were disassembled and analyzed, with special emphasis being given to power electronics and hardware with which it interfaces. Note that the three vehicles analyzed all had a separate motor and generator as itemized in the table, rather than a single motor/generator.

Powers in Table 4-1 are ORNL tested 18 second motor power ratings.

Table 4-1. Nominal weight and specific power for non-energy storage components of Toyota hybrid electric vehicles

\begin{tabular}{|c|c|c|c|c|c|c|}
\hline $\begin{array}{c}\text { Vehicle } \\
\text { Motor Power Rating }\end{array}$ & \multicolumn{2}{|c|}{$\begin{array}{c}2004 \text { Prius } \\
50 \mathrm{~kW}\end{array}$} & \multicolumn{2}{c|}{$\begin{array}{c}2007 \mathrm{Camry} \\
70 \mathrm{~kW}\end{array}$} & \multicolumn{2}{c|}{$\begin{array}{c}2008 \text { Lexus LS600h } \\
110 \mathrm{~kW}\end{array}$} \\
\hline & $\begin{array}{c}\text { Mass } \\
(\mathrm{kg})\end{array}$ & $\begin{array}{c}\text { Specific } \\
\text { Power } \\
(\mathrm{kW} / \mathrm{kg})\end{array}$ & $\begin{array}{c}\text { Mass } \\
(\mathrm{kg})\end{array}$ & $\begin{array}{c}\text { Specific } \\
\text { Power } \\
(\mathrm{kW} / \mathrm{kg})\end{array}$ & $\begin{array}{c}\text { Mass } \\
(\mathrm{kg})\end{array}$ & $\begin{array}{c}\text { Specific } \\
\text { Power } \\
(\mathrm{kW} / \mathrm{kg})\end{array}$ \\
\hline Motor & 45.0 & 1.11 & 41.7 & 1.68 & 44.7 & 2.46 \\
\hline Generator* & 13.2 & 3.79 & 17.3 & 4.05 & 30.2 & 3.64 \\
\hline Power Converter Unit & 21.2 & 2.36 & 17.86 & 3.92 & 17.90 & 6.15 \\
\hline Total & 79.4 & 0.63 & 76.9 & 0.91 & 92.8 & 1.19 \\
\hline
\end{tabular}

*Weight of stator + rotor. No housing weight included. 
The specific power for the individual components has been improved, and the total specific power of the non-energy storage hardware has increased by almost a factor of two. It is expected that a direct comparison can be made for the mechanical powertrain configurations in a hybrid powertrain employing a flywheel for energy storage relative to the latest Lexus LS600h configuration.

Information from the questionnaires has been used to create a series of tables and figures in this assessment. Table 4-2 lists the respondent organizations that submitted completed questionnaires and the shortened names used in tables and figures in this assessment to refer to respondents. Use of shortened names makes tables and figures easier to read. Table 4-3 summarizes the maturity of flywheel systems, as reported in all the questionnaires. Some key performance information in the questionnaires has been summarized in Table 4-4 for hybrid vehicle applications.

Table 4-2. Respondent organizations

\begin{tabular}{|c|l|l|}
\hline \multicolumn{2}{|c|}{$\begin{array}{c}\text { Respondent organizations } \\
\text { (names as provided on questionnaires) }\end{array}$} & Shortened names used in assessment \\
\hline 1 & CCM: Centre for Concepts in Mechatronics & CCM \\
\hline 2 & Flybrid Systems LLP & Flybrid \\
\hline 3 & Flywheel Energy Systems Inc. & Flywheel Energy Systems Inc. \\
\hline 4 & HyKinesys Inc. & HyKinesys \\
\hline 5 & Mario Gottfried & Gottfried \\
\hline 6 & L-3 Communications Magnet-Motor GmbH & L-3 MM \\
\hline 7 & Parry People Movers Ltd & Parry People Movers \\
\hline 8 & POWERTHRU & POWERTHRU \\
\hline 9 & Ricardo UK Ltd & Ricardo \\
\hline 10 & Tribology Systems, Inc. & Tribology Systems, Inc. \\
\hline 11 & University Texas - Center for Electromechanics & UT-CEM \\
\hline 12 & Williams Hybrid Power Limited & WHP \\
\hline
\end{tabular}


Table 4-3. Level of maturity of flywheel systems

\begin{tabular}{|c|c|c|}
\hline $\begin{array}{c}\text { Primary } \\
\text { developer }\end{array}$ & $\begin{array}{c}\text { Application area } \\
\text { in this report }\end{array}$ & Level of maturity \\
\hline $\mathrm{CCM}$ & $\begin{array}{l}\text { Heavy-duty } \\
\text { hybrid }\end{array}$ & $\begin{array}{l}\text { CCM has demonstrated flywheel energy storage technology as a viable energy saving and emission reducing } \\
\text { resource for on-board public transport vehicles. Alpha and Beta models of the RxV-II Flywheel have been tested in } \\
\text { relevant environment (pilots in Citadis Tram of Alstom and AutoTram road vehicle of Fraunhofer Institute), } \\
\text { corresponding with a Technology Readiness Level TRL 6. Extensive validation tests for reliability demonstrated } \\
\text { that the safety level of the Beta model was insufficient. The redesigned Gamma model of the RxV-II Flywheel } \\
\text { with improved safety has been finalized. Testing, validation and certification of the Gamma model are still to be } \\
\text { done. }\end{array}$ \\
\hline Flybrid & $\begin{array}{l}\text { Light-duty } \\
\text { hybrid }\end{array}$ & $\begin{array}{l}\text { Flybrid flywheels systems are being applied to race cars and with several OEM carmakers to road cars. Public } \\
\text { domain Flybrid clients include Jaguar Cars and Volvo Cars. The Jaguar car in particular has completed many } \\
\text { months of testing with very good reliability. It has completed over } 75,000,000 \text { flywheel revolutions in car and } \\
\text { around 5,000 miles of physical testing, while delivering fuel savings up to } 20 \% \text {. Several Flybrid clients are } \\
\text { progressing well towards mass production. The predicted price of mass produced systems is low. The new } \\
\text { Clutched Flywheel Transmission based system raced in the Le Mans } 24 \text {-hour race in June } 2011 \text { and by doing so } \\
\text { powered the first ever hybrid car to compete in that famous race. The CFT may be suitable for small hybrid } \\
\text { passenger cars. }\end{array}$ \\
\hline $\begin{array}{l}\text { Flywheel } \\
\text { Energy Systems } \\
\text { Inc. }\end{array}$ & $\begin{array}{l}\text { Heavy-duty } \\
\text { hybrid }\end{array}$ & $\begin{array}{l}\text { Performance numbers tested and verified in laboratory conditions. Performance and simulated vehicle testing } \\
\text { included over } 1700 \text { hours of run time in the laboratory. The unit is tolerant of all vehicle platform motions. It has } \\
\text { been tested to pitch and/or roll rates of } 10^{\circ} \text { per second, through }+/-10^{\circ} \text { of arc, and under various complex loading } \\
\text { spectra composed of vehicle platform dynamic motions in the range of } 1 \mathrm{~Hz} \text { through } 20 \mathrm{~Hz} \text {. A similar, more } \\
\text { highly stressed composite rotor was tested to over } 105 \text { cycles. There have been no field trials, beta sites or } \\
\text { commercial deployments of the specified flywheel system. }\end{array}$ \\
\hline HyKinesys & $\begin{array}{l}\text { Light-duty } \\
\text { hybrids }\end{array}$ & $\begin{array}{l}\text { Components tested. HyKinesys is convinced that the PowerBeam is the best theoretical way of providing the } \\
\text { highest efficiency hybrid surge power, very durably and at low cost. HyKinesys is now in the process of proving } \\
\text { that the PowerBeam Surge Power Unit is also the best practical solution to the pervasive requirement for hybrid } \\
\text { surge power, measured by the ultimate test, how well it does in real vehicles. }\end{array}$ \\
\hline Gottfried & $\begin{array}{l}\text { Light- \& heavy- } \\
\text { duty hybrids }\end{array}$ & Level of maturity is young, $75 \%$ defined. Enough to encourage making \& testing. \\
\hline L-3 MM & $\begin{array}{c}\text { Heavy-duty } \\
\text { hybrid }\end{array}$ & $\begin{array}{l}\text { MDS-flywheels installed in } 17 \text { hybrid electric urban transport buses operated in Europe. First bus entered service } \\
\text { in } 1988 \text {. Operation experience for } 12 \text { buses: } 60,000 \text { hours \& } 1 \text { million cycles each. } 6 \mathrm{~g} \text {-shock tests demonstrated. } \\
3 \text { systems demonstrated and tested on vehicles of a city train. Advanced system with } 4 \mathrm{kWh} \text { in the same housing } \\
\text { volume ready for tests in summer } 2008 \text {. A bigger system }(5 \mathrm{kWh} / 400 \mathrm{~kW}) \text { demonstrated and tested in a substation } \\
\text { of a city rail ( } 8000 \mathrm{~h} \text { operation experience). Advanced flywheel system with superconducting magnetic bearing } \\
\text { ready for tests in spring } 2008 \text {. }\end{array}$ \\
\hline
\end{tabular}


Table 4-3. Level of maturity of flywheel systems (cont.)

\begin{tabular}{|c|c|c|}
\hline $\begin{array}{c}\text { Primary } \\
\text { developer }\end{array}$ & $\begin{array}{c}\text { Application area } \\
\text { in this report } \\
\end{array}$ & Level of maturity \\
\hline $\begin{array}{l}\text { Parry People } \\
\text { Movers }\end{array}$ & $\begin{array}{l}\text { Heavy-duty } \\
\text { hybrid }\end{array}$ & $\begin{array}{l}\text { Commercial product. Flywheel systems are in use in } 3 \text { operational vehicles. Two railcar fleet at Stourbridge } \\
\text { Junction, UK, has reliability figures of } 99.44 \%(2010) \& 99.74 \% \text { during } 2011 \text { to date. }\end{array}$ \\
\hline POWERTHRU & $\begin{array}{l}\text { Heavy-duty } \\
\text { hybrid }\end{array}$ & $\begin{array}{l}\text { POWERTHRU flywheel systems are based upon the former Pentadyne Power Corporation and Rosen Motors } \\
\text { flywheel systems. Over } \$ 40 \text { million U.S. has been invested in development and commercialization resulting in } 16 \\
\text { patents issued and several pending. Technology demonstrated full power prototype in } 2001 \text { in stationary } \\
\text { application. Company reached } 100 \text { units shipped by end of } 2006 \text {. In } 2007 \text { Pentadyne shipped nearly } 300 \text { units. } \\
2008 \text { shipments were expected to exceed } 500 \text { units of the second generation product. Early systems had } \\
\text { maximum power of } 120 \mathrm{~kW} @ 500 \mathrm{VDC} \text {, the VSS } 120 \text { and new units are capable of } 190 \mathrm{~kW} @ 500 \mathrm{VDC} \text {, the } \\
\text { VSS+DC. }\end{array}$ \\
\hline Ricardo & $\begin{array}{l}\text { Both } \\
\text { Heavy-duty \& } \\
\text { Light-duty } \\
\text { hybrids }\end{array}$ & $\begin{array}{l}\text { Developed from a motorsport heritage, the Ricardo Kinergy system is fundamentally, a mechanical one. It thus } \\
\text { has no power electronics. However based on application analysis it has been developed, so it can be simply } \\
\text { augmented to allow interface to the transmission, (mechanical path), the electrical system (to allow electrics to } \\
\text { be powered during start/stop events), and even hydraulic to reduce accumulator mass. It has been developed so it } \\
\text { does not have a rotating seal, incorporating a passive magnetic/magnetic seal/gear. This obviates the need for } \\
\text { vacuum management and provides a more efficient, high speed torque path than an equivalent mechanical } \\
\text { epicyclic system. This system is currently being installed in a bus application for trials as well as rig evaluation } \\
\text { for off-highway, train(as multiple modules) and passenger car applications. }\end{array}$ \\
\hline $\begin{array}{l}\text { Tribology } \\
\text { Systems, Inc. }\end{array}$ & $\begin{array}{l}\text { Light-duty } \\
\text { hybrid }\end{array}$ & $\begin{array}{l}\text { Prototypes manufactured. Two smaller, basically similar, systems tested successfully hundreds of times in lab } \\
\text { and at customer's beta testing. Measured vibration of only a few tenths of a g running slowly over the entire } \\
\text { supercritical speed range. Completely benign containment of several rotor failures. Tribology Systems, Inc. } \\
\text { claims very low losses; rotor coasting over a year with no power in or out. }\end{array}$ \\
\hline UTCEM & $\begin{array}{l}\text { Heavy-duty } \\
\text { hybrid }\end{array}$ & $\begin{array}{l}\text { Extensive laboratory testing, demonstration on a hybrid bus, preparing for testing on a train. The system was } \\
\text { mounted on a bus to operate as the sole energy storage in a hybrid system. On-road tests verified energy recovery } \\
\text { operating as designed and a significant improvement in performance was achieved. Flywheel systems have been } \\
\text { tested to } 112,000 \text { charge-discharge cycles with no degradation in performance. }\end{array}$ \\
\hline WHP & $\begin{array}{l}\text { Light-duty } \\
\text { hybrid }\end{array}$ & $\begin{array}{l}\text { The company's first application was in the highly competitive and extremely harsh environment of Formula One } \\
\text { motor racing, where WHP flywheel systems are in their second season in Porsche GT3R Hybrid motorsport } \\
\text { application. Design validation is in progress for series production application. Building on the Formula One } \\
\text { project, the company is now making the technology available to meet the high-power energy storage needs in a } \\
\text { variety of applications including hybrid passenger vehicles, hybrid buses, electric trains, military applications and } \\
\text { renewable energy. WHP currently has prototype projects with leading companies in many of these fields. }\end{array}$ \\
\hline
\end{tabular}


Table 4-4. Performance summary of flywheels for hybrid vehicle applications

\begin{tabular}{|c|c|c|c|c|c|c|}
\hline $\begin{array}{c}\text { Primary } \\
\text { developer }\end{array}$ & Applications & $\begin{array}{l}\text { Peak } \\
\text { power } \\
(\mathrm{kW})\end{array}$ & $\begin{array}{c}\text { Delivered } \\
\text { energy } \\
\text { storage } \\
(\mathrm{kWh})\end{array}$ & $\begin{array}{l}\text { Specific } \\
\text { power } \\
(\mathrm{W} / \mathrm{kg})\end{array}$ & $\begin{array}{l}\text { Specific } \\
\text { energy } \\
(\mathrm{Wh} / \mathrm{kg})\end{array}$ & Comments \\
\hline $\mathrm{CCM}$ & $\begin{array}{l}\text { Heavy-duty hybrid } \\
\text { Load leveling in trams \& load leveling for } \\
\text { floating cranes }\end{array}$ & 300 & 4 & 800 & 10.6 & $\begin{array}{l}\text { Specifications apply for RxV-II type of EMAFER } \\
\text { (Electromechanical Accumulator for Energy Re-use) } \\
\text { flywheel systems. }\end{array}$ \\
\hline Flybrid & $\begin{array}{l}\text { Light-duty hybrid } \\
\text { Formula One racing cars, petrol engine prime } \\
\text { mover with mechanical flywheel hybrid kinetic } \\
\text { energy recovery }\end{array}$ & 110 & 0.111 & 8460 & 8.54 & $\begin{array}{l}\text { The Flybrid flywheel system is a fully mechanical system } \\
\text { with no power electronic components. The flywheel is } \\
\text { connected to the transmission of the vehicle via either a } \\
\text { Continuously Variable Transmission (CVT) or a Clutched } \\
\text { Flywheel Transmission (CFT). When the transmission } \\
\text { ratio is changed so as to speed up the flywheel energy is } \\
\text { stored, and when the ratio is changed so as to slow down } \\
\text { the flywheel energy is recovered. }\end{array}$ \\
\hline $\begin{array}{l}\text { Flywheel } \\
\text { Energy } \\
\text { Systems Inc. }\end{array}$ & $\begin{array}{l}\text { Heavy-duty hybrid } \\
\text { Experimental laboratory system with a goal of } \\
\text { use in heavy hybrid vehicles. }\end{array}$ & 120 & 0.75 & 800 & 5 & $\begin{array}{l}\text { This machine combines a short duration, high power } \\
\text { handling capability with low mass and small volume. The } \\
\text { rotor relies upon significant stress margins and test } \\
\text { heritage to provide a safe, long life machine. The machine } \\
\text { has a vacuum enclosure but this enclosure is not intended } \\
\text { to contain a rotor burst. The combination of these } \\
\text { performance characteristics makes this machine a } \\
\text { suitable choice for deployment in heavy hybrid vehicles. }\end{array}$ \\
\hline HyKinesys & $\begin{array}{l}\text { Light-duty hybrid } \\
\text { 'Fuel-only' and 'plug-in' hybrids, plus high } \\
\text { performance all-electrics. Initial focus on } \\
\text { premium car market and urban delivery } \\
\text { vehicles. }\end{array}$ & 100 & $\begin{array}{c}0.3 \\
2 \text { rotors }\end{array}$ & 2000 & 6 & $\begin{array}{l}\text { The survey assumes a 'flywheel battery'. The PowerBeam } \\
\text { is a mechanical Surge Power Unit (SPU). It is the fully } \\
\text { integrated equivalent of a complete electric hybrid drive, } \\
\text { including its battery, controller, generator and motor, or a } \\
\text { flywheel battery plus traction motor and controller, so a } \\
\text { direct numeric comparison can only be made at the } \\
\text { vehicle level. }\end{array}$ \\
\hline Gottfried & Light-duty hybrid & 74.6 & 2.4 & $\begin{array}{l}\text { No } \\
\text { report }\end{array}$ & $\begin{array}{l}\text { No } \\
\text { report }\end{array}$ & $\begin{array}{l}\text { Sets of } 6 \text { double cone } 14 \text { in. }(36 \mathrm{~cm} \text {.) OD flywheels, in a } \\
\text { sphere frame. Specific power and energy values are } \\
\text { pending tests of demonstration hardware. Excellent } \\
\text { surging, charging \& regenerative braking recovery. }\end{array}$ \\
\hline L-3 MM & $\begin{array}{l}\text { Heavy-duty hybrid } \\
\text { Vehicles: Urban transport buses \& light rail } \\
\text { vehicles }\end{array}$ & 300 & 2 & 750 & 5 & $\begin{array}{l}\text { L-3 MM's heavy hybrid system has the most operational } \\
\text { experience and highest level of maturity of any heavy- } \\
\text { duty hybrid systems reported in this assessment. A bigger } \\
\text { system, demonstrated and tested in a substation of a city } \\
\text { rail facility, is documented in Table } 4 \text { stationary } \\
\text { applications. }\end{array}$ \\
\hline
\end{tabular}


Table 4-4. Performance summary of flywheels for hybrid vehicle applications (cont.)

\begin{tabular}{|c|c|c|c|c|c|c|}
\hline $\begin{array}{l}\text { Primary } \\
\text { developer }\end{array}$ & Applications & $\begin{array}{l}\text { Peak } \\
\text { power } \\
(\mathrm{kW})\end{array}$ & \begin{tabular}{|c|} 
Delivered \\
energy \\
storage \\
$(\mathrm{kWh})$
\end{tabular} & $\begin{array}{l}\text { Specific } \\
\text { power } \\
(\mathrm{W} / \mathrm{kg})\end{array}$ & $\begin{array}{l}\text { Specific } \\
\text { energy } \\
(\mathrm{Wh} / \mathrm{kg})\end{array}$ & Comments \\
\hline $\begin{array}{l}\text { Parry People } \\
\text { Movers }\end{array}$ & $\begin{array}{l}\text { Heavy-duty hybrid } \\
\text { Railcars and tramway systems }\end{array}$ & $\begin{array}{c}100 \text { to } \\
200\end{array}$ & 0.9 & 230 & 0.92 & $\begin{array}{l}\text { PPM vehicles incorporate flywheel energy storage, } \\
\text { allowing electric tramway systems without overhead } \\
\text { wires and railcars powered by small prime movers at } \\
\text { very high energy efficiency. Flywheels allow use of } 2.3 \\
\text { litre automobile engine to drive a railcar! }\end{array}$ \\
\hline POWERTHRU & $\begin{array}{l}\text { Heavy-duty hybrid } \\
\text { Primary applications today are stationary } \\
\text { (power quality, UPS, load leveling, storage), } \\
\text { secondary applications for Hybrid electric } \\
\text { vehicle, electric rail (load leveling and power } \\
\text { recycling) }\end{array}$ & 190 & 0.667 & $\begin{array}{c}693 \\
\text { Config. A, } \\
1292 \\
\text { Config. B }\end{array}$ & \begin{tabular}{|c|}
2.43 \\
Config. A, \\
4.53 \\
Config. B
\end{tabular} & $\begin{array}{l}\text { Flywheel system was originally conceived and designed } \\
\text { specifically for hybrid electric vehicle; gimbal, } \\
\text { containment, bearings, and vacuum systems all designed } \\
\text { as a result of the mobile requirement. Stationary market } \\
\text { pursued due to large immediate demand and customer } \\
\text { acceptance. Configuration A is current configuration, } \\
\text { and Configuration B is planned mobile configuration } \\
\text { with composite outer containment. }\end{array}$ \\
\hline Ricardo & $\begin{array}{l}\text { Heavy-duty hybrid and Light-duty hybrid } \\
\text { Buses (FLYBRID project) and light-duty } \\
\text { vehicles (KinerStor project) }\end{array}$ & 60 & 0.22 & 4000 & 14.7 & $\begin{array}{l}\text { The Ricardo flywheel system is a fully mechanical } \\
\text { system with no power electronic components. The } \\
\text { primary power source is an IC engine with the flywheel } \\
\text { deployed for kinetic energy recovery and load leveling. } \\
\text { Magnetic coupling of the flywheel to the transmission } \\
\text { provides key advantages to system reliability. }\end{array}$ \\
\hline $\begin{array}{l}\text { Tribology } \\
\text { Systems, Inc. }\end{array}$ & $\begin{array}{l}\text { Light-duty hybrid } \\
\text { Electric vehicle, light duty }\end{array}$ & 40 & 1 & 317 & 7.9 & $\begin{array}{l}\text { System includes patented bearings with proven } 20 \text {-year } \\
\text { life and completely mechanical rotor dynamics control } \\
\text { system along with a proprietary safety containment. }\end{array}$ \\
\hline UTCEM & $\begin{array}{l}\text { Heavy-duty hybrid } \\
\text { Replacement of chemical batteries on mobile } \\
\text { platforms, e.g. trucks, buses, trains, satellites. }\end{array}$ & $\begin{array}{l}2 \text { to } \\
2000\end{array}$ & $\begin{array}{l}0.4 \text { to } \\
130\end{array}$ & 770 & 5 & $\begin{array}{l}\text { Specification numbers cover ranges or are typical for } \\
\text { the systems UTCEM designs, builds and tests. }\end{array}$ \\
\hline WHP & $\begin{array}{l}\text { Light-duty hybrid } \\
\text { High power, long life energy storage unit for } \\
\text { hybrid electric vehicle applications with the } \\
\text { primary energy source an ICE or fuel cell. }\end{array}$ & 120 & 0.36 & 2180 & 6.55 & $\begin{array}{l}\text { WHP's flywheel solutions incorporate its novel, } \\
\text { patented Magnetically Loaded Composite (MLC) } \\
\text { technology which was originally developed by Urenco } \\
\text { engineers working on the design of uranium centrifuge } \\
\text { machines. The rotor magnets in an MLC system are } \\
\text { comprised of tiny particles embedded in the composite } \\
\text { matrix. With no other metal in the flywheel rotor eddy } \\
\text { current losses and heating are almost zero. }\end{array}$ \\
\hline
\end{tabular}




\subsection{Maturity of Flywheel Systems}

As illustrated in Table 4-3, the level of maturity of flywheel technology has evolved considerably in recent years. The most extensive experience operating flywheel high power energy storage systems in heavy hybrid vehicles is in Europe. In Germany L-3 Communications Magnet-Motor $\mathrm{GmbH}$ has developed an impressive experience base in the development and operation of flywheel systems for heavy-duty hybrid vehicles. Magnet-Motor flywheel systems have been in operation since 1988 on a total of 17 hybrid electric buses in Europe. Each of 12 buses has experienced 60,000 hours of operation or the equivalent of 1,000,000 speed cycles each. To engineer safe operation into their flywheel systems, Magnet-Motor flywheels have been successfully demonstrated in $6 \mathrm{~g}$-shock tests. That total experience constitutes a considerable history of and testament to safe use of flywheels on heavy-duty hybrid vehicles. In the Netherlands, The Centre for Concepts in Mechatronics (CCM) reported testing of Alpha and Beta models of a flywheel system for heavy-duty hybrid application with an improved safety Gamma model yet to be tested. That flywheel high power energy storage technology was furthered in a European technology development program. In the UK, Parry People Movers' steel flywheel systems are used with a mere 2.3 liter automobile engine to drive railcars efficiently. In the USA, the University of Texas Center for Electromechanics (UT-CEM) has demonstrated a flywheel system on a hybrid bus and tested a comparable flywheel to 112,000 charge-discharge cycles in order to demonstrate the ability of composite rotors to withstand mechanical fatigue from speed cycling. Others have developed prototypes and systems for laboratory testing.

Some of the most mature uses of flywheel technology in light-duty vehicles have occurred in European racing (Formula 1, Nurburgring Long Distance, and LeMans). Williams Hybrid Power Limited (WHP), Flybrid Systems LLP, and Ricardo UK Ltd (Ricardo) all in the United Kingdom, have developed Kinetic Energy Recovery System (KERS) flywheel units for racing that are currently being evaluated for mass produced road vehicles. The WHP system makes use of a motor/generator incorporating its novel, patented Magnetically Loaded Composite (MLC) technology which was originally developed by Urenco engineers working on the design of uranium centrifuge machines. The Flybrid and Ricardo flywheel systems use a mechanical powertrain. The Flybrid flywheel is connected to the transmission of the vehicle via either a Continuously Variable Transmission (CVT) or a Clutched Flywheel Transmission (CFT), and manipulation of the transmission ratio achieves control of energy storage and recovery. The Ricardo Kinergy flywheel concept features a flywheel in a hermetically-sealed vacuum/containment vessel, and the flywheel is magnetically coupled to a CVT.

Porsche's 911 GT3 R hybrid racer utilizing a WHP flywheel system demonstrated outstanding success in 2010, its first season. Racing in the Nurburgring Long Distance Championship, the hybrid Porsche took sixth place in Round 1 in March of 2010, took third place in Round 2 in April of 2010, and in the Nurburgring 24 hour race in May led the race for more than 8 hours before succumbing to engine trouble about 23 hours into the race. The WHP flywheel system is powered during regen braking from two each $60 \mathrm{~kW}$ electric motors/generators on the front axle. The 16-in. diameter flywheel rotor spins up to nearly 40,000 rpm $(851 \mathrm{~m} / \mathrm{s}$ peripheral velocity) while storing up to $0.2 \mathrm{kWh}$. To supplement the $353 \mathrm{~kW}$ (480 hp) four-liter flat-six at the vehicle rear when accelerating out of a bend or overtaking, the driver could call for the flywheel 
to deliver up to $120 \mathrm{~kW}$ (160 hp) for about 6 to 8 seconds to the motors/generators on the front axle (Reference 9). The hybrid Porsche has about $25 \%$ better fuel efficiency than vehicles with a standard ICE and drivetrain, resulting in $20 \%$ fewer pit stops for fuel. Brake pads also last longer, with only one brake change during the Nurburgring 24 hour race versus the standard 2 to 3 changes. The flywheel system does not wear out during that race. In contrast the director of Porsche Motorsport, Hartmut Kristen, estimates that in a hybrid electric vehicle the lithium ion battery would wear out about every 8 hours from the grueling power charge/discharge cycles during the 24 Hours of Nurburgring (Reference 10).

Porsche in January of 2011 unveiled its new 918 RSR flywheel hybrid racer based on the 911 GT3 R developments (Reference 11). For this application the WHS flywheel accumulator rotates up to $36,000 \mathrm{rpm}$ to store energy that it can use to drive two motors/generators on the front axle at $75 \mathrm{~kW}$ each for a total of $150 \mathrm{~kW}$ for about eight seconds when the flywheel is fully charged. The flywheel supplements a $560 \mathrm{hp} \mathrm{V8} \mathrm{direct} \mathrm{injection} \mathrm{engine} \mathrm{mounted} \mathrm{forward} \mathrm{of} \mathrm{the}$ rear axle. With the 918 RSR hybrid racer, Porsche is elevating the hybrid concept to the experimental level.

Surge power from a Flybrid flywheel KERS supplemented an ICE to power the Hope Racing LMP1 car in June 2011 and became the first hybrid car to compete in the LeMans 24-hour race (Reference 12,13). The 60,000 rpm flywheel weighed only $11.4 \mathrm{lb}(5.15 \mathrm{~kg})$. The Flybrid system employing a CFT in its mechanical powertrain provided an extra $97 \mathrm{~kW}(130 \mathrm{hp})$ from the $38 \mathrm{lb}(17.2 \mathrm{~kg})$ system, including the CFT. The CFT employs three gears along with highspeed clutches to transmit drive in conjunction with the car gearbox.

A Flybrid flywheel provides energy storage for the new Jaguar XF developed in the United Kingdom Flywheel Hybrid System for Premium Vehicles (FHSPV) project begun in 2008 (References 14,15). Jaguar Land Rover is the lead organization along with consortium members Flybrid (flywheel), Prodrive (vehicle integration, software control and electronics), Ricardo (consultancy), Torotrak (CVT), Xtrac (CVT), and Ford. The Flybrid 60,000 rpm flywheel delivers $60 \mathrm{~kW}(80.4 \mathrm{hp}$ ) for up to seven seconds (delivered energy $0.117 \mathrm{kWh}$ ). Energy is stored in the $143 \mathrm{lb}(64.9 \mathrm{~kg})$ flywheel system, including the CVT, as no batteries are utilized for storage. A $20 \%$ fuel economy improvement is expected. Jaguar says that mechanical flywheel hybrids are smaller, cheaper and more efficient than electrical powertrain hybrids. Ford is said to also be considering the flywheel-CVT system.

Volvo Car Corporation (VCC) is currently evaluating Flybrid flywheel energy storage in a mechanical powertrain employing a Torotrak CVT (References 16,17). Volvo vice-president, Derek Crabb said "Tests in a Volvo car will get under way in the second half of 2011. This technology has the potential for reducing fuel consumption by up to 20 per cent. What is more, it gives the driver an extra horsepower boost, giving a four-cylinder engine acceleration like a sixcylinder unit". The $13.2 \mathrm{lb}(6 \mathrm{~kg})$ flywheel with a diameter of $7.87 \mathrm{in} .(20 \mathrm{~cm})$ running at over $60,000 \mathrm{rpm}$ to provides the rear axle with an additional $60 \mathrm{~kW}(80.4 \mathrm{hp})$ to dramatically improve acceleration. Mr. Crabb also said "The flywheel technology is relatively cheap. It can be used in a much larger volume of our cars than top-of-the-line [hybrid] technology such as plug-in". Flywheel technology can play a major role in reducing CO2 emissions, as under the New European Driving Cycle the ICE should be turned off for about half of the time. 
Flybrid has also partnered with Magneti Marelli Motorsport to develop a flywheel capacitor that uses an electric motor/generator for electrical powertrain application.

The Ricardo Kinergy flywheel concept features a flywheel in a hermetically-sealed vacuum/containment vessel using magnetic gearing to couple the flywheel to a transmission (Reference 18). This eliminates need for a vacuum pump and a vacuum seal on the output rotating shaft. The magnetic gearing is claimed to be extremely efficient ( $>99 \%)$, and it eliminates high speed gear tooth wear and associated vibration in the coupling. Windage losses are significantly reduced, since a magnetic gear ratio of up to 10:1 means that the output shaft operating in air is running at up to 10 times lower angular speed than the flywheel. Ricardo is evaluating their Kinergy flywheel in UK Technology Strategy Board projects for both heavyduty and light-duty hybrids.

The FLYBUS project is evaluating the Ricardo Kinergy flywheel for a heavy-duty hybrid on an Optare Solo bus (Reference $19 \& 20$ ). The flywheel is magnetically coupled to a Torotrak CVT that is coupled to the standard power take-off unit on the bus's Allison automatic transmission. The hardware to be delivered at the end of 2011 is to improve fuel economy by $8 \%$. A benefit of $21 \%$ is projected with upgrades for a $0.56 \mathrm{kWh}(2 \mathrm{MJ})$ flywheel. FLYBUS will demonstrate the potential to retro-fit the current fleet of 500,000 buses in Europe, at a fraction of the cost of a conventional battery hybrid.

The KinerStor project will evaluate two different flywheel systems for light-duty hybrids (Reference 21). Industrial partners include CTG, JCB, Land Rover, SKF, Torotrak and WHP. The Ricardo Kinergy system utilizes a flywheel magnetically coupled to a CVT in a mechanical powertrain, while the WHP flywheel is coupled to a motor/generator in an electrical powertrain. The project has potential for $30 \%$ fuel savings with equivalent $\mathrm{CO}_{2}$ reductions at an on-cost of $\$ 1,660(£ 1,000)$. One conceivable implementation is to magnetically couple a Kinergy flywheel to a power take-off unit on a dual clutch transmission.

Although this report focuses on flywheels for use as high power energy storage in hybrid vehicles, stationary flywheel systems need to be briefly mentioned. Some of the most mature flywheel technology currently resides in applications other than hybrid vehicles. Because stationary flywheels do not have to deal with vehicular travel generated dynamic loads and because light weight is not as much of an issue, development of stationary flywheels has flourished. Stationary flywheel systems offer a great deal of insight into the maturity of flywheel technology, as to-date, commercial activity has been quite prevalent for these flywheel systems. If one is specifically interested in flywheels for stationary application, all of the organizations listed in this assessment should be considered as well as other companies specializing strictly in flywheels for stationary application.

Flywheels are also being developed for space application. NASA worked in the early 2000s on a flywheel system to replace energy storage on the International Space Station (ISS). The flywheel was to replace ISS nickel-hydrogen battery strings. Subscale hardware was tested at $60,000 \mathrm{rpm}$. The design for the flight unit used a $17 \mathrm{in.} \mathrm{long}$ and $13 \mathrm{in}$. diameter composite rotor running at 53,000 rpm $(916 \mathrm{~m} / \mathrm{s}$ peripheral velocity) while delivering $2.8 \mathrm{kWh}$ of energy 
(Reference 22). Development of a standard (Reference 32, for space flywheels was funded by NASA and the Air Force to support the ISS and other flywheels for use in space (see more in Section 5.3). The ISS flywheel did not come to fruition because of ISS funding limitations, but NASA Glenn Research Center has continued to support technology development that will one day lead to a flywheel application in space.

\subsection{Flywheel System Performance Parameters}

Some performance parameters of interest are power and energy, expressed both in absolute terms and also per unit mass (specific values) or per unit volume (density values). Therefore we have plotted peak power versus delivered energy in Figure 4-1, specific power versus specific energy in Figure 4-2, and power density versus energy density in Figure 4-3 using the values reported by flywheel developers in their questionnaires. Values plotted are the same as those listed in Table 4-4. Please note that data for both light-duty and heavy-duty hybrid vehicle systems are plotted on each of the Figures 4-1 to 4-3. To distinguish between light-duty and heavy-duty hybrids, the light-duty hybrids have respondent names printed in regular font while for heavy-duty hybrids the respondent names are in italics.

Delivered energy rather than gross energy is used to calculate specific energy and energy density. Gross energy represents the total kinetic energy stored in the flywheel rotor system at maximum operational speed, but since it is not practical to bring the flywheel to a halt when speed cycling, the delivered energy is less than the gross energy by the amount of kinetic energy remaining in the flywheel at minimum operational speed, as was demonstrated with Figure 3-2.

Figure 4-1 depicts the performance of flywheel system point designs in terms of peak power and delivered energy. Suggested ranges for minimum values of power and energy listed in Table 2-1 for both light-duty and heavy-duty hybrid applications are annotated on the figure. Power or energy levels greater than the minimums are acceptable, but lower levels are not. The suggested range for light-duty vehicles is shown on Figure 4-1 as a box, and one should interpret acceptable levels as either within the box or above and to the right of the box. Many flywheel systems shown on the plot have parameters that meet or exceed one or both of the suggested values. It should be pointed out that many flywheel systems can be operated in a modular fashion, so delivered energy can be multiplied by employing multiple modules. For instance, HyKinesys' PowerBeam flywheel system modules employ pairs of contra-rotating rotors, doubling the stored energy of one rotor. In addition the flywheel system of Mario Gottfried requires two modules to boost peak power levels from the $60 \mathrm{~kW}$ provided from one module to $120 \mathrm{~kW}$ provided by two modules. Consideration of Figure 4-1 might suggest a) how many flywheel modules are needed for a specific organization's point design in order to provide suggested delivered energy and b) how well the point design of a flywheel developer might meet the needs of a hybrid application.

Flywheels for hybrid application should have a high power to energy ratio to serve as a load leveler. It has been stated in the prior Abacus flywheel assessment (Reference 1) that for automotive applications a power to energy ratio below about 20:1 is suitable for an electric vehicle and a ratio above about 50:1 is appropriate for a hybrid electric vehicle requiring almost no electric-only driving range. It must be repeated that these power to energy ratios were stated 
in Reference 1 for light-duty automotive applications only. Lines of power to energy ratios of 20:1, 50:1 and 150:1 have been plotted on Figure 4-1. Note that the DOE suggested minimum requirements for delivered power and energy for light-duty and heavy-duty hybrid vehicles both exhibit power to energy ratios of about 80:1. Since for flywheels the delivered power and energy can be designed independent of one another, flywheel systems for hybrid application can be designed to have high power to energy ratios. Alternatively, other power to energy ratios desired for other specific applications can also be designed into flywheel systems.

A distinction between flywheel systems designated for light-duty and heavy-duty vehicles can be seen in Figure 4-1. For the most part flywheel systems for heavy-duty vehicles (respondent names in italics in figures) are positioned further from the origin of the axes, providing higher peak power and delivered energy than for light-duty vehicles.

Figure 4-2 depicts the specific power versus specific energy for the flywheel system designs. Specific properties are properties per unit mass, as per the definitions

$$
\begin{gathered}
\text { Specific Power } \equiv \text { Peak Power/System Mass } \\
\text { Specific Energy } \equiv \text { Delivered Energy/System Mass }
\end{gathered}
$$

where: system mass excludes the mass of power electronics for the hybrid electrical powertrain and excludes the mass of the CVT for the hybrid mechanical powertrain

High values of specific power and specific energy are representative of higher performance flywheel systems per unit mass.

The previously discussed power to energy ratios of 20:1, 50:1 and 150:1 have been added as lines in Figure 4-2. 


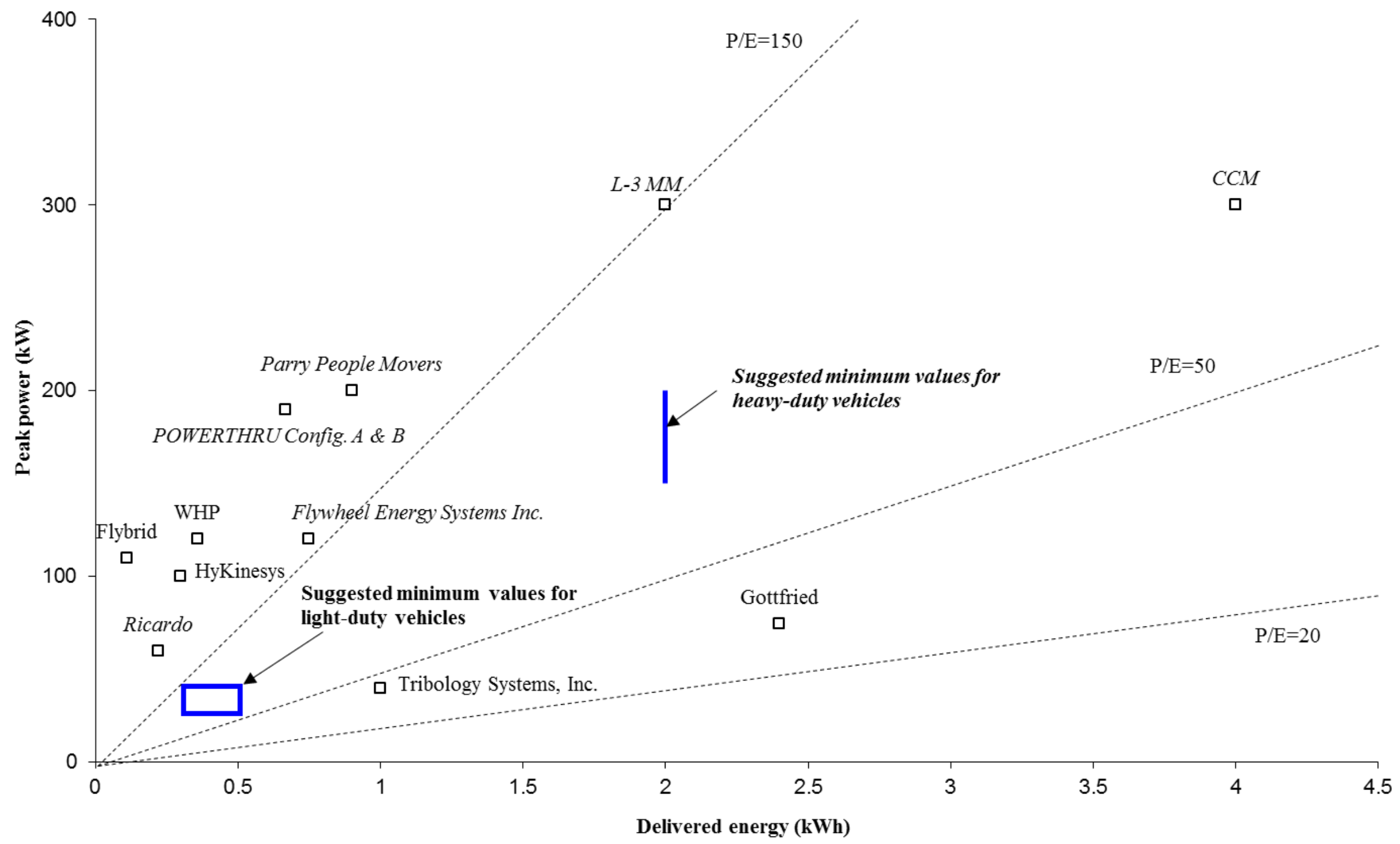

Figure 4-1. Peak power versus delivered energy.

(Light-duty in regular font and heavy-duty in italic font) 


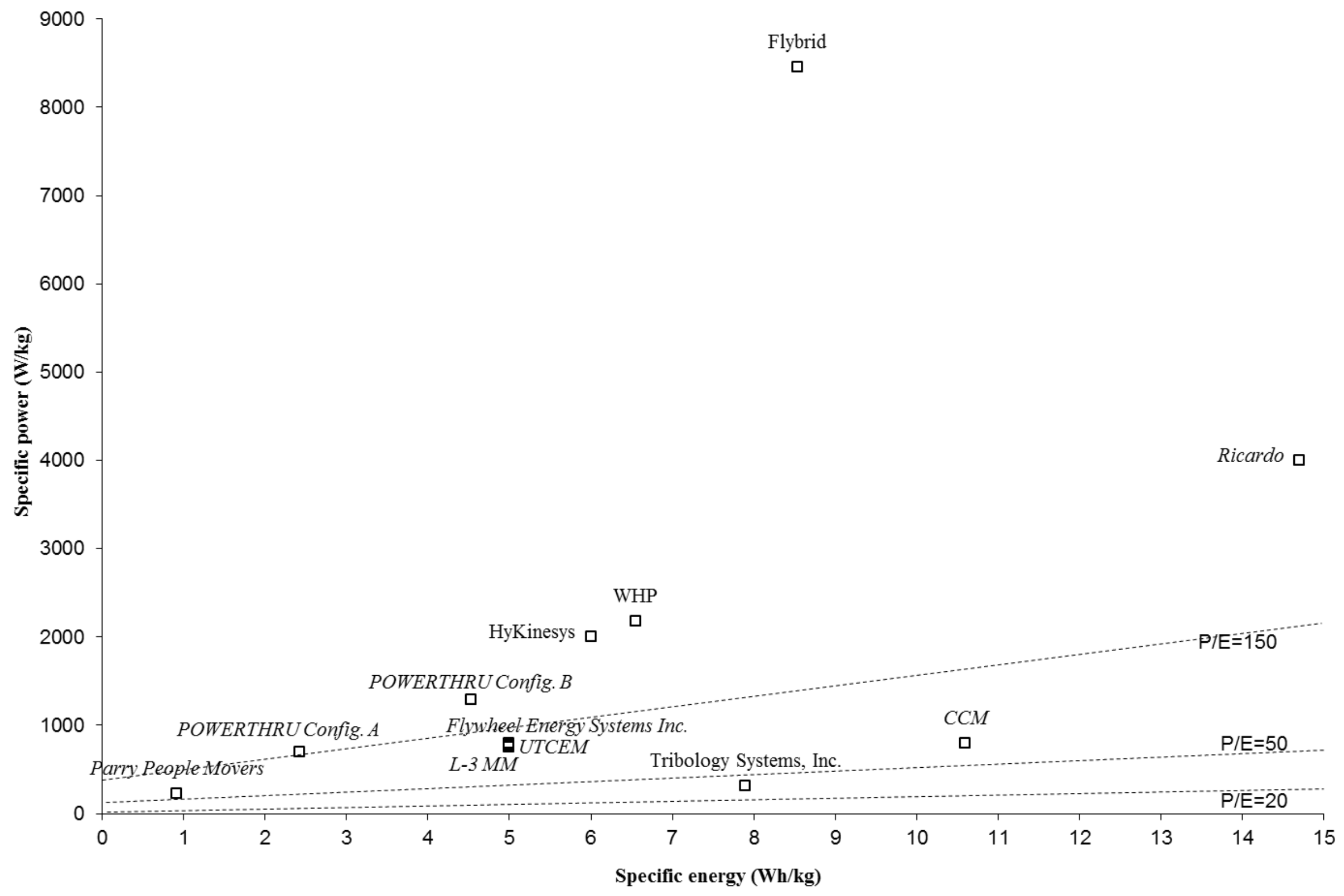

Figure 4-2. Specific power versus specific energy.

(Light-duty in regular font and heavy-duty in italic font) 


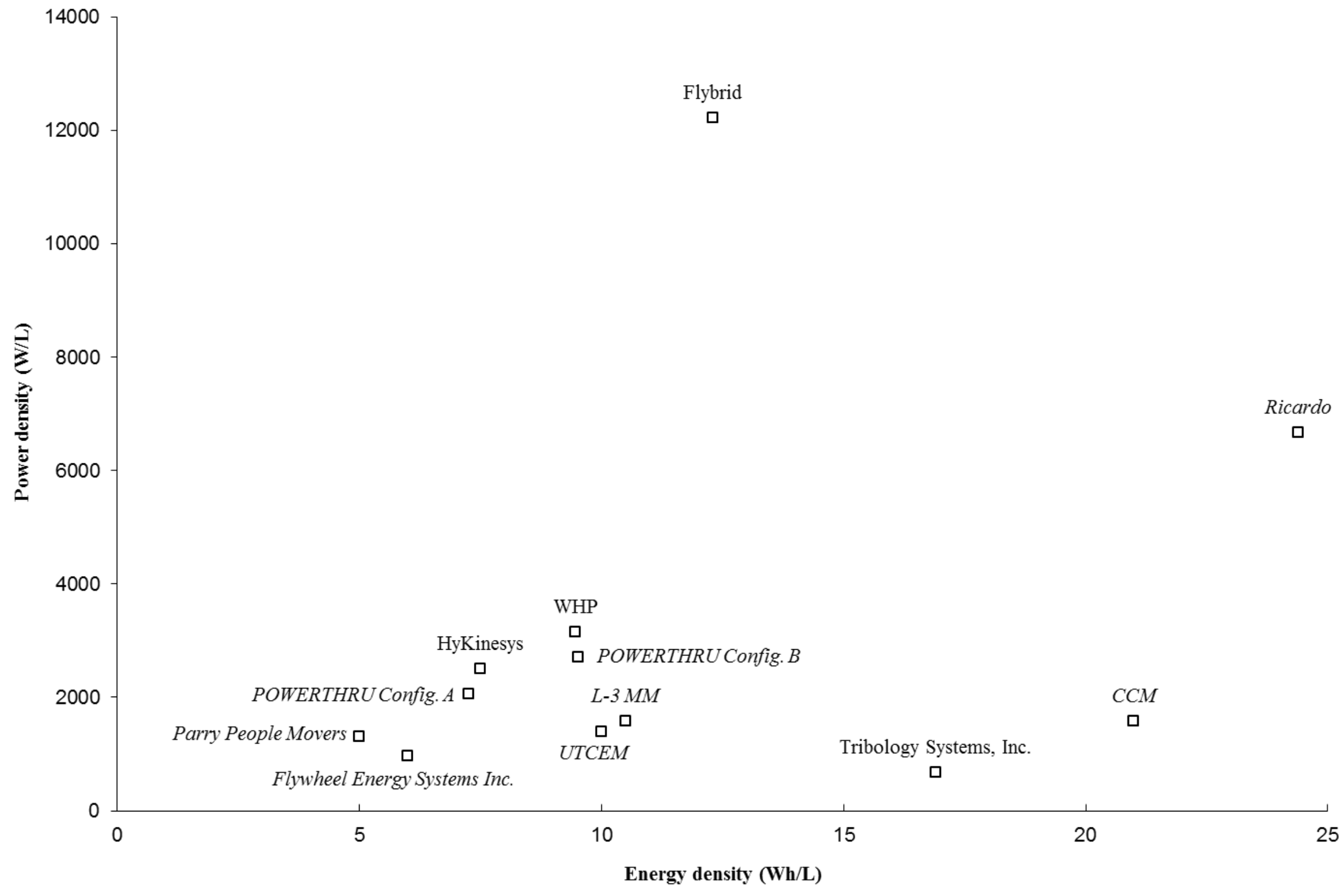

Figure 4-3. Power density versus energy density.

(Light-duty in regular font and heavy-duty in italic font) 
For the systems utilizing a mechanical powertrain, the CVT mass was not included in the system mass used to calculate the specific power and specific energy. The justification for omitting the CVT mass from the calculation is that the mass of non-energy storage components should not be included in the calculation. This is the same reason that the power electronic mass was not included. For calculation of specific power and specific energy for battery energy storage the mass of the non-energy storage components listed in Table 4-1 are typically not included. Comparable non-energy storage components for a hybrid with an electrical powertrain and flywheel energy storage are shown in pink in Figure 3-1.

Figure 4-3 is a plot of power density versus energy density. The density properties are properties per unit volume, defined as

$$
\begin{gathered}
\text { Power Density } \equiv \text { Peak Power /System Volume } \\
\text { Energy Density } \equiv \text { Delivered Energy/System Volume }
\end{gathered}
$$

where: system volume excludes the volume of power electronics for the hybrid electrical powertrain and excludes the volume of the CVT for the hybrid mechanical powertrain

For the systems utilizing a mechanical powertrain, the CVT volume was not included in the system volume used to calculate the power density and energy density. The justification for omitting the CVT volume from the calculation is that the volume of non-energy storage components should not be included in the calculation. This is the same reason that the power electronic volume was not included. For calculation of power density and energy density for battery energy storage the volume of the non-energy storage components listed in Table 4-1 and shown in pink in Figure 3-1 are also typically not included.

High values of both power density and energy density are obviously desirable, as low mass and low volume for the energy storage system improve overall system performance. Relatively large volumes required for a flywheel system designed with low values of power density and/or energy density would be detrimental to a hybrid vehicle. The requirement to provide that "extra" volume would increase the size and mass of the vehicle in order to house a large flywheel system. This points out the benefit of a composite flywheel with its inherent low mass if employed in a compact design.

\subsection{Flywheel Systems Compared to Batteries and Ultracapacitors}

A comparison between the performance of flywheels and batteries is instructive to understanding the difference between the two methods of energy storage and power delivery. This assessment has consistently characterized flywheels as high power energy storage devices. Flywheels are not the greatest in terms of specific energy, but they are outstanding in terms of specific power. Flywheels have the ability to absorb and deliver extremely high power levels; this makes them ideal for the power assist hybrid application.

Information in Tables 4-5, 4-6 and 4-7 is from battery goals for three different types of electric vehicles as set forth by the United States Advanced Battery Consortium LLC (USABC). The complete sets of goals can be accessed at the USABC internet site (Reference 23). In the tables USABC battery goals are listed along with current values for these same characteristics specified by three different flywheel producers. We chose these producers because they both have publicized ongoing exploratory development programs with vehicle original equipment 
manufacturers. Flybrid Systems LLP is working with both Volvo Car Corporation and Jaguar Land Rover on flywheel systems involving a mechanical powertrain, Ricardo is working with Land Rover on flywheel systems magnetically coupled in a mechanical powertrain , and Williams Hybrid Power is collaborating with Porsche SE on flywheel systems involving an electrical powertrain.

The high power (power assist) delivered by a flywheel system in an HEV is probably most appropriately compared with the USABC Power Assist HEV Battery Goals in Table 4-5. Flybrid, Ricardo and WHS flywheels respectively meet and exceed the Maximum Power-Assist goals for discharge and regenerative power. The Flybrid and Ricardo systems do not meet the available energy goal, as they chose not to do so, because they believe that the energy goal value of 0.3 to $0.5 \mathrm{kWh}$ for light-duty hybrids is too high, as discussed in Appendix E. The WHP system exceeds the Minimum Power-Assist energy goal but is less than the Maximum. The Flybrid and Ricardo systems exceed weight and volume goals, i.e. they are lighter and smaller than both the Minimum and Maximum Power-Assist goals. In this regard, the WHS system exceeds the Minimum and is less than the Maximum. The high power capability of flywheels allows them to perform exceptionally well in the Power Assist HEV application.

In Table 4-6 flywheels are compared to USABC PHEV battery goals. Once again the Flybrid, Ricardo and WHS flywheel systems meet or exceed goals relative to discharge power, regenerative power, weight and volume. Their shortcoming is in providing a large quantity of available energy for the charge depleting mode; understandable because flywheels are primarily designed and sized to provide high power. It is clear that flywheels do not compete against batteries for providing bulk energy storage such as is required for a PHEV, but they do exceed power requirements for that application.

The comparison of flywheel performance to USABC Goals for Advanced Batteries for EVs in Table 4-7 emphasizes the points previously made about the strengths and weaknesses of flywheel energy storage. Both flywheel systems dramatically exceed specific power and power density goals for EV batteries. However, flywheels cannot come close to meeting the energy related goals of specific energy, energy density, and total pack size (deliverable energy) for EV batteries. Nevertheless, the ratio of specific power to specific energy is thus hugely exceeded (by over 100 times) for flywheels.

One concludes from the comparison between the performance of flywheels and batteries that the most effective utilization of flywheels is in providing high power while providing just enough energy storage to accomplish the power assist mission effectively. That design philosophy is apparent in the Flybrid flywheel system design that sizes the energy storage based upon the requirements for efficient storage in the flywheel of regenerative braking energy. In addition to providing high power to assist an ICE in one conventional HEV application, flywheels could be effectively utilized in conjunction with and complementary to batteries. A flywheel system operating this way can extend the life of batteries by allowing their charge and discharge to be less demanding and can even allow the batteries to be downsized and made less expensive to purchase and maintain.

The following statements about ultracapacitors are from the section of the DOE Vehicle Technologies Program web site devoted to ultracapacitors (Reference 24): 
"Many applications can benefit from ultracapacitors, especially HEVs and PHEVs. Ultracapacitors can be the primary energy source during acceleration and hill climbing, as well as for recovery of braking energy because they are excellent at providing quick bursts of energy. Using an ultracapacitor in conjunction with a battery combines the power performance of the former with the greater energy storage capability of the latter. It can extend the life of a battery, save on replacement and maintenance costs, and enable a battery to be downsized. At the same time, it can increase available energy by providing high peak power whenever necessary. However, the combination of ultracapacitors and batteries requires additional power electronics, such as a DC/DC converter, which would increase the cost of the vehicle.

The use of ultracapacitors for regenerative braking can greatly improve fuel efficiency under stop-and-go urban driving conditions. Only ultracapacitors can capture and store large amounts of electrical energy (generated by braking) and release it quickly for the next acceleration".

The principal attributes of ultracapacitors stated above can also be attributed to flywheels. However, a significant difference between the capability of ultracapacitors and flywheels is in the discharge pulse size and available energy. As shown by information on ultracapacitors in Table 4-8, extracted from the USABC web site (Reference 23), the Flybrid, Ricardo and WHS flywheel systems specified in this assessment have more available energy and provide a far higher pulse of power than the goals for the most demanding ultracapacitor (42V Transient Power Assist).

Extreme power available from a flywheel can enable vehicle designers to get optimal performance out of HEVs. Engines can be downsized more when the high power from a flywheel is available, leading to further improvements in fuel economy. For instance, Parry People Movers downsized the ICE for railcar propulsion from 14 to 2.3 liters and added regenerative braking by using a low speed, steel flywheel. As a result, fuel economy was increased seven to eight times that of the former diesel railcar, while reducing $\mathrm{CO}_{2}$ emissions by over threefold! The 2.3 liter ICE with flywheel assist drives the 10 ton railcar with such good acceleration that passenger service has increased 50\%. In addition, a smaller ICE for an automobile can allow the designer to better shape the vehicle to reduce the aerodynamic coefficient of drag (to below $C_{D}=0.20$ ) and reduce vehicle frontal area, resulting in especially significant mileage improvements for high speed cruising on the interstate.

The high power capability of flywheels even suggests flywheel applications beyond providing surge power in conjunction with an ICE in a hybrid vehicle. Another possible application is to provide high power assist to hydrogen/fuel cell hybrid vehicles. 
Table 4-5. Flywheels compared with USABC Power Assist HEV Battery Goals (November 2002)

\begin{tabular}{|c|c|c|c|c|c|c|}
\hline & & \multicolumn{2}{|c|}{ HEV Battery Goals } & \multicolumn{3}{|c|}{ Flywheel Producers } \\
\hline Characteristics & Units & $\begin{array}{l}\text { Power-Assist } \\
\text { (Minimum) }\end{array}$ & $\begin{array}{l}\text { Power-Assist } \\
\text { (Maximum) }\end{array}$ & $\begin{array}{c}\text { Flybrid } \\
\text { (Mechanical } \\
\text { Powertrain) }\end{array}$ & $\begin{array}{c}\text { Ricardo } \\
\text { (Mechanical } \\
\text { Powertrain) }\end{array}$ & $\begin{array}{c}\text { WHP } \\
\text { (Electrical } \\
\text { Powertrain) }\end{array}$ \\
\hline Pulse discharge power (10s) & $\mathrm{kW}$ & 25 & 40 & 40 & 79.2 & 130 \\
\hline Peak regenerative pulse power (10s) & $\mathrm{kW}$ & $20(55-$ Wh pulse $)$ & 35 (97-Wh pulse) & 40 & 79.2 & 130 \\
\hline $\begin{array}{l}\text { Total available energy (over DOD } \\
\text { range where power goals are met) }\end{array}$ & $\mathrm{kWh}$ & 0.3 (at $\mathrm{C} / 1$ rate) & 0.5 (at $\mathrm{C} / 1$ rate) & 0.111 & 0.22 & 0.36 \\
\hline Maximum weight & $\mathrm{kg}$ & 40 & 60 & 13 & 15 & 55 \\
\hline Maximum volume & Liter & 32 & 45 & 9 & 9 & 38 \\
\hline
\end{tabular}

Table 4-6. Flywheels compared with USABC Plug-in HEV Battery Goals

\begin{tabular}{|c|c|c|c|c|c|c|}
\hline \multirow[b]{2}{*}{ Characteristics at EOL (End of Life) } & \multirow[b]{2}{*}{ Units } & \multicolumn{2}{|c|}{ PHEV Battery Goals } & \multicolumn{3}{|c|}{ Flywheel Producers } \\
\hline & & $\begin{array}{l}\text { High } \\
\text { Power/Energy } \\
\text { Ratio Battery }\end{array}$ & $\begin{array}{c}\text { High } \\
\text { Energy/Power } \\
\text { Ratio Battery }\end{array}$ & $\begin{array}{c}\text { Flybrid } \\
\text { (Mechanical } \\
\text { Powertrain) }\end{array}$ & $\begin{array}{c}\text { Ricardo } \\
\text { (Mechanical } \\
\text { Powertrain) }\end{array}$ & $\begin{array}{c}\text { WHP } \\
\text { (Electrical } \\
\text { Powertrain) }\end{array}$ \\
\hline Peak pulse discharge power $(10 \mathrm{sec})$ & $\mathrm{kW}$ & 45 & 38 & 40 & 79.2 & 130 \\
\hline Peak regen pulse power $(10 \mathrm{sec})$ & $\mathrm{kW}$ & 30 & 25 & 40 & 79.2 & 130 \\
\hline $\begin{array}{l}\text { Available Energy for CD (Charge Depleting) Mode, } \\
10 \mathrm{~kW} \text { Rate }\end{array}$ & $\mathrm{kWh}$ & 3.4 & 11.6 & 0.111 & 0.22 & 0.36 \\
\hline Available energy for CS (charge sustaining) mode & $\mathrm{kWh}$ & 0.5 & 0.3 & 0.111 & 0.22 & 0.36 \\
\hline Maximum system weight & $\mathrm{kg}$ & 60 & 120 & 13 & 15 & 55 \\
\hline Maximum system volume & Liter & 40 & 80 & 9 & 9 & 38 \\
\hline
\end{tabular}


Table 4-7. Flywheels compared with USABC Goals for Advanced Batteries for EVs

\begin{tabular}{|c|c|c|c|c|c|c|}
\hline \multirow[b]{2}{*}{ Parameter(Units) of fully burdened system } & \multirow[b]{2}{*}{ Units } & \multicolumn{2}{|c|}{$\begin{array}{l}\text { Goals for Advanced Batteries for } \\
\text { EVs }\end{array}$} & \multicolumn{3}{|c|}{ Flywheel Producers } \\
\hline & & $\begin{array}{l}\text { Minimum Goals for } \\
\text { Long Term } \\
\text { Commercialization }\end{array}$ & $\begin{array}{l}\text { Long Term } \\
\text { Goal }\end{array}$ & $\begin{array}{c}\text { Flybrid } \\
\text { (Mechanical } \\
\text { Powertrain) }\end{array}$ & $\begin{array}{c}\text { Ricardo } \\
\text { (Mechanical } \\
\text { Powertrain) }\end{array}$ & $\begin{array}{c}\text { WHP } \\
\text { (Electrical } \\
\text { Powertrain) }\end{array}$ \\
\hline Power density & $\mathrm{W} / \mathrm{L}$ & 460 & 600 & 12,200 & 6670 & 3160 \\
\hline Specific power - discharge, $80 \%$ DOD/30 sec & $\mathrm{W} / \mathrm{kg}$ & 300 & 400 & 8460 & 4000 & 2180 \\
\hline Specific power - regen, $20 \%$ DOD/10 sec & $\mathrm{W} / \mathrm{kg}$ & 150 & 200 & 8460 & 4000 & 2180 \\
\hline Energy density - $\mathrm{C} / 3$ discharge rate & $\mathrm{Wh} / \mathrm{L}$ & 230 & 300 & 12.3 & 24.4 & 9.47 \\
\hline Specific energy - C/3 discharge rate & $\mathrm{Wh} / \mathrm{kg}$ & 150 & 200 & 8.54 & 14.7 & 6.55 \\
\hline Specific power/specific energy ratio & & $2: 1$ & $2: 1$ & 991:1 & $272: 1$ & $333: 1$ \\
\hline Total pack size $(\mathrm{kWh})$ & $\mathrm{kWh}$ & 40 & 40 & 0.111 & 0.22 & 0.36 \\
\hline
\end{tabular}

Table 4-8. Flywheels compared with FreedomCar ultracapacitor end-of-life requirements

\begin{tabular}{|c|c|c|c|c|c|c|c|c|}
\hline & \multirow{2}{*}{\multicolumn{2}{|c|}{$\begin{array}{c}\text { Goals for ultracapacitors } \\
\text { 42V Transient Power } \\
\text { Assist (TPA) }\end{array}$}} & \multicolumn{6}{|c|}{ Flywheel Producers } \\
\hline System Attributes & & & \multicolumn{2}{|c|}{$\begin{array}{c}\text { Flybrid } \\
\text { (Mechanical } \\
\text { Powertrain) } \\
\end{array}$} & \multicolumn{2}{|c|}{$\begin{array}{c}\text { Ricardo } \\
\text { (Mechanical } \\
\text { Powertrain) } \\
\end{array}$} & \multicolumn{2}{|c|}{$\begin{array}{c}\text { WHP } \\
\text { (Electrical } \\
\text { Powertrain) }\end{array}$} \\
\hline Discharge Pulse & $13 \mathrm{~kW}$ & $2 \mathrm{~s}$ & $40 \mathrm{~kW}$ & $10 \mathrm{~s}$ & $79.2 \mathrm{~kW}$ & $10 \mathrm{~s}$ & $130 \mathrm{~kW}$ & $10 \mathrm{~s}$ \\
\hline Regenerative Pulse & $8 \mathrm{~kW}$ & $2 \mathrm{~s}$ & $40 \mathrm{~kW}$ & $10 \mathrm{~s}$ & $79.2 \mathrm{~kW}$ & $10 \mathrm{~s}$ & $130 \mathrm{~kW}$ & $10 \mathrm{~s}$ \\
\hline Available Energy (CP @1kW) & \multicolumn{2}{|c|}{$60 \mathrm{Wh}$} & \multicolumn{2}{|c|}{$111 \mathrm{Wh}$} & \multicolumn{2}{|c|}{$220 \mathrm{Wh}$} & \multicolumn{2}{|c|}{$360 \mathrm{Wh}$} \\
\hline
\end{tabular}




\section{FLYWHEEL SAFETY AND CONTAINMENT}

By far the greatest technical challenge facing the developer of mobile flywheel systems is the issue of safety and containment. A Partnership for a New Generation of Vehicles (PNGV) hearing report (Reference 25) contains the following entries concerning flywheel safety:

- "With respect to safety, it is not clear that a satisfactory solution has been found to the problem of burst containment. It may be that avoidance of catastrophic burst - rather than burst containment - is necessary for industry and public acceptance.” (p. 235)

- "From both a customer acceptance and a product liability standpoint, it may be necessary for vehicle manufacturers to make flywheels "fracture proof," that is, to eliminate the possibility they could come apart in a catastrophic fashion." (p. 273)

For vehicular applications, it is extremely difficult to design a lightweight, low cost containment system which can contain a full, high speed composite rotor burst failure. Therefore an approach consistent with the previously quoted comments from the PNGV Program is to establish designs and operating procedures such that full rotor burst failure modes are avoided. To be successful at this approach it is essential that the designer be aware of the failure characteristics and potential hazards that exist for high speed flywheels, as will be discussed henceforth.

\subsection{Composite Rotors Have Different Failure Characteristics}

The failure characteristics for composite flywheel rotors are significantly different than for metal flywheel rotors, and the failure of a high speed composite rotor can create enormous loads due to the very high energy transfer occurring over a short period of time. Large energy and short time means high power. In the early days of composite flywheel rotor development, there existed a period where the flywheel advocates were naive and made sales pitches which included the "fact" that composite flywheels are "inherently safe because the rotor turns to fluff." It is true that some composite flywheel rotor failures have demonstrated benign failure modes where the material became fuzzy or fluffy. Also, it is true that failed composite flywheels do not penetrate their containment vessels like metal fragments; however, there can be large, unexpected loads during the high speed failure of a composite flywheel. The tendency for the rotor to turn to fluff may have been related to the use of Kevlar fiber or fiberglass composites and it may have been characteristic of failures at lower tip speeds, below a threshold speed that is both material and design dependent (nominally less than 800 to $900 \mathrm{~m} / \mathrm{s}$ for Kevlar or fiberglass). Carbon fiber composites behave dramatically different than Kevlar fiber or fiberglass composites.

Carbon fiber composite is a material of choice for many of the flywheels on the market today. Table 3-1 showed that carbon/epoxy flywheels can exhibit very high specific kinetic energy. When a carbon composite flywheel rotor fails and impacts a solid containment vessel above a threshold speed, the rotor is broken into fine particles as the result of the impact. The particles tend to move around the inside of the containment vessel, acting much like a fluid flowing on a curved surface. The fluid-like phenomenon can lead to significant axial loads impacting the ends of the containment structure, in addition to the expected radial and circumferential loads from impact. This fluid flow phenomenon was discussed in detail, with both analytical and experimental supporting evidence, at the flywheel workshops held in Oak Ridge Tennessee in 1993 (Reference 26) and 1995 (Reference 27). There have been numerous experimental tests 
where the fluid flow phenomenon has been experienced. The dramatic, high speed burst mode failures of carbon-fiber-reinforced composite flywheels exhibit the fluid flow phenomenon and resulting impulse loads (short duration and extremely high magnitude). Some of the experimental evidence for this phenomenon are:

1. Tests at Oak Ridge National Laboratory (especially the $1405 \mathrm{~m} / \mathrm{s}$ Demo $1 \mathrm{C}$ failure in 1985). The results of this test were shared with the international technical community in the previously mentioned flywheel workshops in Oak Ridge. The large axial load on the lid of the containment vessel broke numerous 0.75 -inch diameter high strength lid bolts, but the lid was held onto the tank by a set of larger bolts. A detailed evaluation of this rotor failure is provided in the report ORNL/TM-13159 (Reference 28).

2. The intentional burst failure of a flywheel rotor in Europe in 1995 resulted in the death of one of the test operators. The test chamber lid was not bolted onto the test chamber and operators were in the same room with the test chamber. The test operators were apparently unaware of the possibility of the large axial loads resulting from the burst failure of the composite rotor. When the rotor failed, the axial load overcame the rig's vacuum seal, forcing the lid open and ejecting some rotor material from the containment vessel at high speed. The testing was being performed for BMW in a laboratory near Munich, Germany run by IABG, a leading European technology and service provider (Reference 29).

3. The Flywheel Safety and Containment program supported by the Defense Advanced Research Projects Agency (DARPA) resulted in a number of dramatic, high-load burst failures of composite flywheel rotors. Flywheel spin testing was conducted in the DARPA program at Test Devices Incorporated, in Hudson, Massachusetts.

\subsection{Design Approaches To Reduce Flywheel Risk}

With the significant amount of evidence showing the hazards involved with a high speed flywheel burst mode failure, it is not acceptable for flywheel advocates to downplay the issue of safety and containment. It would be unprofessional and unethical to continue to advocate the use of composite rotors based on a claim that they are "inherently safe". Flywheel rotors must be designed to operate with low risk, as has been successfully accomplished for rotors in gas turbine engines, which also run at very high speeds.

The general public accepts the very low risk associated with gas turbine jet engine failures. The issue is risk, which is the product of probability (of a particular failure mode) and consequence (of the same failure mode). For the jet engine the risk is maintained at a low level by a combination of design, certification, manufacturing controls, inspections, operating procedures, and maintenance. The risk for the failure mode of a broken blade is treated completely different from failure of the relatively massive hub on which the blades are mounted. A containment shroud is provided to stop broken blades, thereby mitigating the consequence of a failed blade. However, the containment shroud is not designed to contain a hub failure. The consequence of an engine hub failure is likely a lost aircraft, so the probability of a hub failure must be set infinitesimally small so that risk, the product of probability and consequence, is acceptably small. Basically it is the responsibility of jet engine designers to make sure that a hub failure "never happens" and to assure that a broken blade is always contained. 
Flywheel safety issues must be addressed during the design and testing phases of development to ensure that production flywheel systems can be used with adequately low risk. The flywheel developer is responsible for conduct of the necessary tests to demonstrate that a given flywheel system design can be operated with extremely low risk for all failure modes. As for the jet engine, the issue is risk, which is the product of probability and consequence. Flywheel developers must consider all possible failure modes, while working to reduce the probability of their occurrence and to reduce their consequence such that the product of probability and consequence is acceptable.

A combination of design approaches to reduce flywheel risk can lead to a safe design. Individual design approaches are discussed below:

1. Stay away from ultimate stress. This approach involves designing with a significant stress margin between operating stress and ultimate stress. The designer must, of course, consider radial and axial stresses in addition to the large hoop stresses. Using a rotor design with a large stress margin can result in long rotor life. The designer must include consideration of stress life and cyclic fatigue failure modes.

Some flywheel developers have come to the conclusion that, for mobile applications, it is extremely difficult to design a lightweight, low cost containment system which can contain a full, high speed composite rotor burst failure. Their approach then is to establish designs and operating procedures such that these full rotor burst failure modes are absolutely avoided. A review (Reference 30) of the PNGV program expressed the foregoing sentiments in the following way:

"A key development is the design of an adequate containment mechanism in the case of failure. The flywheel technical team has followed several strategies and has essentially overcome this significant barrier. Perhaps the most important advance is the growing evidence that flywheels (or portions thereof) that fail at low stress-to-strength ratios do not "burst" but remain intact. This knowledge dictates that the rotating parts have a high ultimate strength-to-maximum operating stress ratio (about 4:1).

Retaining "loose flywheels" is significantly easier than containing fragments because of the increased time for energy dissipation. The new design strategy for flywheel housings is designed to retain loose flywheels and contain fragments from partial flywheel failures instead of containing a complete burst and disintegration of a flywheel. This design strategy also attempts to manage energy as it dissipates. Limiting the use of flywheels to fast-response power plants reduces the energy storage requirements and permits the design to meet the safety goal for strength-to-stress ratio with a manageable increase in weight."

2. Design a rotor that fails incrementally. Various schemes have been proposed where a small outer portion of the rotor is operating at higher stress, making it the most likely failure point. The strategy is to let part of the rotor fail, but avoid burst mode failure of the remainder of the flywheel. The containment system can then be designed to contain the smaller amount of energy which is released when the outer portion of the rotor fails.

\section{Use instrumentation to detect changes in rotor operation and stop operation before failure} occurs. This strategy is probably not sufficient to ensure that a burst mode failure will not occur, but it can be used in combination with other methods to help reduce the probability of having a 
burst mode failure. Several types of instrumentation can be considered: Runout probes can detect small changes in rotor balance. Accelerometers can detect changes in vibration. Acoustic sensors can detect rotor cracking. Magnetic bearings can be used as vibration detectors.

4. Incorporate containment tailored to the flywheel design. If the probability of a rotor burst cannot be set sufficiently low, containment is needed to reduce the consequence of the burst. If burst can be avoided through design, containment must still retain flywheels that could come loose and must contain fragments from partial flywheel failures.

An example of tailoring containment for flywheels is use of a "rotatable liner" to significantly reduce potentially huge torques from a burst flywheel. An example of this approach by the University of Texas Center for Electromechanics (UT-CEM) was part of their participation in the DARPA Flywheel Safety and Containment program. The flywheel failure mode documented in the article (Reference 31) was rotor burst. The approach to demonstrating low risk for this failure mode was to mitigate the consequence of a carbon-fiber-reinforced rotor burst by use of a free-floating, rotatable composite containment structure, basically cylindrical in shape. The article discusses reducing the effect of impulsive burst loads as measured by restraining torque and side loads that were reduced by an order of magnitude over results of previous tests. The experiment demonstrated safe containment of a flywheel burst at full speed.

In the event of a vehicle collision the designer must consider loads transmitted from the vehicle to the flywheel system for any design approach. These crash events are what make design of vehicular mounted flywheels so much more challenging than stationary flywheels used for other applications. Some items which must be considered are vehicle high-g loading, impact loads on the flywheel system, shaft and web integrity, touch-down bearings, radial and axial clearances, etc. Magnet Motor, $\mathrm{GmbH}$ has conducted tests where an operating flywheel system that was conservatively designed was subjected to a sudden side load of $15 \mathrm{~g}$ to simulate the loads of a vehicle collision. Their flywheel system survived the test. A Flybrid flywheel, designed for a race car, was tested at $>20 \mathrm{~g}$ deceleration in a Formula One crash test facility while spinning at full speed $(64,500 \mathrm{rpm})$. The flywheel was undamaged and still spinning after the test. Many different mounting arrangements are possible for the flywheel system, including soft suspensions or gimbals, and the capacity to handle vehicle collision loads must be demonstrated by testing.

The authors of this assessment report containment masses provided by respondents in their completed questionnaires, but the authors do not purport that the respondents' containment systems are adequate for safety. As previously stated the PNGV program (Reference 31) guideline for avoiding rotor burst was to have an ultimate strength of about 4 times the operating stress. For flywheel systems operating at a peripheral velocity or tip speed of $\geq 700 \mathrm{~m} / \mathrm{s}$ the material ultimate strengths are probably not $>4$ times operating stress, so a robust containment system is necessary. Furthermore it is questionable whether the flywheel systems with peripheral velocities of $\geq 700 \mathrm{~m} / \mathrm{s}$ and low containment mass are adequate to provide the low risk required for vehicular applications. Of course the use of about a factor of safety of 4 on hoop stress is only a guideline, and flywheel designs must be exhaustively tested to assure safe operation, as is discussed in the next section on a flywheel standard. The proof that systems with low peripheral velocity that employ Design Approach 1 "Stay away from ultimate stress" can operate safely is borne out by the L3-MM operation since 1988 of 12 buses with >60,000 hours of operation or the equivalent of 1,000,000 speed cycles each. 


\subsection{Flywheel Standard for Safe and Reliable Operation for Space Applications}

An effort funded by NASA and the Air Force succeeded in developing an ANSI/AIAA standard for flywheel rotor assemblies for space applications. The standard entitled "Space Systems Flywheel Rotor Assemblies" can be purchased from the American Institute of Aeronautics and Astronautics (Reference 32). The standard established baseline requirements for the design, fabrication, test, inspection, storage, and transportation of flywheel rotor assemblies used in a spaceflight flywheel system for energy storage and/or spacecraft attitude control. These requirements when implemented on a particular spaceflight system will assure a high level of confidence in achieving safe and reliable operation.

The approach taken in the standard for flywheel rotor assemblies for space systems is to build in sufficient safety margin so that a containment system for the purpose of containing a failed rotor is not required. To verify the design a series of qualification tests are conducted, including running a test article at 1.225 times the Maximum Expected Operating Speed (MEOS) for a minimum of five minutes without catastrophic failure. Each rotor to be fielded must pass a series of acceptance tests, including a proof spin test at 1.1 times MEOS for ten minutes. Since as explained in Section 3.4 the hoop stress in the rotor is proportional to the square of the operating speed, the speeds of 1.225 times MEOS and 1.1 times MEOS produce hoop stresses in the rotor of 1.5 and 1.21 times operating stress respectively.

The spaceflight standard could be an excellent starting point for a standard for safety of flywheels for ground based vehicular application. Most of the spaceflight standard is directly applicable to a vehicular application. 


\section{CONCLUSIONS}

Flywheel high power energy storage system technology applicable to load leveling in a heavyduty hybrid vehicle has matured dramatically in recent years. Magnet-Motor $\mathrm{GmbH}$ flywheel systems operated on a fleet of heavy-duty hybrid buses in Europe since 1988 provide a considerable history of and testament to safe use of flywheels on heavy-duty hybrid vehicles. Demonstration of flywheel systems on heavy-duty hybrid buses by the Centre for Concepts in Mechatronics (CCM) in the Netherlands provided added experience of successful application directly relevant to Department of Energy heavy-duty hybrid vehicle development programs.

Mature uses of flywheel technology in light-duty vehicles have occurred exclusively in Europe in a number of racing venues and also in road car advanced evaluations. WHP flywheels have raced for two years in the Nurburgring Long Distance Championship, and Flybrid flywheels raced in the LeMans 24-hour race. Relative to road vehicles, WHP is working with Porsche on the 918 RSR flywheel electrical powertrain application. Flybrid is developing flywheels with mechanical powertrains with two OEMs: with Jaguar Land Rover on the Jaguar XF hybrid and with Volvo on a low cost hybrid road car. A $20 \%$ fuel economy improvement is expected for both the Jaguar and Volvo flywheel hybrid applications. Ricardo is applying flywheels with mechanical powertrains on buses and automobiles. The FLYBUS project promises to improve bus fuel economy by 8 to $21 \%$ with a retro-fit of a flywheel and CVT coupled to the power takeoff unit on the Optare Solo bus's Allison automatic transmission. The KinerStor project with OEM Land Rover targets a goal of 30\% fuel savings for autos at a flywheel /transmission system on-cost of only $\$ 1,660(£ 1,000)$ !

One concludes from the comparison between the performance of flywheels and batteries that the most effective utilization of flywheels is in providing high power while providing just enough energy storage to accomplish the power assist mission effectively. Flywheels meet or exceed the power related goals (discharge power, regenerative power, specific power, power density, weight and volume) for HEV and EV batteries and also for ultracapacitors. Flywheels provide high power energy storage, with emphasis on the high power.

Stationary applications of flywheels by a host of companies are pushing technology improvements that may benefit use of flywheels on hybrid vehicles.

Safety issues that have held back the application of high power flywheels on automobiles continue to receive attention. DARPA has sponsored programs to study flywheel failure mechanisms and flywheel safe use. The ANSI/AIAA standard for flywheel rotor assemblies for space applications established requirements for safe and reliable operation of flywheels. Most of the spaceflight standard is directly applicable to a vehicular application. The spaceflight standard can be an excellent starting point for a standard for safety of flywheels for ground based vehicular application.

The October 2009 FIA endorsement of flywheels in hybrid vehicles, stating that "Technology such as flywheels reducing dependence on batteries and concentrating on ICE load shift proves to be the most promising way forward" is relevant to desired vehicular efficiency improvements. The time is right for evaluation of flywheel high power energy storage systems for both lightduty and heavy-duty vehicular application. The benefits may be worth pursuing in earnest at this time. 


\section{RECOMMENDATIONS}

In light of the strong endorsement given to flywheels by FIA in October 2009 (see FIA policy statement on page 4), it is recommended that DOE programs give flywheel high power energy storage renewed consideration for application in hybrid vehicles. Europeans are leading the application of flywheels to both light-duty and heavy-duty hybrid vehicles. There is extensive European experience with flywheels for heavy-duty vehicles, i.e. buses, city trains or trams. For recent European flywheel developments for light-duty hybrid race vehicles and in mass produced hybrid road vehicles see Williams Hybrid Power Limited, Flybrid Systems LLP, and Ricardo UK Ltd developments in Section 4.1 of this report. These European developments demonstrate the potential of flywheels for both heavy- and light-duty hybrid vehicles.

Some European flywheel developers question the level of energy storage required for a high power flywheel in an HEV application, as explained in Appendix E. A study should be undertaken to determine the level of delivered energy to maximize system performance.

A major technical issue for flywheel developers is the necessity to maintain safety for the high speed flywheel rotor, and to appropriately balance the management pressure to produce a lightweight system. With many flywheel developers working on numerous configurations, it is important that they place first priority on demonstration of containment safety. Developers of high speed rotating equipment have encountered a long list of surprises in dealing with containment issues. Those developers with limited actual experience with high speed rotors will inevitably face many of the same surprises. Benefitting from past experience and documented test experience can help new flywheel developers attain a safe containment configuration. Achieving a safe flywheel system requires careful attention to design issues, extensive failure testing to demonstrate the containment method, and formal certification procedures. An industry-wide peer-reviewed standard certification process could be a significant benefit to the flywheel development community and to vehicle OEMs. An accident resulting from a containment failure by any one of the flywheel developers would be detrimental to the entire industry. DOE could be the catalyst in establishing a flywheel standard certification process and perhaps standardized testing procedures for ground vehicles, following the approach taken by NASA and the Air Force in developing a standard for flywheel applications in space. 


\section{REFERENCES}

1. Abacus Technology Corporation, "An Assessment of Flywheel Energy Storage Technology for Hybrid and Electric Vehicles," prepared for U.S. Department of Energy, Office of Transportation Technologies, July 3, 1996.

2. FIA Commission for Environmentally Sustainable Motor Sport, "FIA Environmentally Sustainable Motor Sport Policy,” Paris, France, October, 2009.

3. Ruddell, A., "Storage Technology Report: WP-ST6 Flywheel in Investigation on Storage Technologies for Intermittent Renewable Energies: Evaluation and Recommended R\&D Strategy," European Community $5^{\text {th }}$ Framework Programme Contract No. ENK5-CT-200020336, June 17, 2003.

4. Taylor, P., et al., "A Summary of the State of the Art of Superconducting Magnetic Energy Storage Systems, Flywheel Energy Storage Systems, and Compressed Air Energy Storage Systems," SAND99-1854, Sandia National Laboratories, Albuquerque, New Mex., July, 1999.

5. Military Handbook 5G, "Metallic Materials and Elements for Aerospace Vehicle Structures," U.S. Department of Defense, November 1, 1994.

6. Burress, T.A., et al., "Evaluation of the 2008 Lexus LS 600H Hybrid Synergy Drive System," ORNL/TM-2008/185, Oak Ridge National Laboratory, Oak Ridge, Tennessee, January, 2009.

7. Burress, T.A., et al., "Evaluation of the 2007 TOYOTA CAMRY Hybrid Synergy Drive System," ORNL/TM-2007/190, Oak Ridge National Laboratory, Oak Ridge, Tennessee, April, 2008.

8. Ayers, C.W. , et al., "Evaluation of the 2004 Toyota Prius Hybrid Electric Drive System Interim Report-Revised," ORNL/TM-2004/247, Oak Ridge National Laboratory, Oak Ridge, Tennessee, July, 2007.

9. Porsche AG Press Release, "911 GT3 R Hybrid Celebrates World Debut in Geneva," http://www.porsche.com/usa/aboutporsche/pressreleases/pag/?id=2010-0211\&pool=international-de, February 11, 2010.

10. Popular Mechanics, "How It Works: Porsche 911's GT3R Hybrid Flywheel," www.popularmechanics.com/cars/alternative-fuel/hybrids/porsche-911-gt3r-hybrid-flywheel, October 8, 2010.

11. Electric Vehicle News, "Porsche unveils 918 RSR flywheel hybrid racer @ Detroit," www.electric-vehicles-cars-bikes.blogspot.com/2011/01/porsche-unveils-918-rsr-flywheelhybrid.html, January 10, 2011.

12. Eisenstein, P.A., "A Hybrid Without the Battery?," http://www.thedetroitbureau.com/2011/06/a-hybrid-without-the-battery/, Jun.30, 2011.

13. Racecar Engineering, "Flywheel hybrid systems (KERS)," http://www.racecarengineering.com/articles/f1/flywheel-hybrid-systems-kers/, April 24, 2011.

14. Kong, B., Motor Trend, "Jaguar XF Puts Prototype Flywheel Hybrid System to the Test," http://wot.motortrend.com/jaguar-xf-puts-prototype-flywheel-hybrid-system-to-the-test9614.html, September 202010.

15. Squatriglia, C., Autopia, "KERS Comes to Cars as Jaguar Tests Flywheel Hybrid," http://www.wired.com/autopia/2010/10/flywheel-hybrid-system-for-premium-vehicles/, October 28, 2010.

16. The Engineer, "CVT Technology Set For Key Role In Volvo Flywheel Evaluation," http://www.theengineer.co.uk/sectors/automotive/cvt-technology-set-for-key-role-in-volvoflywheel-evaluation/1008854.article, June 1, 2011. 
17. Automotive Engineering International Online, "Volvo Spins Up Flywheel Technology Research," http://www.sae.org/mags/aei/9924, June 19, 2011.

18. "Wheels: The Science of Spin-Flywheels," Ricardo Quarterly Review, Q4, December 2009.

19. Fuller, J. and Atkins, A., "Hardware Development of FLYBUS - Flywheel Based Mechanical Hybrid Systems for Bus \& Commercial Vehicles," Presentation at 2nd VDI Conference -Transmission in Commercial Vehicles 2011, Friedrichshafen, Germany, June 7 , 2011.

20. Fuller, J. and Atkins, A., "Flywheel Based Mechanical Hybrid System For Bus \& Commercial Vehicle Applications Including Retrofit Programme," Presentation at Low Carbon Vehicles Show, Rockingham, U.K., September 2011.

21. Press Release, "KinerStor Project Aims To Demonstrate Viability Of Low Cost Flywheel Hybrid Systems," Ricardo Plc., November 24, 2009.

22. NASA Glenn Research Center, "Flywheel Energy Storage system Designed for the International Space Station," www.grc.nasa.gov/WWW/RT/RT2001/6000/6910tyburski.html, June 2002.

23. USABC internet site for Energy Storage System Goals, http://www.uscar.org/guest/article_view.php?articles_id=85, July 2011.

24. DOE Vehicle Technologies Program internet site for ultracapacitors, http://www1.eere.energy.gov/vehiclesandfuels/technologies/energy_storage/ultracapacitors.html, July 2011.

25. "The Partnership for a New Generation of Vehicles (PNGV): Assessment of Program Goals, Activities and Priorities, Hearing Before the Subcommittee on Energy and Environment of the Committee on Science," U.S. House of Representatives, July 30, 1996 [No. 75].

26. O’Kain, D. and Howell, D., "Flywheel Energy Storage Technology Workshop," Conference 9311155, Oak Ridge National Laboratory, Oak Ridge, TN, December 31, 1993.

27. O’Kain, D., et al., "Flywheel Energy Storage Workshop," Conference 9510242, Oak Ridge National Laboratory, Oak Ridge, TN, December 31, 1995.

28. Kass, M.D., et al., "Evaluation of Demo 1C Composite Flywheel Rotor Burst Test And Containment Design," ORNL/TM-13159, Oak Ridge National Laboratory, Jul 1, 1998.

29. Ashley, S., "Designing Safer Flywheels," Mechanical Engineering Magazine, ASME International, Vol. 118, No. 11, pp. 88-91, November, 1996.

30. National Research Council, "Review of the Research Program of the Partnership for a New Generation of Vehicles: Fourth Report by Standing Committee to Review the Research Programs of the Partnership for a New Generation of Vehicles," National Academy Press, Washington D.C., 1998.

31. Strubhar, J. L., et al., "Lightweight Containment for High-Energy Rotating Machines," IEEE Transactions on Magnetics, Vol. 39, No. 1, pp. 378-383, January 2003.

32. ANSI/AIAA S-096-2004, "Space Systems - Flywheel Rotor Assemblies," American Institute of Aeronautics and Astronautics, November 30, 2004.

33. Ugural, A. C. and Fenster, S. K., "Advanced Strength and Applied Elasticity," Elsevier North Holland Publishing Company, Inc., New York, New York, 1979.

34. Bolund, B., et. al., "Flywheel Energy and Power Storage Systems," Renewable and Sustainable Energy Reviews, Elsevier, Vol. 11, pp. 235-258, 2007.

35. USABC internet site for Energy Storage System Goals, http://www.uscar.org/guest/article_view.php?articles_id=87, January 2012.

Note: References 6, 7, 8, 27, 28, and 29 are available on the DOE Information Bridge at http://www.osti.gov/bridge/. 


\section{APPENDIX A - SUMMARY INFORMATION PROVIDED BY DEVELOPERS OF}

FLYWHEEL ENERGY STORAGE SYSTEMS

\section{CONTENTS OF APPENDIX A}

CCM: Centre for Concepts in Mechatronics

Flybrid Systems LLP

Flywheel Energy Systems Inc

HyKinesys Inc

L-3 Communications Magnet-Motor GmbH

Mario Gottfried

Parry People Movers Ltd

POWERTHRU

Ricardo UK Ltd

Tribology Systems, Inc

University of Texas-Center for Electromechanics

Williams Hybrid Power Limited

Instructions for Completing Questionnaire Items 
This page intentionally left blank. 
Flywheel Energy Storage System Specification (Heavy-duty Vehicle)

\begin{tabular}{|c|c|}
\hline $\begin{array}{l}\text { Primary Developer and } \\
\text { Contact Information }\end{array}$ & $\begin{array}{l}\text { CCM: Centre for Concepts in Mechatronics; Dr.ir. Frans Thoolen } \\
\text { P.O. Box 12, NL-5670 AA Nuenen; De Pinckart 24, NL-5674 CCM } \\
\text { Nuenen; Phone +31 (0)40-2635000; Fax +31 (0)40-2635555; The } \\
\text { Netherlands; E-mail Frans.Thoolen @ @ccm.nl; Internet www.ccm.nl }\end{array}$ \\
\hline Other Partners & Cooperation with industrialization partner(s) is sought. \\
\hline Rotor & $\begin{array}{l}\text { Rotor module is composed of thick rim carbon composite flywheel, integrated } \\
\text { with rotor of permanent magnet machine. Rotor is attached via rotor flange to } \\
\text { bearing spindle }\end{array}$ \\
\hline - Design and Materials & $\begin{array}{l}\text { Rotor composed of steel cylinder at inner bore lined with permanent magnets } \\
\text { (=outer rotor electrical machine) and at outer bore enclosed by flywheel rim, } \\
\text { made of filament wound carbon fibre-epoxy composite material }\end{array}$ \\
\hline - Operating Speed Range & Max $22,000 \mathrm{rpm}$ \\
\hline - Maximum Tip Speed (m/s) & $700 \mathrm{~m} / \mathrm{s} ; 840 \mathrm{~m} / \mathrm{s}$ at over speed test \\
\hline \multicolumn{2}{|c|}{\begin{tabular}{|l|l|} 
Motor/Generator & \\
\end{tabular}} \\
\hline - Description & $\begin{array}{l}3 \text { Phase synchronous permanent magnet, exterior type (rotor runs integrate } \\
\text { outside stator), integrated in hub of flywheel }\end{array}$ \\
\hline $\begin{array}{l}\text { Voltage, Current, and } \\
\text { Waveform }\end{array}$ & $\begin{array}{l}\text { System can directly be coupled to DC Voltage bus: DC voltage } 420 \text { - } 800 \text { V max; } \\
\text { DC current } 400 \text { A max }\end{array}$ \\
\hline - Number of Phases (AC) & 3 \\
\hline - Frequency Range (AC) & I kHz max. \\
\hline Power Electronics & $\begin{array}{l}\text { Current Source Inverter based on thyristors with integrated chopper based on } \\
\text { IGBT switches }\end{array}$ \\
\hline Bearings & $\begin{array}{l}\text { Bearing cartridge based on ceramic ball bearings (grease lubricated; design life } \\
50.000 \mathrm{~h} \text { ) }\end{array}$ \\
\hline Containment & $\begin{array}{l}\text { Light weight (100 kg) containment structure for vacuum environment (no } \\
\text { continuous vacuum pumping); System safety is under redesign }\end{array}$ \\
\hline \multicolumn{2}{|l|}{ System $^{1}$} \\
\hline - Delivered Energy (kWh) & 4 \\
\hline - Peak (continuous) Power & $300 \mathrm{~kW}$ peak; $200 \mathrm{~kW}$ continuously \\
\hline - System $^{1}$ Mass $(\mathrm{kg})$ & $375 \mathrm{~kg}$ \\
\hline - Containment Mass (kg) & 100 \\
\hline - System $^{1}$ Volume (L) & $190 \mathrm{~L}$ \\
\hline - Specific Energy (Wh/kg) & 10.6 Wh/kg (usable) \\
\hline - Specific Power $(\mathrm{W} / \mathrm{kg})$ & $800 \mathrm{~W} / \mathrm{kg}$ \\
\hline - Energy Density (Wh/L) & $21 \mathrm{Wh} / \mathrm{L}$ \\
\hline - Power Density (W/L) & $1578 \mathrm{~W} / \mathrm{L}$ \\
\hline $\begin{array}{l}\text { - Round-trip Efficiency } \\
\text { and Measurement Method }\end{array}$ & $90 \%$, measured during one cycle of full charge $\&$ discharge \\
\hline - Cost of System ${ }^{1}$ & N.A. \\
\hline - Primary Application & $\begin{array}{l}\text { Load leveling in trams for eco mode (with overhead wire as primary power } \\
\text { source) and autonomy mode (off-wire operation); load leveling for floating cranes } \\
\text { (energy and emission reduction) }\end{array}$ \\
\hline - Level of Maturity & $\begin{array}{l}\text { Beta model testing has shown insufficient safety; Gamma model design with } \\
\text { improved safety ready; Testing, Validation and Certification of Gamma model still } \\
\text { to be done. }\end{array}$ \\
\hline - Comments & $\begin{array}{l}\text { Above specs apply for RxV-II type of EMAFER (Electromechanical } \\
\text { Accumulator for Energy Re-use) flywheel systems. The RxV-II type is a medium } \\
\text { sized flywheel system; other system sizes for lower (Light -Duty vehicles) and higher } \\
\text { energy and power ratings (from } 0,3 \mathrm{kWh} \text { and } 50 \mathrm{~kW} \text { up to } 10 \mathrm{kWh} \text { and } 600 \mathrm{~kW} \text { ) are } \\
\text { possible and partly in preparation. }\end{array}$ \\
\hline
\end{tabular}

${ }^{1}$ The flywheel system is defined here as including the energy storage rotor, the motor/generator, the bearings, and the containment. Power electronics weight, volume and cost are not considered, in order to allow a more direct comparison with published chemical battery data 


\section{Synopsis}

\section{General}

The EMAFER flywheel system is based on a high speed composite (carbon fibre) flywheel integrated with a synchronous permanent magnet motor/generator and controlled by a powerful bidirectional power converter with high frequency power switches. The complete flywheel system can, e.g. for rail vehicle application, be packaged into a roof cabinet as illustrated below and is comprised of the following modules, see also next Figure.

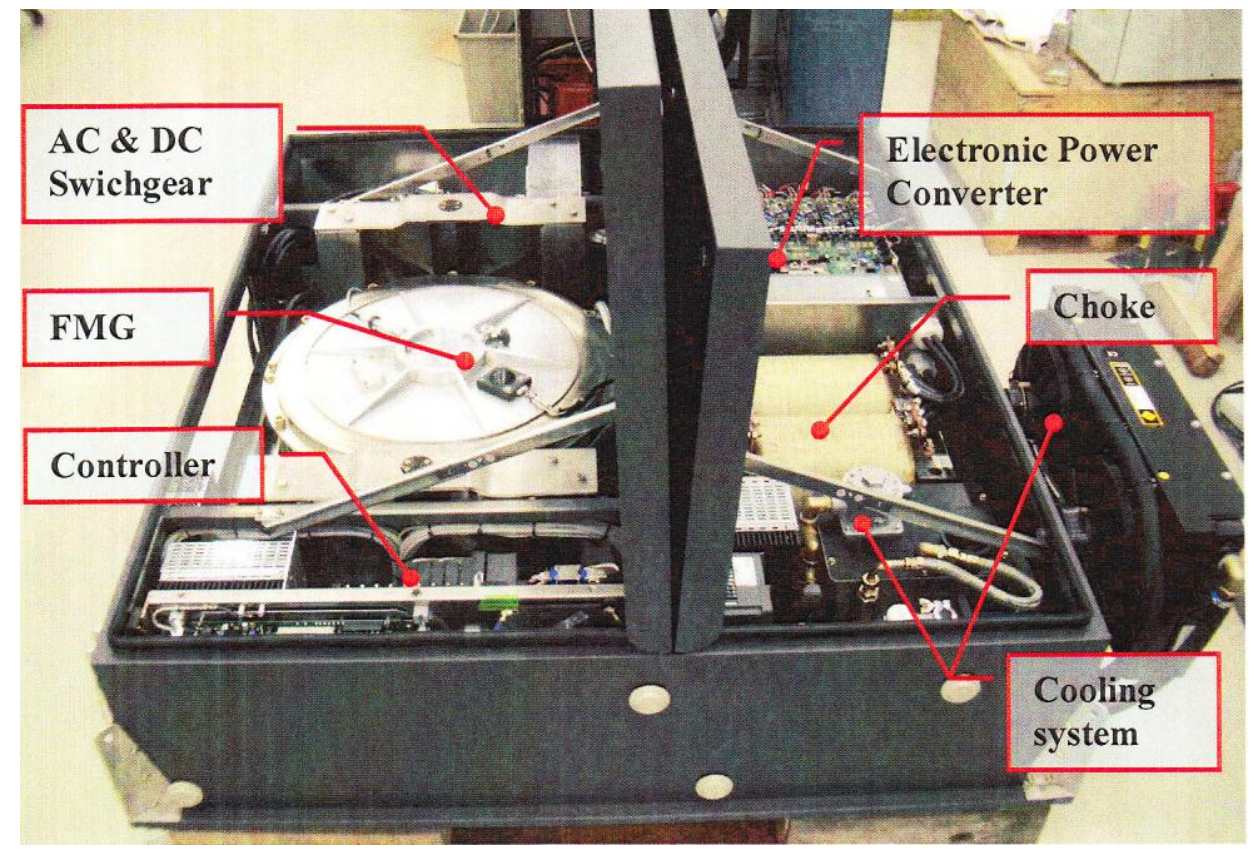

Figure: Flywheel box

\section{Flywheel-Motor/Generator-Unit (FMG)}

The FMG is very compact by its modular construction. The energy is stored as mechanical energy (rotational) and is exchanged electrically via the three phases of the synchronous permanent magnet machine (motor/generator).

The containment is coupled to the vehicle via a cardanic suspension. This cardanic suspension isolates vibrations and gyroscopic forces to and from the vehicle.

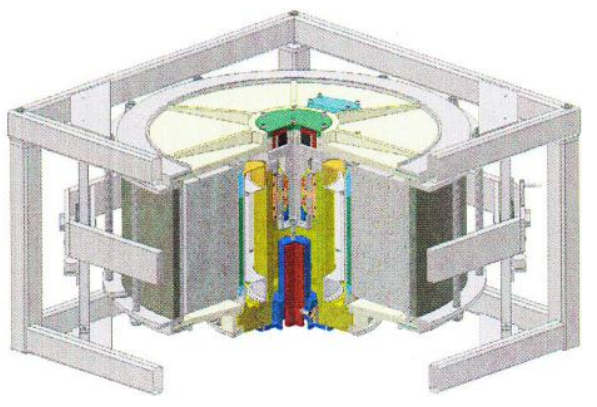

EMAFER RxV-II:

$4 \mathrm{kWh} / 300 \mathrm{~kW}, 22000$

rpm 0780 x $450 \mathrm{~mm}, 375$ 


\section{Electronic power converter}

The electronic power converter couples the three phases of the FMG with the vehicle DC link. The converter is composed of a current source inverter with a chopper, linked to each other via a choke. The chopper allows for fluctuations in DC voltage level, enabling all electric compatibility (for use in autonomous vehicles as well as vehicles with external energy supply). Also it allows for direct coupling with the DC bus of the vehicle thus enabling integration of the flywheel system as a "click-on" system.

\section{Controller}

The controller controls the converter and the auxiliary, monitors the condition and takes care of the communication with the vehicle control via a serial link (CAN, MVB or others on request). As an option the EMAFER flywheel system can be equipped with an intelligent power and energy management system for optimum performance and efficiency.

\section{Cooling system}

There is a cooling system for heat removal and temperature control of the FMG and the converter. A vacuum pump is only at start up required. These are the only auxiliaries, there is no lubrication pump required.

\section{$A C$ and $D C$ switchgear}

The AC-switch gears (contactors), including fuses, provide system safety by coupling and decoupling of the FMG and converter in case of emergency situations. The DC-switch gears enable the coupling and decoupling of the PPU to the vehicle DC-link and provides as well system safety in case of emergency situations.

\section{Benefits}

Benefits of the EMAFER in vehicular application are:

Energy savings (up to $40 \%$ in urban operation); Peak power capability enabling high vehicle performance with excellent drivability; Dispense with electric supply infrastructure; Emissions from less than EURO 5 standards to zero; Minimization of noise; Environmental protection.

\section{Maturity}

CCM has a long experience in flywheel technology. The flywheel project, commenced in 1986, has demonstrated flywheel energy storage technology as a viable energy saving and emission reducing resource for on-board public transport vehicles. Alpha and Beta models of the RxV-II Flywheel have been tested in relevant environment (pilots in Citadis Tram of Alstom and AutoTram road vehicle of Fraunhofer Institute), corresponding with a Technology Readiness Level TRL 6 (on a scale 1 to 9 , where 1 is concept level and 9 is product level).

Extensive validation tests for reliability have demonstrated that the safety level of the Beta model was insufficient and that, also for certification purposes, a flywheel and containment redesign were required.

The new design of the Gamma model of the RxV-II Flywheel has been finalized. Testing, Validation and Certification of the Gamma model are still to be done. 
This page intentionally left blank. 


\section{Flywheel Energy Storage System Specification (Light-duty Vehicle)}

\begin{tabular}{|c|c|}
\hline $\begin{array}{l}\text { Primary Developer and } \\
\text { Contact Information }\end{array}$ & $\begin{array}{l}\text { Flybrid Systems LLP. } \\
\text { Silverstone Innovation Centre, Silverstone Circuit, Silverstone, } \\
\text { Northamptonshire, NN12 8GX, United Kingdom } \\
\text { Tel: } 00441327856106 \quad \text { email: mail@ @lybridsystems.com }\end{array}$ \\
\hline Other Partners & $\begin{array}{l}\text { The Flybrid system uses CVT technology under license from Torotrak } \\
\text { and the transmission is engineered and manufactured by Xtrac }\end{array}$ \\
\hline \multicolumn{2}{|l|}{ Rotor } \\
\hline - Design and Materials & Steel hub with a carbon fiber filament wound rim \\
\hline - Operating Speed Range (rpm) & Up to $60,000 \mathrm{rpm}$ \\
\hline - Maximum Tip Speed (m/s) & 675 \\
\hline Motor/Generator & None \\
\hline - Description & \\
\hline $\begin{array}{l}\text { Voltage, Current, and } \\
\text { Waveform }\end{array}$ & \\
\hline \multicolumn{2}{|l|}{ - Number of Phases (AC) } \\
\hline \multicolumn{2}{|l|}{ - Frequency Range (AC) } \\
\hline Power Electronics & None \\
\hline Bearings & Rolling element \\
\hline Containment & $\begin{array}{l}\text { Proprietary design of lightweight containment system covered by } \\
\text { patent application }\end{array}$ \\
\hline \multicolumn{2}{|l|}{ System $^{1}$} \\
\hline - Delivered Energy (kWh) & $0.111 \mathrm{kWh}(400 \mathrm{~kJ})$ but scalable to larger sizes \\
\hline - Peak (continuous) Power (kW) & $110 \mathrm{~kW}$, minimum $60 \mathrm{~kW}$ anywhere in the running range \\
\hline - System ${ }^{1}$ Mass (kg) & $25 \mathrm{~kg}$ complete, $13 \mathrm{~kg}$ excluding transmission \\
\hline - Containment Mass (kg) & $5 \mathrm{~kg}$ \\
\hline - System ${ }^{1}$ Volume (L) & $18 \mathrm{~L}, 9 \mathrm{~L}$ excluding transmission \\
\hline - Specific Energy (Wh/kg) & 8.54 (for system excluding transmission) \\
\hline - Specific Power (W/kg) & 8460 (for system excluding transmission) \\
\hline - Energy Density (Wh/L) & 12.3 (for system excluding transmission) \\
\hline - Power Density (W/L) & 12,200 (for system excluding transmission) \\
\hline $\begin{array}{l}\text { - Round-trip Efficiency and } \\
\text { Measurement Method }\end{array}$ & $\begin{array}{l}70 \% \text { for a storage event from zero to full storage capacity followed by } \\
\text { a } 5 \text { second wait and then complete release of all stored energy }\end{array}$ \\
\hline - Cost of System ${ }^{1}$ & $\begin{array}{l}\$ 2,000 \text { for mass produced units in quantities of } 150,000 \text { per annum } \\
\text { (predicted) }\end{array}$ \\
\hline - Primary Application & $\begin{array}{l}\text { Passenger cars, petrol or diesel engine prime mover with mechanical } \\
\text { flywheel hybrid kinetic energy recovery }\end{array}$ \\
\hline - Level of Maturity & $\begin{array}{l}\text { Prototype vehicle built and tested by Jaguar Cars. Delivering fuel } \\
\text { savings up to } 20 \% \text { on real world test cycles. }\end{array}$ \\
\hline - Comments & $\begin{array}{l}\text { This is a fully mechanical system with no power electronic } \\
\text { components. }\end{array}$ \\
\hline
\end{tabular}

${ }^{1}$ The flywheel system is defined here as including the energy storage rotor, the motor/generator, the bearings, and the containment. Power electronics weight, volume and cost are not considered, in order to allow a more direct comparison with published chemical battery data. 


\section{Synopsis}

The Flybrid system is a high-speed flywheel based energy storage and recovery system.

The flywheel is connected to the transmission of the vehicle via a Continuously Variable Transmission (CVT) and manipulation of the CVT ratio achieves control of energy storage and recovery. When the ratio is changed so as to speed up the flywheel energy is stored, and when the ratio is changed so as to slow down the flywheel energy is recovered.

This technology is not new. Flywheel energy storage has been used in hybrid vehicles such as busses, trams and prototype cars before, but the installation tended to be heavy and the gyroscopic forces of the flywheel were significant. Flybrid Systems have now overcome these limitations.

The key difference with the Flybrid device is the flywheel speed. Rotating at up to 64,500 RPM the flywheel can be very much smaller and lighter than has previously been possible and the gyroscopic forces are also reduced to a level that can be considered insignificant. This advance in speed has been made possible by several key inventions for which patent protection has been applied.

The Flybrid system is very powerful and of course power is important in a racing car, but in fact it is also very important in a road car. All road cars are capable of very high power transfer during braking, and the key to hybrid system effectiveness is capturing as much of this normally wasted energy as possible.

The Flybrid system is very efficient in comparison to electric alternatives, has a long life with very low performance degradation and has no end of life recycling issues.

Road car systems have been developed and demonstrated in conjunction with several OEM carmakers. Public domain Flybrid clients include Jaguar Cars and Volvo Cars. The Jaguar car in particular has completed many months of testing with very good reliability. It has completed over 75,000,000 flywheel revolutions in car and around 5,000 miles of physical testing.

Several Flybrid clients are progressing well towards mass production. The predicted price of mass produced systems is low, as the system is made almost entirely of conventional materials processed by conventional means.

In 2010 Flybrid Systems developed a new version of the mechanical flywheel hybrid system that does not need a CVT transmission. The new system uses a Flybrid patented Clutched Flywheel Transmission or CFT to achieve an even smaller size, lower weight and lower cost. In this new system a series of small clutches perform a controlled slip to transmit the drive between the flywheel and the vehicle. This system has an efficiency of $64 \%$ round trip.

This new CFT based system raced in the Le Mans 24-hour race in June 2011 and by doing so powered the first ever hybrid car to compete in the famous race. The new system is rated at $100 \mathrm{~kW}$ with $540 \mathrm{~kJ}(150 \mathrm{Wh})$ of storage and weighs less than $38 \mathrm{~kg}$ complete including the flywheel, containment, transmission, lubrication, fluids, cooling and control systems.

The new CFT transmission opens up the possibility for very small and low cost hybrid systems such as may be suitable for small passenger cars.

Flybrid also have clients in bus, truck and off-highway fields of application. 


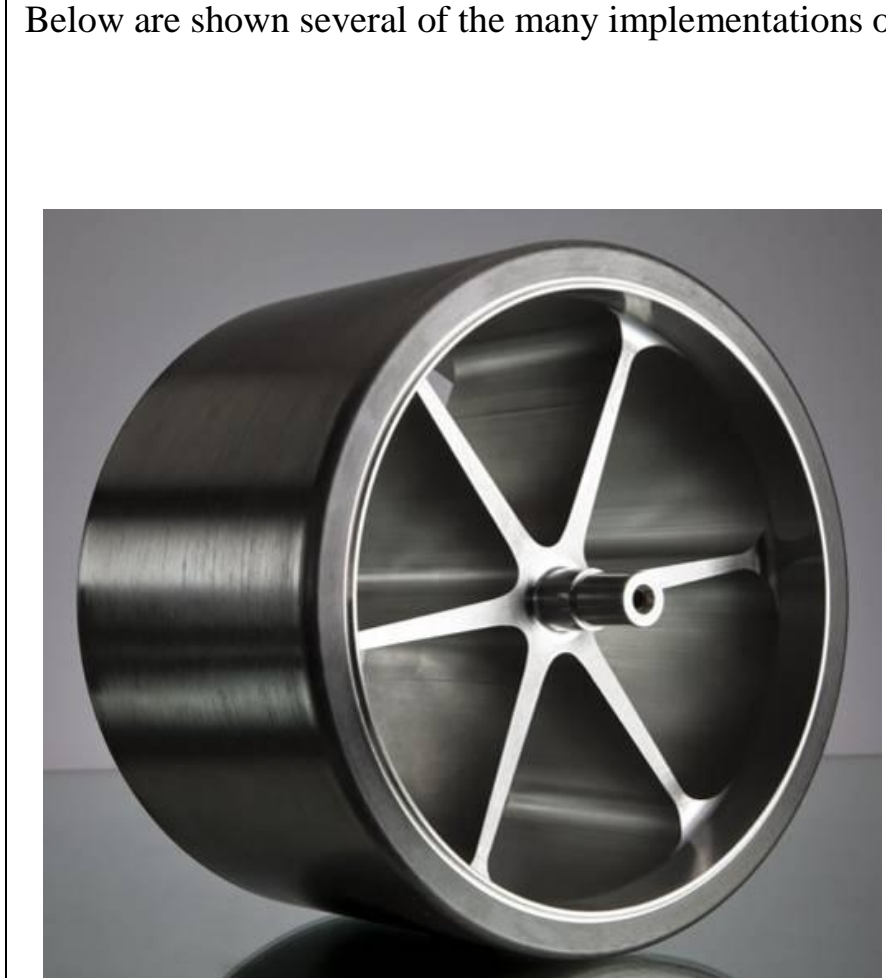

Typical Flybrid flywheel

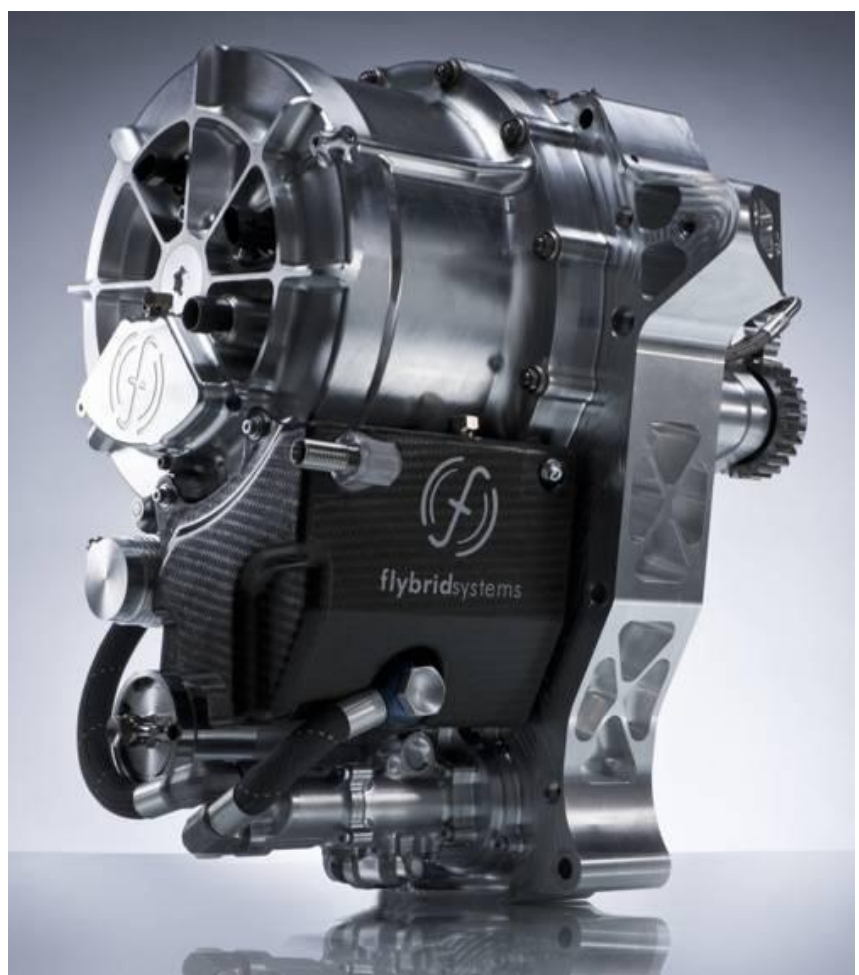

Flybrid Kinetic Energy Recovery System with Clutched Flywheel Transmission.

This new CFT based system raced in the Le Mans 24hour race in June 2011 and by doing so powered the first ever hybrid car to compete in that famous race.

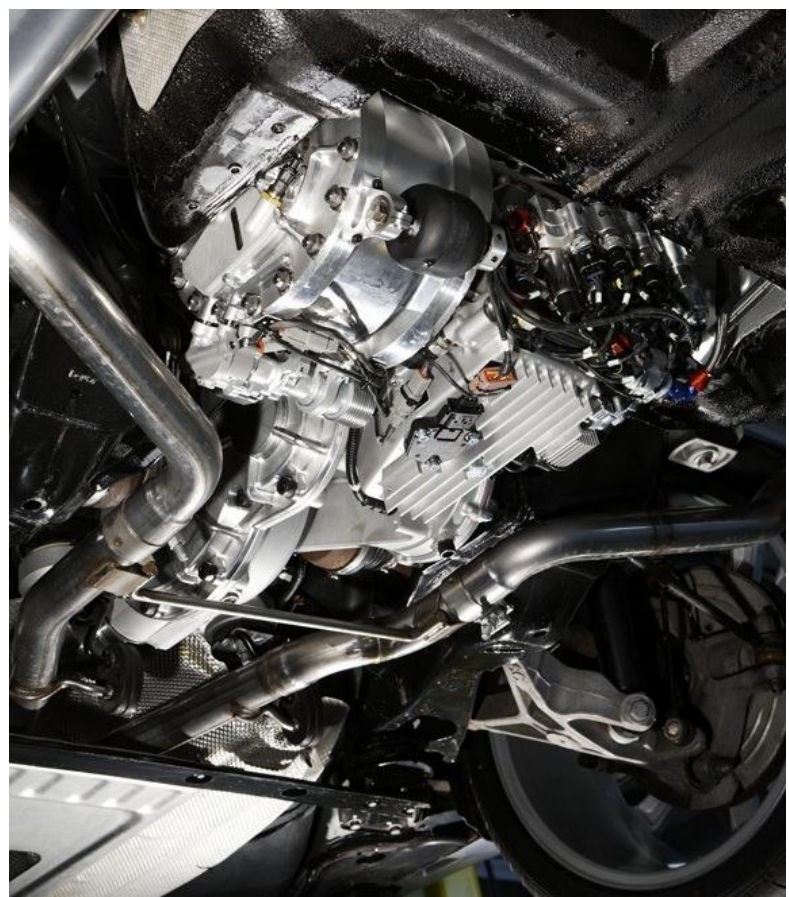

Flybrid flywheel system fitted to Jaguar test car in Flywheel Hybrid System for Premium Vehicles Project

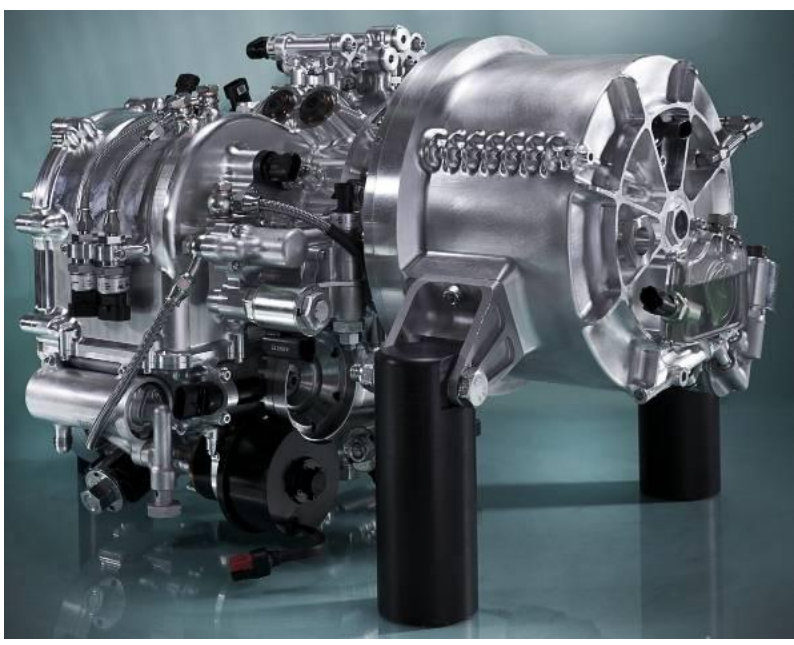

Flybrid supercar hybrid system now on test with the client 
This page intentionally left blank. 


\begin{tabular}{|c|c|}
\hline $\begin{array}{l}\text { Primary Developer and } \\
\text { Contact Information }\end{array}$ & $\begin{array}{l}\text { Flywheel Energy Systems Inc. } \\
\text { 25C Northside Road } \\
\text { Ottawa, Ontario } \\
\text { K2H 8S1Canada } \\
\text { T: 613-596-0856 } \\
\text { F: 613-596-6052 } \\
\text { dean.flanagan@ blueprintenergy.com }\end{array}$ \\
\hline Other Partners & None \\
\hline \multicolumn{2}{|l|}{ Rotor } \\
\hline - Design and Materials & $\begin{array}{l}\text { Aluminum alloy hub } \\
\text { Glass and carbon reinforced epoxy rim }\end{array}$ \\
\hline - Operating Speed Range (rpm) & $14,000 \mathrm{rpm}-28,000 \mathrm{rpm}$ \\
\hline - Maximum Tip Speed (m/s) & $730 \mathrm{~m} / \mathrm{s}$ \\
\hline \multicolumn{2}{|l|}{ Motor/Generator } \\
\hline - Description & Permanent magnet, synchronous ac, liquid cooled \\
\hline $\begin{array}{l}\text { - Voltage, Current, and } \\
\text { Waveform }\end{array}$ & No comment. \\
\hline - Number of Phases (AC) & 3 \\
\hline - Frequency Range (AC) & $467 \mathrm{~Hz}-933 \mathrm{~Hz}$ \\
\hline Power Electronics & DSP controlled bi-directional variable frequency converter \\
\hline Bearings & Hybrid ceramic ball bearings \\
\hline Containment & None \\
\hline \multicolumn{2}{|l|}{ System $^{1}$} \\
\hline - Delivered Energy (kWh) & $0.750 \mathrm{kWh}$ \\
\hline - Peak (continuous) Power (kW) & $120 \mathrm{~kW}$ peak (70 kW continuous) \\
\hline - System ${ }^{1}$ Mass (kg) & $150 \mathrm{~kg}$ \\
\hline - Containment Mass (kg) & $0 \mathrm{~kg}$ \\
\hline - System ${ }^{1}$ Volume (L) & 125 litres \\
\hline - Specific Energy (Wh/kg) & $5 \mathrm{Wh} / \mathrm{kg}$ \\
\hline - Specific Power $(\mathrm{W} / \mathrm{kg})$ & $800 \mathrm{~W} / \mathrm{kg}$ peak (467 W/kg continuous) \\
\hline - Energy Density (Wh/L) & $6 \mathrm{Wh} /$ litre \\
\hline - Power Density (W/L) & $960 \mathrm{~W} /$ litre peak (560 W/litre continuous) \\
\hline $\begin{array}{l}\text { - Round-trip Efficiency and } \\
\text { Measurement Method }\end{array}$ & $>86 \%$ at $70 \mathrm{~kW}(\mathrm{DC} \rightarrow \mathrm{AC} \rightarrow$ Flywheel Rotor $\rightarrow \mathrm{AC} \rightarrow \mathrm{DC})$ \\
\hline - Cost of System ${ }^{1}$ & Present: $\$ 75,000$. Future goal: $<\$ 20,000$. \\
\hline - Primary Application & $\begin{array}{l}\text { Experimental laboratory system with a goal of use in heavy hybrid } \\
\text { vehicles. }\end{array}$ \\
\hline - Level of Maturity & $\begin{array}{l}\text { Performance numbers tested and verified in laboratory conditions. } \\
\text { No field trials, beta sites or commercial deployments. }\end{array}$ \\
\hline - Comments & $\begin{array}{l}\text { The containment mass is cited as } 0 \mathrm{~kg} \text {. The machine has a vacuum } \\
\text { enclosure but this enclosure is not intended to contain a rotor burst. }\end{array}$ \\
\hline
\end{tabular}

1 The flywheel system is defined here as including the energy storage rotor, the motor/generator, the bearings, and the containment. Power electronics weight, volume and cost are not considered, in order to allow a more direct comparison with published chemical battery data. 


\section{Synopsis}

This machine combines a short duration, high power handling capability with low mass and small volume. The rotor relies upon significant stress margins and test heritage to provide a safe, long life machine. The combination of these performance characteristics makes this machine a suitable choice for deployment in heavy hybrid vehicles.

A similar, more highly stressed composite rotor was tested to over $10^{5}$ cycles.

The unit is tolerant of all vehicle platform motions. It has been tested to pitch and/or roll rates of $10^{\circ}$ per second, through $+/-10^{\circ}$ of arc, and under various complex loading spectra composed of vehicle platform dynamic motions in the range of $1 \mathrm{~Hz}$ through $20 \mathrm{~Hz}$.

Performance and simulated vehicle testing included over 1700 hours of run time in the laboratory. Power profiles were designed to simulate operation in a hybrid city bus on the Manhattan, New York Composite and Orange County Transit Authority schedules. Simultaneously, random vibration testing signatures were applied to provide a high fidelity laboratory simulation of deployment on a hybrid city bus.

This machine was developed by Flywheel Energy Systems Inc. with financial assistance from the CANMET Energy Technology Centre, Natural Resources Canada. 
Flywheel Energy Storage System Specifications (Light-duty Vehicle)

\begin{tabular}{|c|c|}
\hline $\begin{array}{l}\text { Primary Developer and } \\
\text { Contact Information }\end{array}$ & $\begin{array}{l}\text { HyKinesys } \\
\text { Cyrus Irani, President, } 310265 \text { 2252, cyrus.irani@ @ykinesys.com } \\
27520 \text { Hawthorne Boulevard \#205, Rolling Hills Estates, CA } 90274\end{array}$ \\
\hline Other Partners & DuPont and IBM \\
\hline \multicolumn{2}{|l|}{ Rotor } \\
\hline - Design and Materials & $\begin{array}{l}\text { 'Self-contained' design principle, with one or more pairs of counter- } \\
\text { rotating rotors made of steel and fiber composite. }\end{array}$ \\
\hline - Operating Speed Range (rpm) & 10,000 to $20,000 \mathrm{rpm}$ in the initial version \\
\hline - Maximum Tip Speed (m/s) & Currently deliberately limited to 350 meters per second \\
\hline \multicolumn{2}{|l|}{ Motor/Generator } \\
\hline - Description & $\begin{array}{l}\text { The Surge Power Unit (SPU) integrates the traction motor and energy } \\
\text { storage functions. Uses CVT consisting of two motor/generators and } \\
\text { planetary gear set. }\end{array}$ \\
\hline $\begin{array}{l}\text { Voltage, Current, and } \\
\text { Waveform }\end{array}$ & $400 \mathrm{~V} \mathrm{AC}$ \\
\hline - Number of Phases (AC) & Three \\
\hline - $\quad$ Frequency Range (AC) & NA \\
\hline Power Electronics & $\begin{array}{l}\text { Single integrated controller for twin motor/generators and optional } \\
\text { plug-in battery pack. }\end{array}$ \\
\hline Bearings & Hybrid ceramic ball bearings \\
\hline Containment & $\begin{array}{l}\text { Rotor casings of stainless steel } \\
\text { Each rotor is self-contained by its lightly-stressed fiber outer rim }\end{array}$ \\
\hline \multicolumn{2}{|l|}{ System 1} \\
\hline - $\quad$ Delivered Energy (kWh) & $0.3 \mathrm{kWh}$ with two short rotors \\
\hline - $\quad$ Peak (continuous) Power & $100+\mathrm{kW}$ Initial market is high power for both light and heavy duty \\
\hline - $\quad$ System $^{1}$ Mass $(\mathbf{k g})$ & $\sim 50 \mathrm{~kg}$ without motor function \\
\hline - Containment Mass (kg) & Primary containment is outer rim of rotor. Total containment $\sim 20 \mathrm{~kg}$ \\
\hline - $\quad$ System $^{1}$ Volume $(L)$ & $\sim 40 \mathrm{~L}$ \\
\hline - $\quad$ Specific Energy $(\mathrm{Wh} / \mathrm{kg})$ & $\sim 6 \mathrm{Wh} / \mathrm{kg}$ \\
\hline - $\quad$ Specific Power $(W / k g)$ & $>2,000 \mathrm{~W} / \mathrm{kg}$ \\
\hline - $\quad$ Energy Density $(\mathrm{Wh} / \mathrm{L})$ & $\sim 7.5 \mathrm{Wh} / \mathrm{L}$ \\
\hline - $\quad$ Power Density (W/L) & $\sim 2,500 \mathrm{~W} / \mathrm{L}$ \\
\hline $\begin{array}{l}\text { - Round-trip Efficiency and } \\
\text { Measurement Method }\end{array}$ & $\begin{array}{l}\text { Better than } 70 \% \text { expected at urban speeds, measured installed in the } \\
\text { vehicle as a percentage after a full brake-and-accelerate cycle }\end{array}$ \\
\hline - Cost of System ${ }^{1}$ & $\begin{array}{l}\text { Projected initial cost for after-market add-on for large sedan - } \$ 10,000 \text {. } \\
\text { Target for OEM in volume }<\$ 1000 \text {, net of engine downsizing }\end{array}$ \\
\hline - Primary Application & $\begin{array}{l}\text { 'Fuel-only' and 'plug-in' hybrids, plus high performance all-electrics. } \\
\text { Initial focus on premium car market and urban delivery vehicles. }\end{array}$ \\
\hline - Level of Maturity & Under development \\
\hline - Comments & $\begin{array}{l}\text { This surge power unit is the fully integrated equivalent of a complete } \\
\text { electric hybrid drive, including its battery, controller, generator and } \\
\text { motor, or a flywheel battery plus traction motor and controller, so a } \\
\text { direct numeric comparison can only be made at the vehicle level. }\end{array}$ \\
\hline
\end{tabular}

${ }^{1}$ The flywheel system is defined here as including the energy storage rotor, the motor/generator, the bearings, and the containment. Power electronics weight, volume and cost are not considered, in order to allow a more direct comparison with published chemical battery data. 


\section{Synopsis}

A typical battery-electric hybrid is capable of carrying out a 'round trip' from, say, $30 \mathrm{mph}$ to a stop and back up to 30 again with an efficiency of around $35 \%$, at best. There are two main reasons for this low level of efficiency. The battery in a typical hybrid car cannot accept a charge at more than $30 \mathrm{~kW}$, causing the friction brakes to be invoked in all but the gentlest of applications. Second, there are four energy transformations inherent in the 'round trip' if a battery is used, each of these necessarily wasting significant amounts of energy, particularly at peak power. These transformations are mechanical-to-electrical in the initial braking/generating phase, electrical-to-chemical through the controller and into the battery, then chemical-toelectrical from the battery back through the controller and finally into the motor for the last, electrical-to mechanical, transformation. Each transformation may be relatively efficient, say 70 to $80 \%$ at peak power, but there are four of them and their inefficiencies compound to give the disappointing result.

In contrast, there are only two energy transfers in the all-mechanical version of the SPU described here, because the 'surplus' kinetic energy of the vehicle is transferred into the rotors through the CVT at over $90 \%$, and then transferred back a few seconds later at a similar level of efficiency. Kinetic energy is only being transferred, not transformed, so an overall efficiency of $80 \%$ is quite possible, which will transform the urban energy consumption of hybrids and EVs. The high power levels available will also facilitate radical engine downsizing in many applications, thus contributing to a significant reduction in fuel consumption cruising at the freeway limit. An important consideration is that these high levels of efficiency obtain right up to peak power, unlike many other systems, which is ideal in a surge power unit. This capability in a PHEV or BEV allows the surge power unit to shield the battery from the vehicle's peak energy flows, thus helping to extend the life of the battery, and allow the choice of battery to focus on minimizing the full-life cost-per-mile. Basically, for the same range, the battery can be less expensive to buy, and should last longer.

In its simplest form for a 'fuel-only' hybrid, the all-mechanical version of the SPU needs no high-power electric circuits or controllers. As a rough guide, the CVT (complete with its controller) is likely to be a little less expensive than a conventional automatic transmission of similar torque capacity. In a PHEV, a typical light vehicle will need no more than $20 \mathrm{~kW}$ (continuous) from its battery, the rest being provided entirely by the SPU when the engine is off. All this speaks to low cost. Initial investigations at the sub- $\$ 5,000$ vehicle level indicate that a combined transmission for a small engine and a basic SPU could cost only \$300 more that a conventional CVT alone.

In summary, this solution to the pervasive requirement for surge power across 'fuel-only' and 'plug-in' hybrids, fuel cell vehicles and BEVs can be shown to be the best theoretical way of providing the highest efficiency, very durably and at low cost. We are in the process of proving it is also the best practical solution, measured by the ultimate test, how well it does in real vehicles. 
Flywheel Energy Storage System Specifications (Heavy-duty Vehicle)

\begin{tabular}{|c|c|}
\hline $\begin{array}{l}\text { Primary Developer and } \\
\text { Contact Information }\end{array}$ & $\begin{array}{l}\text { L-3 Communications Magnet-Motor GmbH (L-3 MM) } \\
\text { Dr. Peter Ehrhart, Petersbrunner Strasse 2, 82319 Starnberg, } \\
\text { Germany, +49-8151-262-171, Peter.Ehrhart@L-3Com.com }\end{array}$ \\
\hline Other Partners & -- \\
\hline \multicolumn{2}{|l|}{ Rotor } \\
\hline - Design and Materials & $\begin{array}{l}\text { Hollow cylindrical rotor, } \\
\text { filament wound carbon fiber and glass fiber }\end{array}$ \\
\hline - Operating Speed Range (rpm) & $12,000 \mathrm{rpm}$ \\
\hline - Maximum Tip Speed (m/s) & $390 \mathrm{~m} / \mathrm{s}$ \\
\hline \multicolumn{2}{|l|}{ Motor/Generator } \\
\hline - Description & $\mathrm{PM}$, radial gap synchronous machine, mounted in flywheel rotor bore \\
\hline $\begin{array}{l}\text { Voltage, Current, and } \\
\text { Waveform }\end{array}$ & $\begin{array}{l}750 \mathrm{VDC} \text {, lower voltage possible, } 500 \mathrm{~A} \\
\text { Quasi sine }\end{array}$ \\
\hline - Number of Phases (AC) & 6 \\
\hline - Frequency Range (AC) & $1.2 \mathrm{kHz}$ \\
\hline Power Electronics & (L-3 MM) IGBT-inverter \\
\hline Bearings & $\begin{array}{l}\text { Steel and ceramic ball bearings, rotor weight supported by permanent } \\
\text { magnets }\end{array}$ \\
\hline Containment & Safety based on conservative rotor design with a high safety factor \\
\hline \multicolumn{2}{|l|}{ System $^{1}$} \\
\hline - Delivered Energy (kWh) & $2 \mathrm{kWh}$ \\
\hline - Peak (continuous) Power (kW) & $300(100) \mathrm{kW}$ \\
\hline - System ${ }^{1}$ Mass (kg) & $400 \mathrm{~kg}$ \\
\hline \multicolumn{2}{|l|}{ - Containment Mass (kg) } \\
\hline - System ${ }^{1}$ Volume (L) & $190 \mathrm{~L}$ \\
\hline - Specific Energy (Wh/kg) & $5 \mathrm{Wh} / \mathrm{kg}$ \\
\hline - Specific Power (W/kg) & $750 \mathrm{~W} / \mathrm{kg}$ \\
\hline - Energy Density (Wh/L) & $10.5 \mathrm{Wh} / \mathrm{L}$ \\
\hline - Power Density (W/L) & $1,580 \mathrm{~W} / \mathrm{L}$ \\
\hline $\begin{array}{l}\text { - Round-trip Efficiency and } \\
\text { Measurement Method }\end{array}$ & $87 \%$ \\
\hline \multicolumn{2}{|l|}{ - Cost of System ${ }^{1}$} \\
\hline - Primary Application & $\begin{array}{l}\text { Vehicles: Urban transport buses, light rail vehicles } \\
\text { Stationary: substation of city rails, UPS }\end{array}$ \\
\hline - Level of Maturity & $\begin{array}{l}12 \text { systems have about } 60,000 \text { hours of operation in buses each. } \\
\text { Additional systems demonstrated and tested in buses and trains. }\end{array}$ \\
\hline - Comments & \\
\hline
\end{tabular}

1 The flywheel system is defined here as including the energy storage rotor, the motor/generator, the bearings, and the containment. Power electronics weight, volume and cost are not considered, in order to allow a more direct comparison with published chemical battery data. 


\section{Synopsis}

MDS-flywheels installed in 17 hybrid electric urban transport buses operated in Europe. First bus entered service in 1988. Operation experience for 12 buses: 60,000 hours /

1 million cycles each. $6 \mathrm{~g}$-shock tests demonstrated.

3 systems demonstrated and tested on vehicles of a city train.

Advanced system with $4 \mathrm{kWh}$ in the same housing volume ready for tests in summer 2008.

A bigger system $(5 \mathrm{kWh} / 400 \mathrm{~kW})$ demonstrated and tested in a substation of a city rail $(8000 \mathrm{~h}$ operation experience).

Advanced flywheel system with superconducting magnetic bearing ready for tests in spring 2008 .
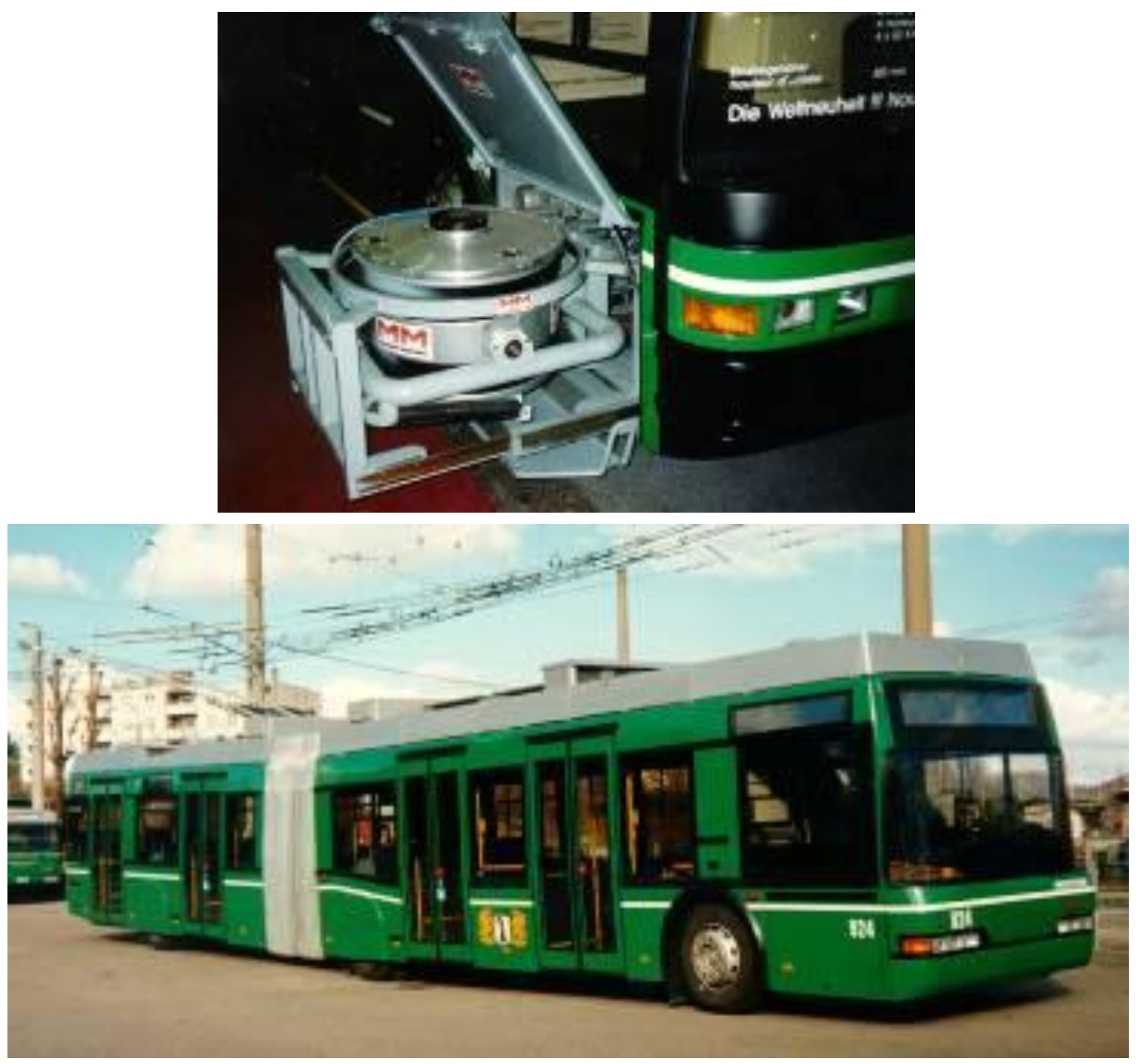

$2 \mathrm{kWh} / 150 \mathrm{~kW}$ MDS flywheel, mounted in gimbals. Operated in trolleybuses in Basel, Switzerland 
Flywheel Energy Storage System Specifications (Heavy-duty Vehicle)

\begin{tabular}{|c|c|}
\hline $\begin{array}{l}\text { Primary Developer and } \\
\text { Contact Information }\end{array}$ & $\begin{array}{l}\text { Mario Gottfried } \\
\text { Ermita Ixtapalapa 466, } 09090 \text { Mexico D.F. MEXICO } \\
\text { Tel/Fax: 52-55-82-0057 or mario@tradex.com.mx }\end{array}$ \\
\hline Project name & $\begin{array}{l}3 \text { Dimensional Counter Rotating Kinetic Electro-Mechanical Energy } \\
\text { Accumulator. 3D CR KEMEA Common name "K-Sphere" }\end{array}$ \\
\hline Rotor (s) PORTABLE UNIT & 6 Double cone 14 inch OD flywheels, in a sphere frame. \\
\hline - Design and Materials & $\begin{array}{l}\text { Double cone flywheel, steel shaft \& hub, wound ring layers of } \\
\text { boron glass \& tungsten wire+epoxy composite, carbon fiber rims. }\end{array}$ \\
\hline $\begin{array}{l}\text { - Operating Speed Range } \\
\text { (rpm) }\end{array}$ & $\begin{array}{l}\text { Est. max. portable speed to } 49,000 \mathrm{rpm} \text { for rail } \& \text { trams. }+49,000 \mathrm{rpm} \text { for tugs } \& \\
\text { cranes, for stationary UPS, gen-set substitute, etc. to }+/-60,000 \mathrm{rpm} \text {. }\end{array}$ \\
\hline - Maximum Tip Speed (m/s) & Portable: $671 \mathrm{~m} / \mathrm{s}$ at +/-36,000 rpm. Stationary, rated over $1,200 \mathrm{~m} / \mathrm{s}$ \\
\hline Motor/Generator & Induction and/or brushless DC motor/generator. \\
\hline - Description & $\begin{array}{l}5 \mathrm{HP} \text {, motor/generator core. rated } 100^{\circ} \mathrm{C} \text {, with added strength overall, } 155 \mathrm{C} \text {. } \\
\text { insulation, pre-formed brass pipe on electric coils and steel core water cooling. }\end{array}$ \\
\hline $\begin{array}{l}\text { - Voltage, Current, and } \\
\text { Waveform }\end{array}$ & $\begin{array}{l}120 \text { to } 1200 \text { volts. Controlled surge to } 100 \mathrm{amps}(30 \mathrm{~kW}) \text { per K-Sphere set. } \\
\text { Induction AC or permanent magnet rotor DC motor/generator. }\end{array}$ \\
\hline - Number of Phases (AC) & 3 AC circuits for plug-in or 2 lines when connected to a DC buss. \\
\hline - Frequency Range (AC) & 60 to $2,400 \mathrm{~Hz}$. driving 4 pole induction or permanent magnet rotors. \\
\hline Power Electronics & $\begin{array}{l}\text { Commercial or custom; Variable AC and VOLTAGE speed controllers with } \\
\text { sustained regeneration. }\end{array}$ \\
\hline Bearings & $\begin{array}{l}\text { Pin and Jewel, rubber mounted, lube Krytox }{ }^{\circledR},+ \text { shaft mounted magnet/doughnut, } \\
\text { When stationary, only magnet suspension with stiff pin \& jewel-soft touch. }\end{array}$ \\
\hline Containment & $\begin{array}{l}\text { Injected composite sphere frame, } 6 \text { cavities and lids that seal, a very strong } \\
\text { vacuum is pulled using fire. The container is burst protected. }\end{array}$ \\
\hline System $^{1}$ & PORTABLE (as in rail or trams) or STATIONARY (as in UPS or aux. power) \\
\hline - Delivered Energy (kWh) & $2.4 \mathrm{kWh}$ at $36,000 \mathrm{rpm},+6 \mathrm{kWh}$ at $55,000 \mathrm{rpm}$ for six, $40 \mathrm{~kg} . f l y w h e e l s$ \\
\hline - Peak (continuous) Power & $74.6(22.4) \mathrm{kW}$ per set or $100(30) \mathrm{HP}$ per set \\
\hline - System ${ }^{1}$ Mass (kg) & $\sim 400 \mathrm{~kg}$ for rotors+motors + frame and cradle \\
\hline - Containment Mass (kg) & $\sim 150 \mathrm{~kg}$ \\
\hline - System ${ }^{1}$ Volume (L) & 400 liters to include suspension+mounting cage for vehicles. \\
\hline - Specific Energy (Wh/kg) & Pending prototype, tabulations vary by weight and weight distribution. \\
\hline - Specific Power (W/kg) & Pending prototype results “ \\
\hline - Energy Density (Wh/L) & Expect very good, pending prototype. \\
\hline - Power Density (W/L) & Expect very good, pending prototype. \\
\hline $\begin{array}{l}\text { - Round-trip Efficiency and } \\
\text { Measurement Method }\end{array}$ & $\begin{array}{l}\sim 76 \% \text { efficient at } 60 \% \text { to } 90 \% \text { to } 60 \% \text { in speed vs. load. Estimated rundown is } \\
2.25 \% \text { at } 36,000 \mathrm{rpm} \text {, at no-load per } 24 \text { hour period. }\end{array}$ \\
\hline - Cost of System ${ }^{1}$ & $\begin{array}{l}\text { Wholesale from fabricator; } 1^{\text {st }} 1000 \text { units/12months, } \$ 3,390 \text { per unit; } \\
2^{\text {nd }} 1000 \text { units per month, } \$ 2,750 \text { ea.; }+50,000 / \text { yr., } ~ \$ 1,900 \text { ea. }\end{array}$ \\
\hline - Primary Application & $\begin{array}{l}\text { Rail and trams, stationary UPS, emergency power -up, solar/wind daily cycling } \\
\text { batteries, lighting, communications, etc. Regenerative braking. Fast loading. }\end{array}$ \\
\hline - Level of Maturity & $\begin{array}{l}\text { Young, } 75 \% \text { defined. Enough to encourage making \& testing. } \\
\text { Project scope: Stationary and EV/HEV prototypes. }\end{array}$ \\
\hline - Comments & $\begin{array}{l}\text { Excellent surging, charging \& regenerative braking recovery. Safe, using heavy } \\
\text { duty air bags to retain bits in a burst. Using Patent, US 6,232,671 B1 plus } \\
\text { several new concepts in process \& Patent Pending. }\end{array}$ \\
\hline
\end{tabular}




\section{Synopsis}

3D CR KEMEA, 3 Dimensional, Counter-Rotating, Kinetic Electro-Mechanical Energy Accumulator is a 6 flywheel electric battery set for road, rail, water, air \& space vehicles, or stationary uses. The design involves six double cone flywheels, each with its own motor in three pairs that counter-rotate on three perpendicular axis. Encapsulated in a strong cube or sphere frame; a hard vacuum pulled by burning hydrogen with oxygen forming H20. A stationary unit may allow a larger in mass, at $+60,000 \mathrm{rpm}$ rotor mass limits seem to render about $10 \mathrm{kWh}$. per KSphere set.

6 over strong double cone rotor sets are gyro free 3D+counter rotation, in a vacuum sphere frame, are believed to be safe, as flywheel engineering tames harmonics with high precision balance and strength.

Portable units $\sim 38,000 \mathrm{rpm}$, may add up to $2.4 \mathrm{kWh} /$ unit, pending testing in rail or trams, to measure changes of angular momentum at low road shock, vibration damping includes soft flywheel bearing seats, plus accumulated safely measures.

The 12 magnet, suspending 6 rotors, plus pin and jewel soft mounted. Flow can be increased to cool overloading. Due to closed circuit cooling, cryogenic cooling may become feasible, where fast charging may take only a few minutes.

Life is estimated over 20 years, even at continuous cycling.

KEMEA systems for hybrid vehicles may be competitive because of fuel savings in superior regenerative braking and recycling valuable energy vs. the future price of fuel. Further; fuel cells, super-capacitors, hydrides, nicads, zinc balls, etc. need to be complimented with kinetics, to better cover the power curve and future power parameters.

Flywheel stress is damped with precision super strong rings, made in molds; wound, baked \& balanced; harmonics and vibration are not shared by adjacent rings. In volume; frames, lids, motors, and flywheels are all ideal for mass production via injection and automated winding machines.

Higher strength heavy ceramics may also become a volume option to make heavy flywheel rings.

The frame, lids and rotors are very strong composites, so in the case of a burst, the expansion of fiber cotton, dust and splinters becomes like a high pressure fluid, in a power expansion, against yielding concave frame lids, secured by wound layers of stainless steel cable. Portable units include a strong "bag"(air bag technology) adapted to catch everything and expand without rupture.

Slowdown measures to avoid a burst....., loss of a vacuum, reverse motors, injection of goo-fire retardant, flywheel rings slip and rub and slow, the rotor may counter-rub and slow. A fast spinning rotor is formidable, and the stored energy suddenly released is fearsome. A burst would be rare but possible. Portable uses may further use "proximity detectors" to avoid collisions, the main threat.

Multiple KEMEA battery banks mounted in buses and trucks may reduce or eliminate fuel and engines. The idea is to provide a freeway quality road, to trolley-connect at stops every 2-3 miles, for 20 or 30 seconds charge, then off again. Applies to delivery trucks, school buses, public buses, mail runs, etc., reducing big costs by eliminating fuel. Valuable re-generative braking is likewise recycled at every opportunity, savings as high as $35 \%$ in re-cycling energy. Pre-designed routes may further help to eliminate heat engines, targeting to eliminating fuel altogether for many fleets.

Historic trauma with flywheels dealt with gyro, precession, bulky frames, etc. KEMEA is tabulated as the highest regenerative and fast-charging system, surging rate, longest life, low maintenance \& high efficiency battery. Storage capacity is compared to lead-acid by weight.

Vehicles visualized to use PORTABLE K-SPHERE uses are:

1. Golf cart \& people movers range extender w/o lead acid batteries adding 1-2 spheres.

2. Vehicle machine tools, cranes, tugs, off road trucks, lighting towers, etc.

3. PENDING Hybrid sedan or minivan with std. engine front wheel drive, electric rear wheel differential action with 2 spheres in a suspension cage, use half the trunk. Feasible for taxi, route, or all day duty vehicles, saving estimated at half the fuel, to pay off in less than 1 year.

4. $\mathrm{NEV} \mathrm{w/std.} \mathrm{sedan} \mathrm{or} \mathrm{van} \mathrm{for} \mathrm{all} \mathrm{electric,} \mathrm{home/office/store} \mathrm{2,} 3$ or 4 spheres.

5. Airport/hotel vans, hybrid, std. engine plus electric wheel drives, 6 or 8 spheres for extended duty, no engine or fuel.

6. Railroad, trams, subway, etc. regenerative recovery in running and downhills, to return to assist in climbing and accelerating.

7. Public/school/personnel buses can quick load energy at stops, trolley arrangement hook-up 8 to 14 spheres, w/enough power to reach the next stop. $\sim 1000 \mathrm{~kW}$ feed for $\sim 30$ seconds. 
8. Hybrid or electric; cranes, tugs, emergencies, boats, submarines, satellites, space stations

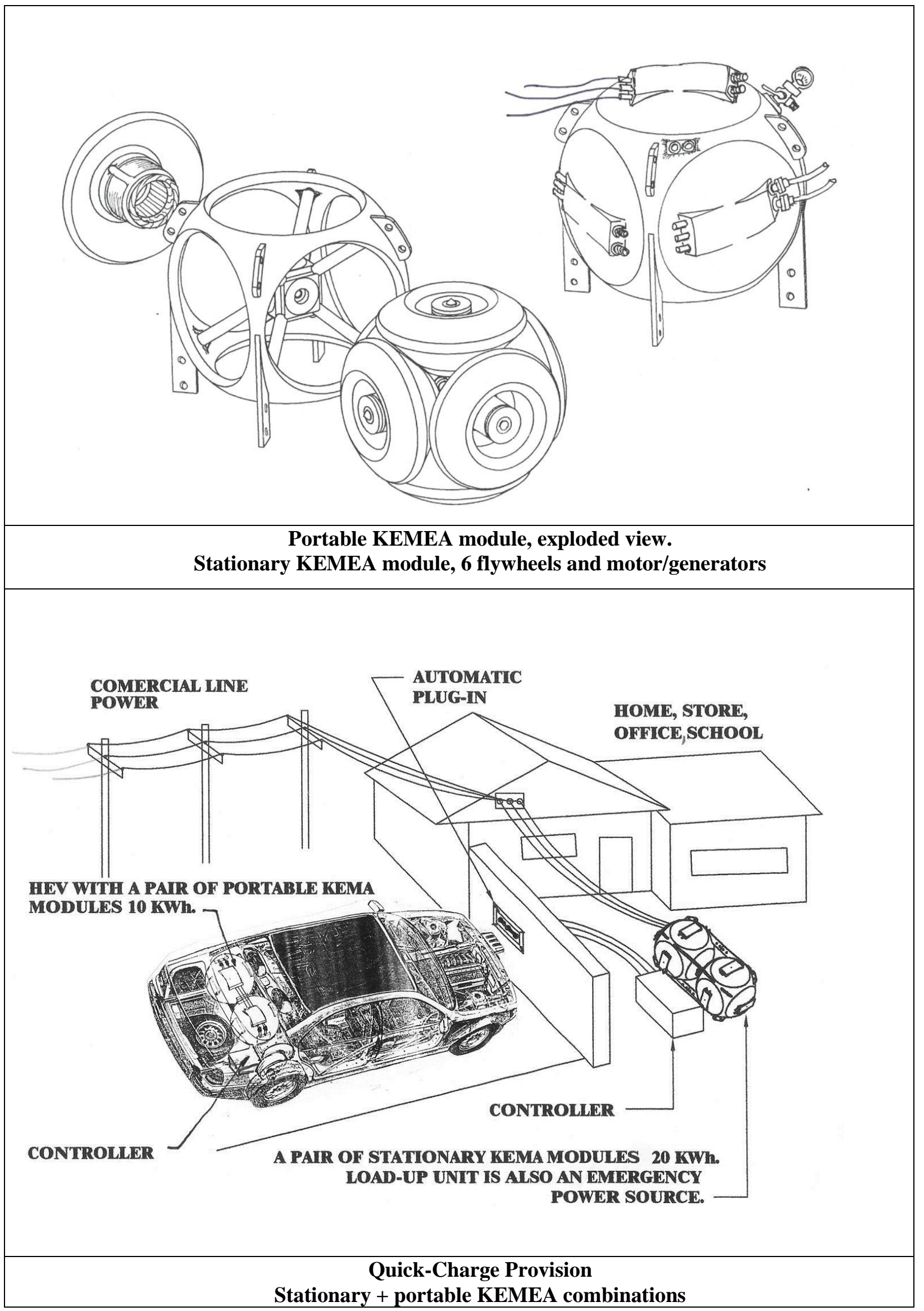


This page intentionally left blank. 
Flywheel Energy Storage System Specification (Heavy-duty Vehicle)

\begin{tabular}{|c|c|}
\hline $\begin{array}{l}\text { Primary Developer and } \\
\text { Contact Information }\end{array}$ & $\begin{array}{l}\text { John Parry MBE, JPM Parry and Associates, Overend Road, Cradley Heath, B64 } \\
\text { 7DD, UNITED KINGDOM. Tel: } 00441384569171 \\
\text { email:info @ parryassociates.com } \\
\text { www.parryassociates.com / www.parrypeoplemovers.com }\end{array}$ \\
\hline Other Partners & Parry People Movers Ltd 00441384569553 \\
\hline \multicolumn{2}{|l|}{ Rotor } \\
\hline - Design and Materials & $\begin{array}{l}\text { Multi-layer steel disc mounted on steel hub. Vertical axis. } \\
\text { Disc comprises three layers of 30mm thick EN8 steel, Loctite bonded. }\end{array}$ \\
\hline - Operating Speed Range (rpm) & $1000-2000$ normally but 3000 peak available \\
\hline - Maximum Tip Speed (m/s) & $160(157)$ \\
\hline Motor/Generator & Engine Distributors Inc. DSG 423 (similar to Ford Ranger pickup truck engine) \\
\hline - Description & $\begin{array}{l}\text { Series hybrid: Ford LPG-fueled engine driving through the flywheel } \\
\text { to a hydrostatic transmission }\end{array}$ \\
\hline - Voltage, Current, and Waveform & $\mathrm{n} / \mathrm{a}$ \\
\hline - Number of Phases (AC) & $\mathrm{n} / \mathrm{a}$ \\
\hline - Frequency Range (AC) & $\mathrm{n} / \mathrm{a}$ \\
\hline Power Electronics & $\mathrm{n} / \mathrm{a}$ \\
\hline Bearings & $\begin{array}{l}\text { Roller ball bearings on upper shaft, taper roller bearings on the bottom } \\
\text { shaft. }\end{array}$ \\
\hline Containment & Steel fabrication thickness edge $-42.7 \mathrm{~mm}$, top - $10 \mathrm{~mm}$, base $-20 \mathrm{~mm}$ \\
\hline \multicolumn{2}{|r|}{ e } \\
\hline - Delivered Energy (kWh) & 0.9 total, 0.8 based on speed range \\
\hline - Peak (continuous) Power (kW) & Limited by transmission, approx $100-200$ \\
\hline - System ${ }^{1}$ Mass (kg) & 870 (500 flywheel) or approx 1100 including engine and input/output \\
\hline - Containment Mass (kg) & 370 \\
\hline - System ${ }^{1}$ Volume (L) & Approx. 160 or 250 including engine etc. \\
\hline - Specific Energy (Wh/kg) & 0.92 (0.73 including engine etc.) \\
\hline - Specific Power $(\mathrm{W} / \mathrm{kg})$ & 230 (180 including engine etc.) \\
\hline - Energy Density (Wh/L) & 5 (3.2 including engine etc.) \\
\hline - Power Density (W/L) & 1300 (832 including engine etc.) \\
\hline $\begin{array}{l}\text { - Round-trip Efficiency and } \\
\text { Measurement Method }\end{array}$ & $\begin{array}{l}\mathrm{n} / \mathrm{a} \text { (acts mainly as a load leveler). Mechanical efficiency is very high, } \\
\text { probably } 95 \%+\text { but if used as an energy store efficiency depends on } \\
\text { how rapidly the flywheel is charged/discharged. In present application } \\
\text { flywheel alone loses } 50 \% \text { of energy (half life) in less than } 1 \text { hour, } \\
\text { hence losses are of the order of } 1 \mathrm{~kW} \text { at higher speeds. }\end{array}$ \\
\hline - Cost of System ${ }^{1}$ & $\begin{array}{l}\text { Fully installed driveline from prime mover to input to final drive } \\
\text { gearbox on axle; approx } £ 40,000 \text { (actual) }\end{array}$ \\
\hline - Primary Application & $\begin{array}{l}\text { Series hybrid - Load leveler / power booster in a mechanical } \\
\text { transmission (light rail vehicle/railcar). Primary power source is an } \\
\text { internal combustion engine fueled by liquefied petroleum gas } \\
\text { (LPG/propane). }\end{array}$ \\
\hline - Level of Maturity & $\begin{array}{l}\text { Commercial product. In use in } 3 \text { operational vehicles. } 2 \text { Car fleet at } \\
\text { Stourbridge Junction, UK, have reliability figures of } 99.44 \%(2010) \& 99.74 \% \\
\text { during } 2011 \text { to date. }\end{array}$ \\
\hline - Comments & $\begin{array}{l}\text { In performance, the most noticeable aspect of the flywheel power } \\
\text { enhanced driveline is the very good acceleration of a vehicle weighing } \\
10 \text { tonnes even though the LPG powered engine, which is never under } \\
\text { stress, has a cubic capacity of only } 2.4 \text { litres, ( } 140 \text { cubic inches })\end{array}$ \\
\hline
\end{tabular}

${ }^{1}$ The flywheel system is defined here as including the energy storage rotor, the motor/generator, the bearings, and the containment. Power electronics weight, volume and cost are not considered, in order to allow a more direct comparison with published chemical battery data. 


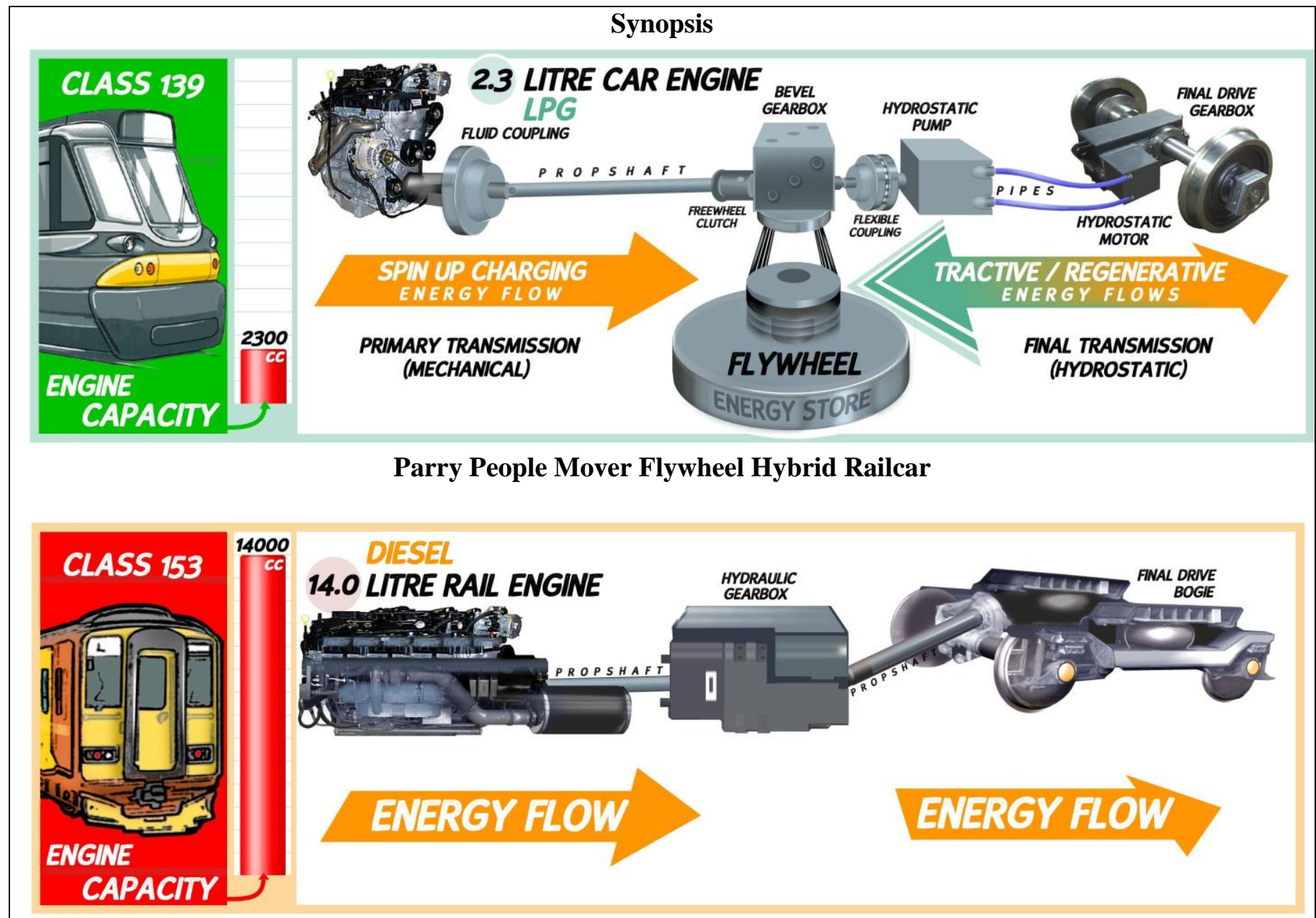

Class 153 Conventional Diesel Railcar

Above, diagrams of the drivetrain of the Class 139 railcar and the Class 153 conventional diesel railcar it directly replaced. Note the difference in engine capacity. Using the New Parry Class 139, service frequency has increased $50 \%$ from 4 services per hour to 6 . Running costs have been halved.

(Images by Will Jarman MDes info@parryassociates.com / skua49@ hotmail.com)

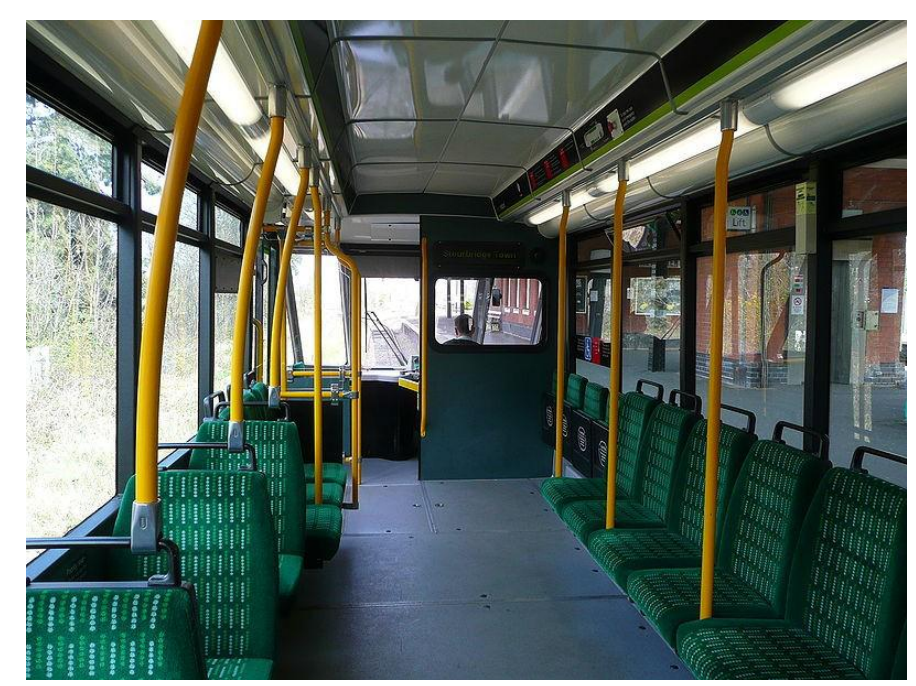

Class 139 (Parry People Mover) interior

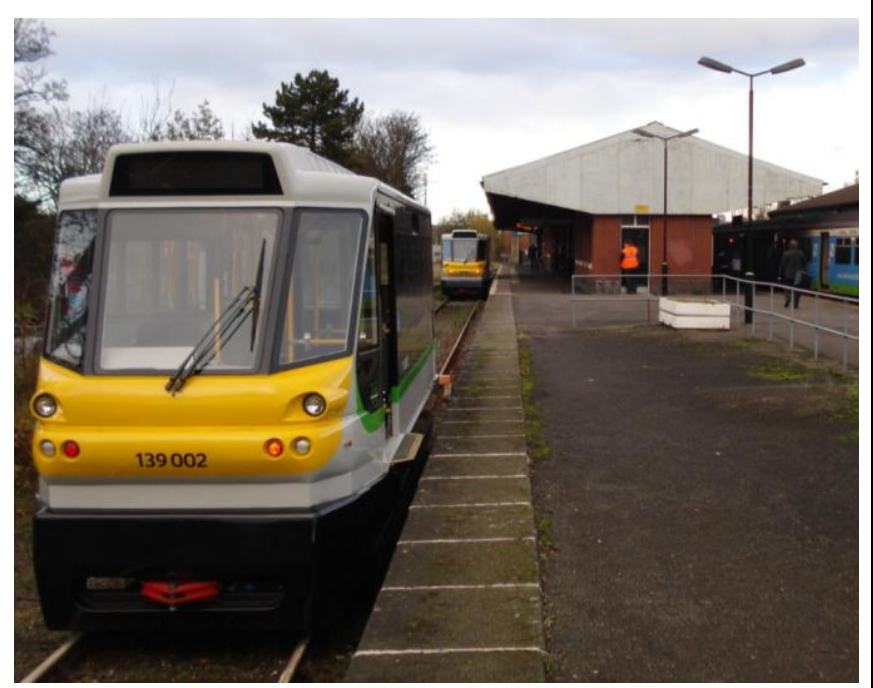

Class 139s at Stourbridge Junction, UK 


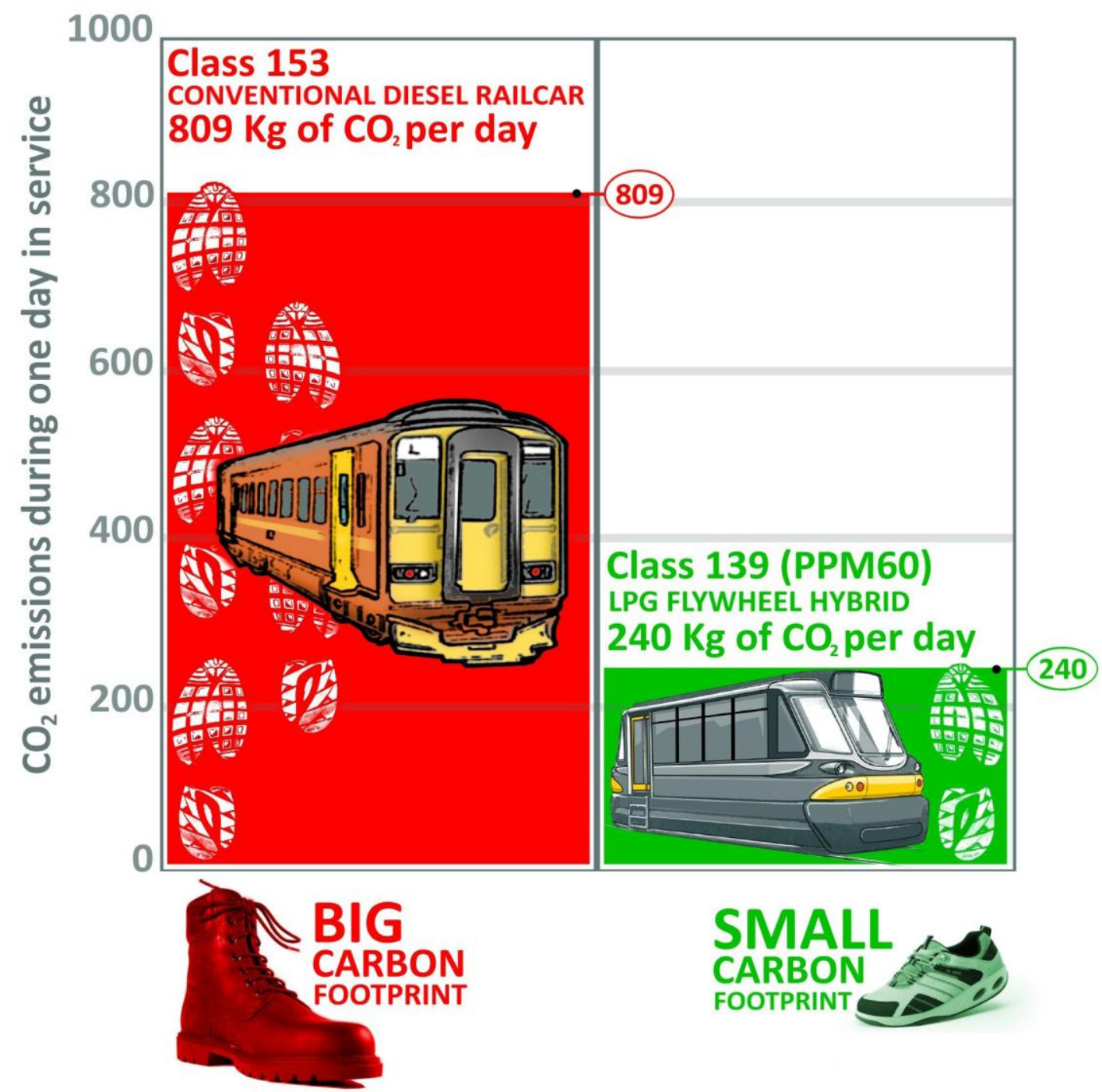

Comparison of Parry People Mover carbon emissions (over a single day in service) and a conventional diesel railcar.

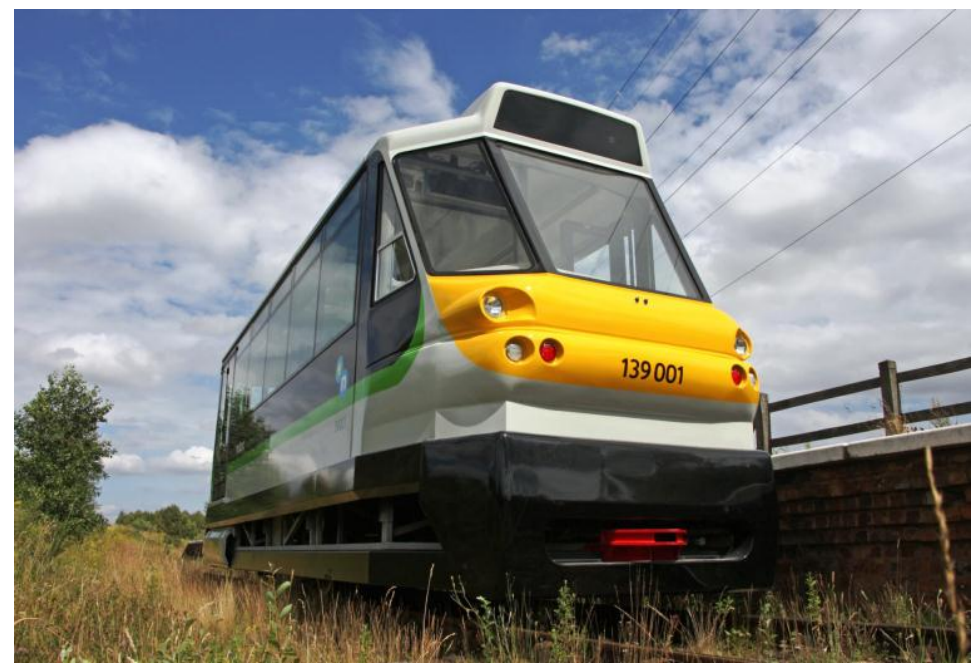

Parry People Movers Class 139 
This page intentionally left blank.

A-24 
Flywheel Energy Storage System Specification (Heavy-duty Vehicle)

\begin{tabular}{|c|c|}
\hline $\begin{array}{l}\text { Primary Developer and } \\
\text { Contact Information }\end{array}$ & $\begin{array}{l}\text { POWERTHRU } \\
\text { Contact: Lee Pichan, Director of Sales } \\
11825 \text { Mayfield, Livonia, MI, } 48150 \text { (734)-853-5322 }\end{array}$ \\
\hline \multicolumn{2}{|l|}{ Other Partners } \\
\hline \multicolumn{2}{|l|}{ Rotor } \\
\hline - Design and Materials & $\begin{array}{l}\text { A carbon fiber composite flywheel mounted on a fiberglass rim and } \\
\text { titanium hub }\end{array}$ \\
\hline - Operating Speed Range (rpm) & 25,000 to $52,500 \mathrm{rpm}$ \\
\hline - Maximum Tip Speed (m/s) & $1000 \mathrm{~m} / \mathrm{s}$ \\
\hline \multicolumn{2}{|l|}{ Motor/Generator } \\
\hline - Description & Synchronous reluctance motor, 4 pole \\
\hline $\begin{array}{l}\text { Voltage, Current, and } \\
\text { Waveform }\end{array}$ & $\begin{array}{l}\text { Fixed carrier frequency, variable sinusoidal fundamental frequency, } \\
\text { varying voltage \& current, AC motor }\end{array}$ \\
\hline - Number of Phases (AC) & Three phase \\
\hline - Frequency Range (AC) & $0-2000 \mathrm{kHz}$ \\
\hline Power Electronics & 1200 volt, $1800 \mathrm{amp}$ bi-directional IGBT based inverter \\
\hline Bearings & $\begin{array}{l}\text { Primary: Five axis active magnetic bearings, (*Note; designed for } \\
\text { mobile applications; capable of }>5+\text { g's vertical and } 3 \text { g's lateral.) } \\
\text { Secondary: Mechanical touchdown bearings for shipment and } \\
\text { excessive momentary shock loads and/or vibration. }\end{array}$ \\
\hline Containment & $\begin{array}{l}\text { Two part integrated containment system. Inner primary containment, } \\
\text { steel pressure vessel with carbon fiber wrap, for flywheel and bearing } \\
\text { systems and a steel outer containment separated by liquid coolant } \\
\text { barrier. Both are suspended and positioned by gimbal system for } \\
\text { mobile applications. *Note; Lighter weight chopped fiber outer } \\
\text { containment planned. }\end{array}$ \\
\hline \multicolumn{2}{|l|}{ System $^{1}$} \\
\hline - Delivered Energy (kWh) & .667 \\
\hline - Peak (continuous) Power (kW) & $190 \mathrm{~kW}$ \\
\hline - System ${ }^{1}$ Mass (kg) & $\begin{array}{l}274 \mathrm{~kg} \text { (Current configuration) Configuration A } \\
147 \mathrm{~kg} \text { (with planned mobile composite outer containment) } \\
\text { Configuration B } \\
\text { *Note; weight includes system liquid coolant as part of containment }\end{array}$ \\
\hline - Containment Mass (kg) & $\begin{array}{l}240 \mathrm{~kg} \text { (Current configuration) Configuration A } \\
102 \mathrm{~kg} \text { (with planned mobile composite outer containment) Config. B } \\
\text { * Note; weight includes system coolant, which acts as liquid barrier in } \\
\text { containment. }\end{array}$ \\
\hline - System $^{1}$ Volume (L) & $\begin{array}{l}\text { 92L Configuration A } \\
\text { 70L Configuration B }\end{array}$ \\
\hline - Specific Energy (Wh/kg) & $\begin{array}{l}2.43 \mathrm{Wh} / \mathrm{kg}(667 \mathrm{Wh} / 274 \mathrm{~kg}) \text { Configuration } \mathrm{A} \\
4.53 \mathrm{Wh} / \mathrm{kg}(667 \mathrm{Wh} / 147 \mathrm{~kg}) \text { Configuration B }\end{array}$ \\
\hline - Specific Power (W/kg) & $\begin{array}{l}693 \mathrm{~W} / \mathrm{kg}(190,000 \text { watts } / 274 \mathrm{~kg}) \text { Configuration A } \\
1292 \mathrm{~W} / \mathrm{kg}(190,000 \text { watts } / 147 \mathrm{~kg}) \text { Configuration B }\end{array}$ \\
\hline - Energy Density (Wh/L) & $\begin{array}{l}\text { 7.25 Wh/L (667 wh/ 92L) Configuration } \mathrm{A} \\
\text { 9.52 Wh/L (667 wh/ 70L) Configuration B }\end{array}$ \\
\hline - Power Density (W/L) & $\begin{array}{l}2065 \text { W/L (190,000 watts/92L) Configuration A } \\
2714 \text { W/L (190,000 watts/70L) Configuration B }\end{array}$ \\
\hline
\end{tabular}




\begin{tabular}{|c|c|}
\hline $\begin{array}{l}\text { - Round-trip Efficiency and } \\
\text { Measurement Method }\end{array}$ & $\begin{array}{l}\text { Round trip efficiency is approximately } 90 \% \text {. This is measured by the } \\
\text { ratio between the electric energy to kinetic energy back to electric } \\
\text { energy at peak power measured at the motor/generator terminals. The } \\
\text { round trip efficiency for the complete integrated flywheel system; } \\
\text { from the DC power input to the bi-directional inverter to the motor and } \\
\text { back through the inverter producing DC power output is } \\
\text { approximately } 70 \% \text {. }\end{array}$ \\
\hline - Cost of System ${ }^{1}$ & $\begin{array}{l}\text { MSRP } \$ 47,500.00 * \text { US for stationary package. } \\
* \text { Note; System requires magnetic bearing controllers, motor } \\
\text { controllers, and power electronics for operation and is therefore sold as } \\
\text { a complete package. Mobile package with gimbal system available in } \\
2004 \text { will be priced similarly as complete package. Estimated } \\
\text { Prototype or preliminary price for mobile package would be additional } \\
25 \% \text { cost initially. }\end{array}$ \\
\hline - Primary Application & $\begin{array}{l}\text { Primary applications today are stationary (power quality, UPS, load } \\
\text { leveling, storage), secondary applications for Hybrid electric vehicle, } \\
\text { electric rail (load leveling and power recycling). Note* Flywheel } \\
\text { system was originally conceived and designed specifically for hybrid } \\
\text { electric vehicle; gimbal, containment, bearings, and vacuum systems } \\
\text { all designed as a result of the mobile requirement. Stationary market } \\
\text { pursued due to large immediate demand and customer acceptance. }\end{array}$ \\
\hline - Level of Maturity & $\begin{array}{l}\text { POWERTHRU flywheel systems are based upon the former } \\
\text { Pentadyne Power Corporation's flywheel systems. Over } \$ 40 \text { million } \\
\text { U.S. has been invested in development and commercialization } \\
\text { resulting in } 16 \text { patents issued and several pending. Technology } \\
\text { demonstrated full power prototype in } 2001 \text { in stationary application. } \\
\text { Company reached } 100 \text { units shipped by end of } 2006 \text {. In } 2007 \\
\text { Pentadyne shipped nearly } 300 \text { units. } 2008 \text { shipments were expected to } \\
\text { exceed } 500 \text { units of the second generation product. Early systems had } \\
\text { maximum power of } 120 \mathrm{~kW} @ 500 \text { VDC, the VSS } 120 \text { and new units } \\
\text { are capable of } 190 \mathrm{~kW} @ 500 \mathrm{VDC} \text {, the VSS+DC. }\end{array}$ \\
\hline - Comments & $\begin{array}{l}\text { POWERTHRU is currently in development of a scaled version of the } \\
\text { VSS+DC which will provide peak power of approximately } 500 \mathrm{~kW} \\
\text { and stored energy will be approximately } 8 \text { MJ. The first production } \\
\text { units for stationary applications are estimated to be available in early } \\
2009 \text {. }\end{array}$ \\
\hline
\end{tabular}

1 The flywheel system is defined here as including the energy storage rotor, the motor/generator, the bearings, and the containment. Power electronics weight, volume and cost are not considered, in order to allow a more direct comparison with published chemical battery data. 
POWERTHRU designs, manufactures, tests and delivers flywheel power systems that provide clean high power electricity for power-sensitive customers in today's digital economy. The flywheel systems are designed to provide high power output and energy storage in an efficient, compact, self contained package. POWERTHRU flywheels are a long lasting, low maintenance, lightweight, and environmentally sound alternative to conventional energy storage devices.

POWERTHRU flywheel technology dates back to 1993, when a privately funded research and development firm cofounded by Ben and Harold Rosen, Rosen Motors, began development of its flywheel power systems for the vehicular passenger market. In 1998, Pentadyne secured an exclusive intellectual property license agreement to utilize the flywheel technology for stationary power quality and backup power applications. In 2002, the patents and technology became the property of Pentadyne Power Corporation. POWERTHRU acquired the assets of the former Pentadyne Power Corporation in 2010.

The heart of the product is a high-speed flywheel comprised of a multi-layer carbon-fiber composite cylinder with a titanium hub attached to a nickel alloy shaft. Three sets of magnetic bearings (five-axis control) levitate the entire rotating assembly and allow high rotational speeds to be realized with no friction or maintenance. Two touchdown shafts act as support during transit and non-operation. An integrated vacuum pump continuously provides pressures one million times lower than atmospheric pressure, virtually eliminating aerodynamic drag. The flywheel's mechanical energy is converted to electrical power through a synchronous reluctance motor. The flywheel system provides up to $190 \mathrm{~kW}$ to the load upon demand and may be recharged equally fast if sufficient power is available. To control the flow of electrical energy, the flywheel power controller utilizes high power IGBTs (Insulated Gate Bipolar Transistors) and PWM (Pulse Width Modulation) to either extract or supply energy. It uses two DSP's (Digital Signal Processor) to provide control with all other parts of the power and magnetic bearing system and the user interface. Safety is ensured by large safety margins in the innovative system design and a patented energy absorbing and dissipation system.

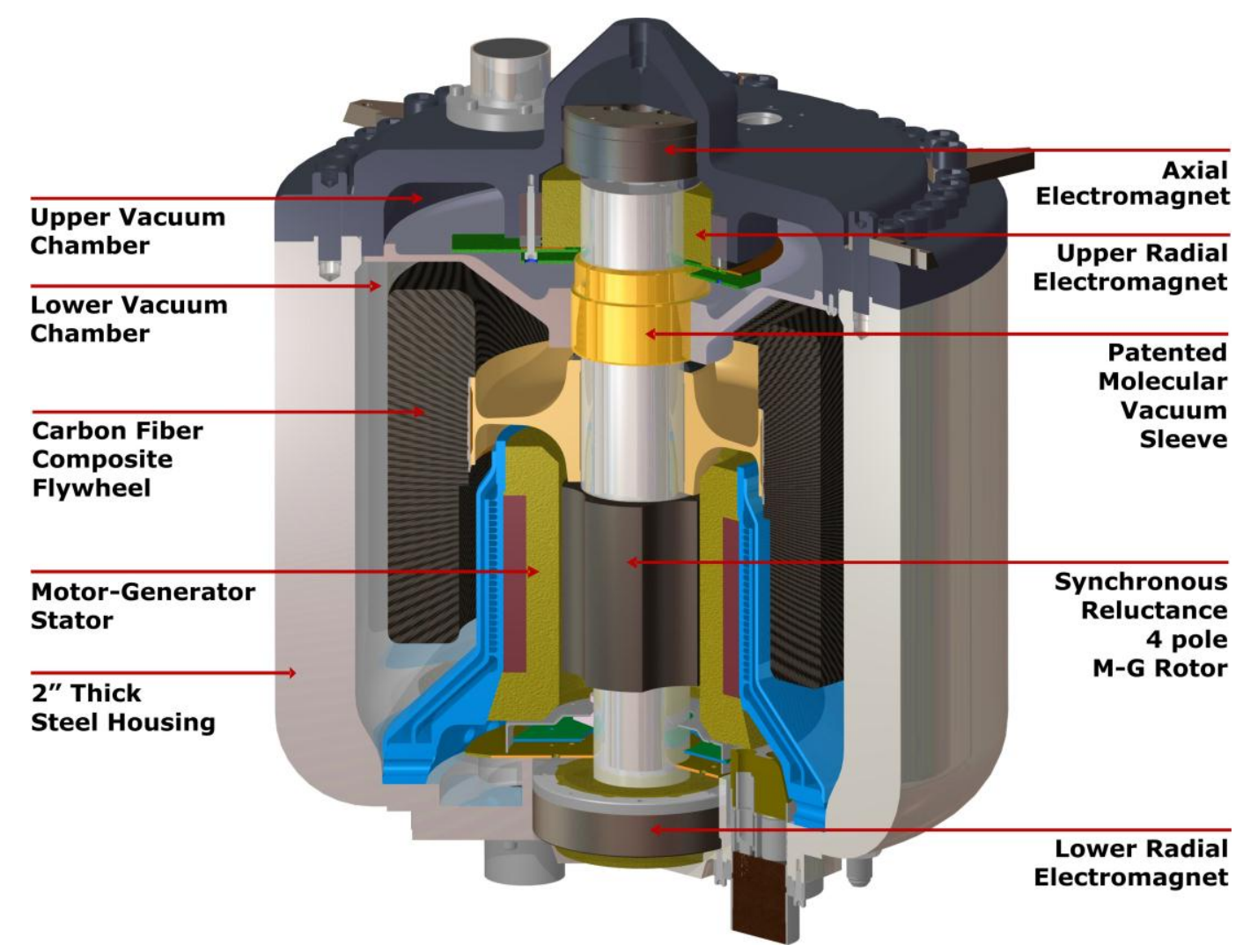


The POWERTHRU high speed composite flywheel system excels in several key areas when compared to competitors' systems. Features that differentiate the POWERTHRU flywheel from other energy storage products result in a more compact and lightweight system, easier and less expensive to install, needing far less maintenance and requiring much less power to operate. This saves the end user thousands of dollars per unit in costs over the life of the machine. These advantages are achieved with the following key patented designs:

\section{Patented flywheel design}

2. A five axis active magnetic bearing system resulting in a fully levitated rotor

3. Internal vacuum system eliminating maintenance and parasitic load losses

4. Synchronous reluctance motor/generator eliminating eddy current losses during quiescent operation and avoiding high costs of rare earth magnets

5. An innovative and proven Safety System

As government regulations and consumers continue to demand more environmentally friendly energy storage alternatives, flywheels are expected to replace conventional electrochemical batteries and ultra capacitors as the power management system of choice for hybrid electric vehicle drive-trains. This is particularly the case in heavy duty vehicles that make frequent starts and stops, such as metro rail, urban transit buses, service vehicles, and refuse trucks. The POWERTHRU flywheel can most effectively absorb the vehicle's regenerative braking energy and reuse that energy for acceleration or load.

The POWERTHRU system is in commercial production for power quality and backup power markets. Over 400 systems are operating in the field in a variety of power quality and voltage support applications with nearly 2 million hours of operation. The technology is well suited for current and future energy recycling and renewable energy applications. POWERTHRU systems are being considered for transportation, utility, and defense applications. 
Flywheel Energy Storage System Specification (Light-duty and Heavy-duty Vehicles)

\begin{tabular}{|c|c|}
\hline $\begin{array}{l}\text { Primary Developer and } \\
\text { Contact Information }\end{array}$ & $\begin{array}{l}\text { Ricardo UK Ltd } \\
\text { Shoreham Technical Centre } \\
\text { Shoreham-by-Sea, West Sussex, BN43 5FG, United Kingdom } \\
\text { Tel: } 00441273794158\end{array}$ \\
\hline \multicolumn{2}{|l|}{ Other Partners } \\
\hline \multicolumn{2}{|l|}{ Rotor } \\
\hline - Design and Materials & Filament wound carbon fiber \\
\hline - Operating Speed Range (rpm) & $60,000 \mathrm{rpm}$ \\
\hline - Maximum Tip Speed (m/s) & $>722 \mathrm{~m} / \mathrm{s}$ \\
\hline Motor/Generator & $\begin{array}{l}\text { None - Mechanically driven flywheel utilizing Kinergy magnetic } \\
\text { drive into vacuum chamber. }\end{array}$ \\
\hline \multicolumn{2}{|l|}{ - Description } \\
\hline \multicolumn{2}{|l|}{$\begin{array}{l}\text { - Voltage, Current, and } \\
\text { Waveform }\end{array}$} \\
\hline \multicolumn{2}{|l|}{ - Number of Phases (AC) } \\
\hline \multicolumn{2}{|l|}{ - Frequency Range (AC) } \\
\hline \multicolumn{2}{|l|}{ Power Electronics } \\
\hline Bearings & Rolling element, sealed and greased \\
\hline Containment & Outer composite ring containment system \\
\hline \multicolumn{2}{|l|}{ System $^{1}$} \\
\hline - Delivered Energy (kWh) & $\sim 0.220 \mathrm{kWh}$ \\
\hline - Peak (continuous) Power $(\mathrm{kW})$ & $60 \mathrm{~kW}$ peak (30 kW continuous), could be significantly higher \\
\hline - System ${ }^{1}$ Mass (kg) & $\begin{array}{l}\sim 50 \mathrm{~kg} \text { (prototype), } 30 \mathrm{~kg} \text { (projected), } \\
15 \mathrm{~kg} \text { (projected) excluding transmission, } 10 \mathrm{~kg} \text { (rotor only) }\end{array}$ \\
\hline - Containment Mass (kg) & $\sim 18 \mathrm{~kg}$ \\
\hline - System ${ }^{1}$ Volume $(\mathrm{L})$ & Approximately $18 \mathrm{~L}$ complete, $9 \mathrm{~L}$ excluding transmission \\
\hline - Specific Energy (Wh/kg) & 8.8 (prototype), 14.7 (projected) ${ }^{2}, 22$ (rotor only) Excludes transmission \\
\hline - Specific Power (W/kg) & 2400 (prototype), 4000 (projected) $^{2}, 6000$ (rotor only) Excludes transmission \\
\hline - Energy Density (Wh/L) & $24.4 \quad$ Excludes transmission \\
\hline - Power Density (W/L) & $6670 \quad$ Excludes transmission \\
\hline $\begin{array}{l}\text { Round-trip Efficiency and } \\
\text { Measurement Method }\end{array}$ & $\begin{array}{l}>90 \% \text { at full power based upon measured standing losses and max } \\
\text { power }\end{array}$ \\
\hline - Cost of System ${ }^{1}$ & Prototype cost $(3$ off $) \sim \$ 50 \mathrm{k}$ \\
\hline - Primary Application & $\begin{array}{l}\text { Mechanical hybridisation for transportation applications. Primary } \\
\text { power source IC engine with flywheel deployed for kinetic energy } \\
\text { recovery and load leveling. }\end{array}$ \\
\hline - Level of Maturity & Prototype unit tested on test rig \\
\hline - Comments & Flywheel system utilizes novel magnetic drive into vacuum chamber. \\
\hline
\end{tabular}

${ }^{1}$ The flywheel system is defined here as including the energy storage rotor, the motor/generator, the bearings, and the containment. Power electronics weight, volume and cost are not considered, in order to allow a more direct comparison with published chemical battery data.

${ }^{2}$ Projected values of specific energy and specific power are plotted in Figure 4-2 and used in Tables 4-4 to 4-8 of this report. 


\section{Synopsis}

Developed from a motorsport heritage, the Ricardo Kinergy system is fundamentally, a mechanical one. It thus has no power electronics. However based on application analysis it has been developed, so it can be simply augmented to allow interface to the transmission, (mechanical path), the electrical system (to allow electrics to be powered during start/stop events), and even hydraulic to reduce accumulator mass. It has been developed so it does not have a rotating seal, incorporating a passive magnetic/magnetic seal/gear. This obviates the need for vacuum management and provides a more efficient, high speed torque path than an equivalent mechanical epicyclic system. This system is currently being installed in a bus application for trials as well as rig evaluation for offhighway, train(as multiple modules) and passenger car applications.

\section{Ricardo is leading a number of collaborative programmes, including both UK Government sponsored \& commercial projects}

\section{Flybus Project}

Flybus is a $£ 1.2 \mathrm{M}$ project to develop a demonstrator bus using the Kinergy technology on a PSV (Optare bus) for real world testing. Partners include Torotrak, Ricardo, Optare, and Allison.
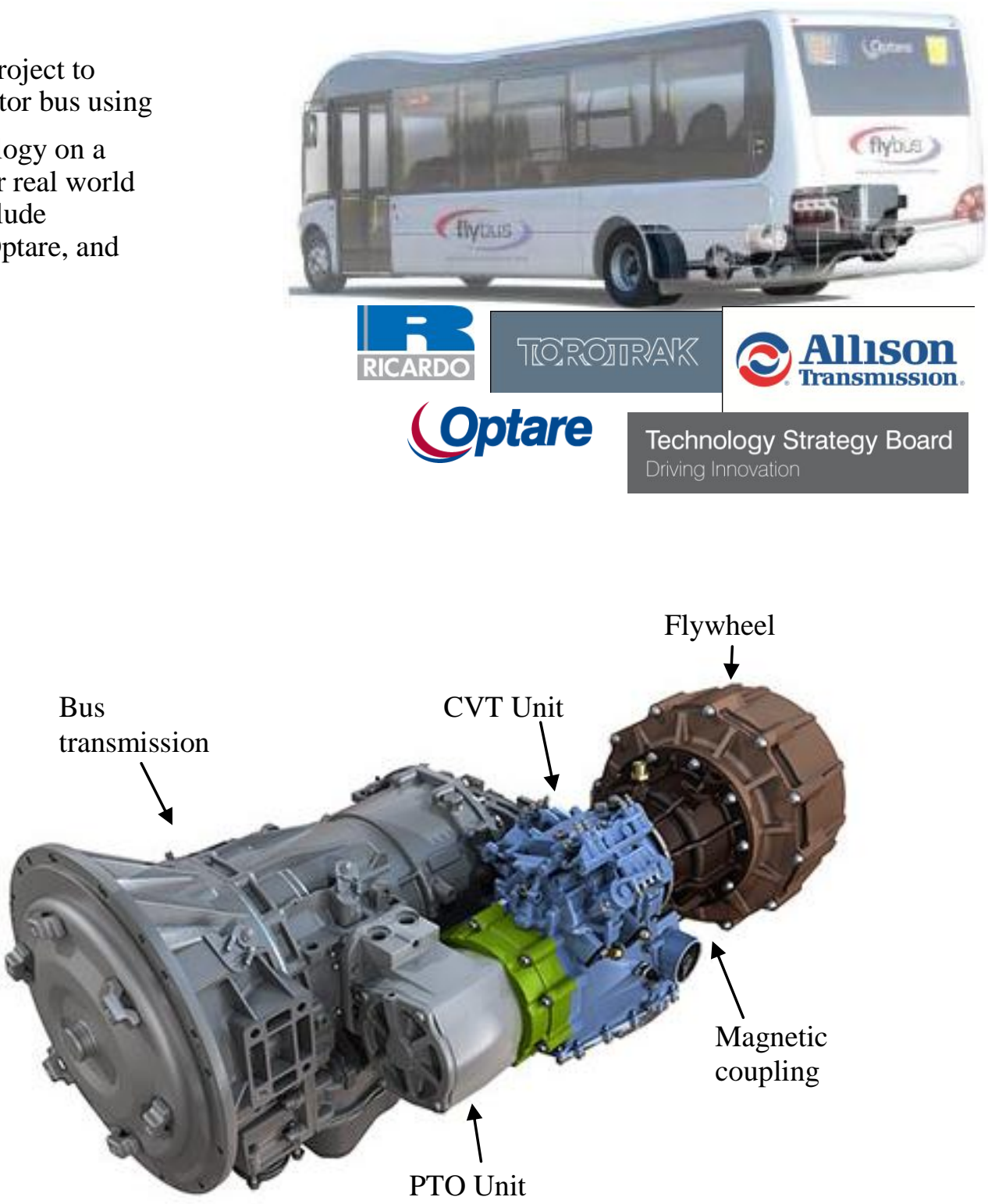


\section{Kinerstor Project}

Kinerstor is a $£ 4.3$ million project to deliver a kinetic energy store for application to Low Carbon Vehicle propulsion. The aim is to build and test fully at rig level a Kinergy® store that is correctly sized for a number of light duty applications. Partners are Ricardo, JLR, JCB, CTG, Torotrak, SKF, and Williams Hybrid Power. Exciting development has been made in flywheel and magnetic gear designs. Flywheel and magnetic gear development tests and iterations in hardware have led to integrated flywheel and magnetic drive testing at high speed.

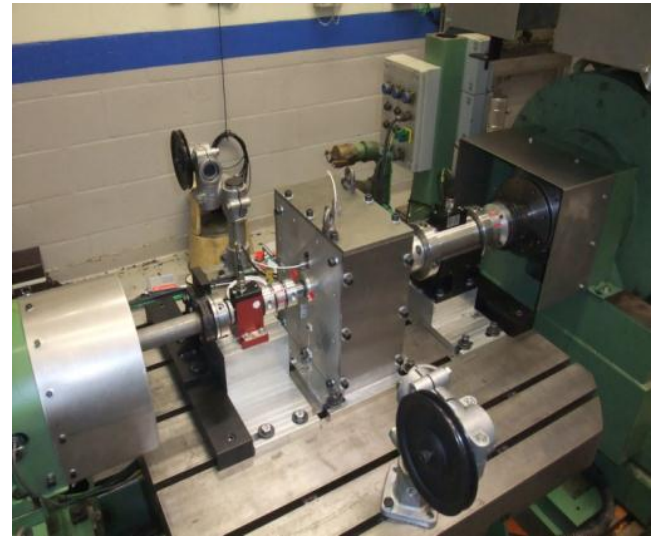

Magnetic gear test rig

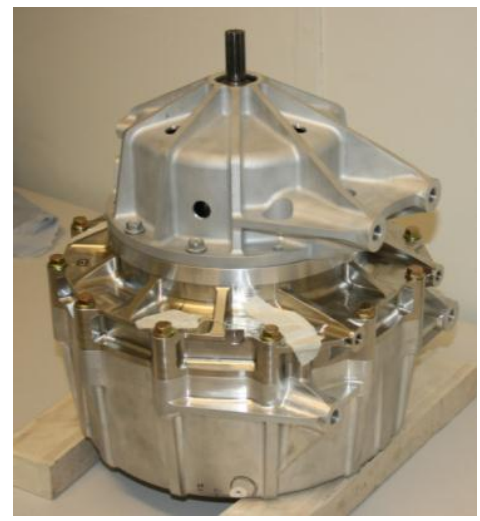

Flywheel module assembly

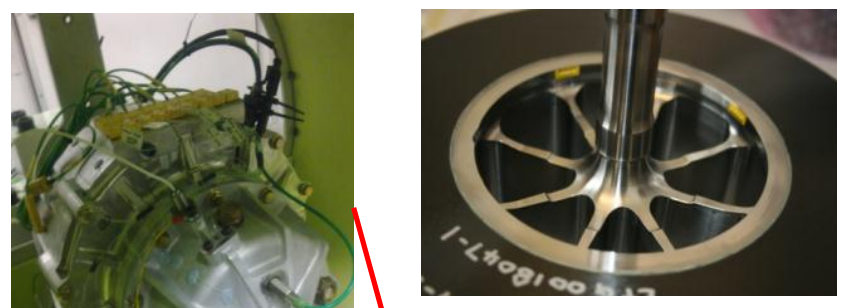

Flywheel rotor

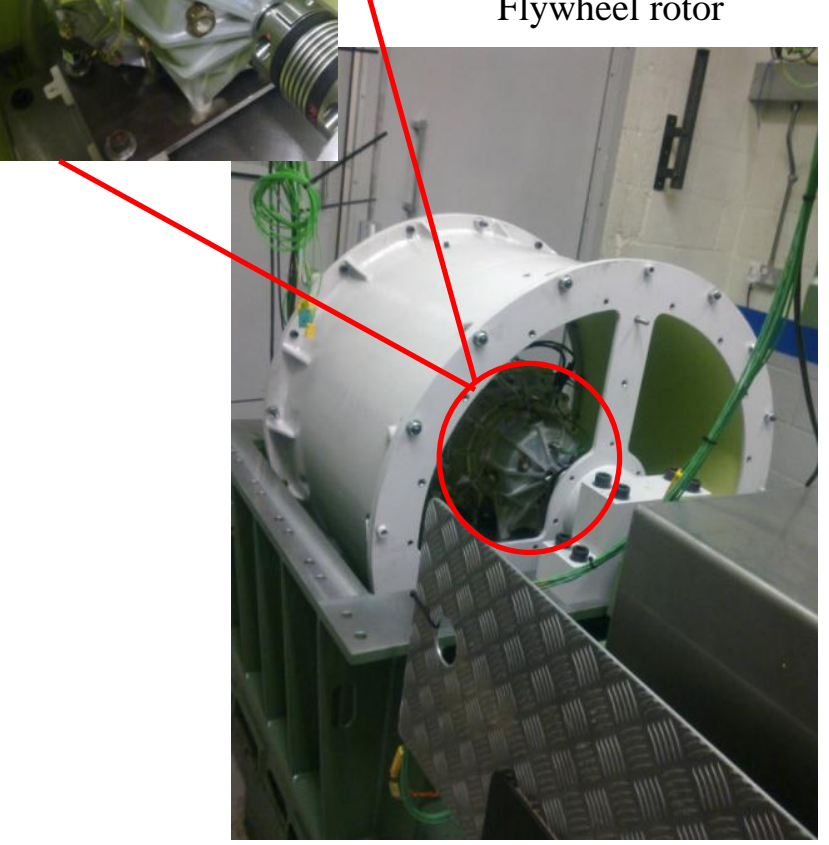

Flywheel in spin test chamber

\section{Kinergy Technology}

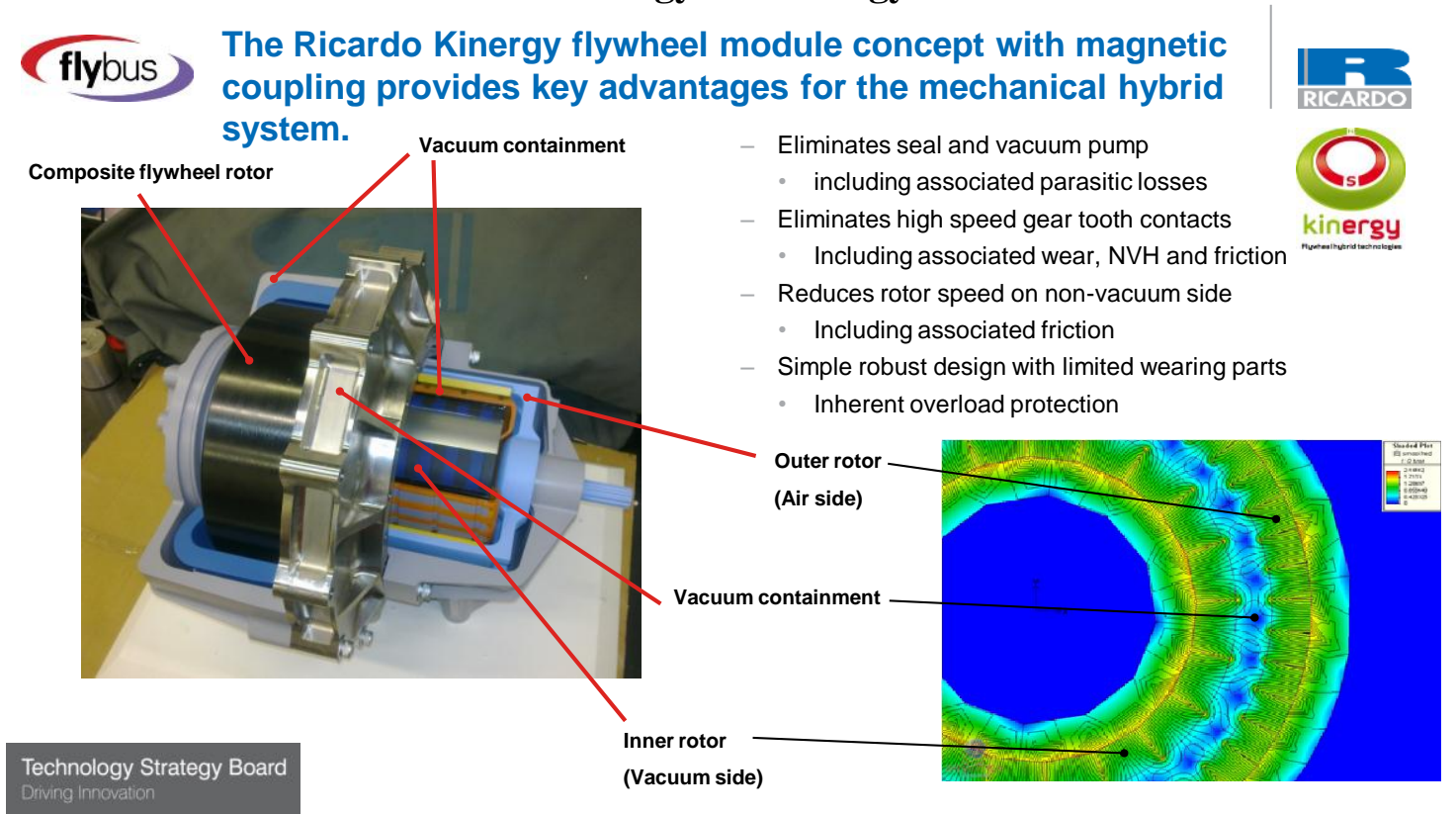


This page intentionally left blank.

A-32 
Flywheel Energy Storage System Specification (Light-duty Vehicle)

\begin{tabular}{|c|c|}
\hline $\begin{array}{l}\text { Primary Developer and } \\
\text { Contact Information }\end{array}$ & $\begin{array}{l}\text { Tribology Systems, Inc. } \\
\text { 239K Madison Ave., Warminster PA } 18974 \\
\text { Lew Sibley (610)466-7547, lew4tsi @ aol.com } \\
\text { www.tribologysystems.com }\end{array}$ \\
\hline Other Partners & Applied Synergy, aplsynergy@ aol.com \\
\hline \multicolumn{2}{|l|}{ Rotor } \\
\hline - Design and Materials & Continuous-wound biannular carbon/glass fiber composite \\
\hline - Operating Speed Range (rpm) & $0-30,000 \mathrm{rpm}$ \\
\hline - Maximum Tip Speed (m/s) & 624 \\
\hline \multicolumn{2}{|l|}{ Motor/Generator } \\
\hline - Description & Proprietary fault tolerant \\
\hline $\begin{array}{l}\text { Voltage, Current, and } \\
\text { Waveform }\end{array}$ & 400 vdc bus, 110 A peak, PWM \\
\hline - Number of Phases (AC) & Three \\
\hline - Frequency Range (AC) & Up to $25 \mathrm{kHz}$ \\
\hline Power Electronics & IGBT controller \\
\hline Bearings & $\begin{array}{l}\text { Patented mechanical replenished solid-lube-film hybrid ceramic ball } \\
\text { bearings (no magnetic bearings) }\end{array}$ \\
\hline Containment & Proprietary benign full energy absorption, tested successfully \\
\hline \multicolumn{2}{|l|}{ System $^{1}$} \\
\hline - Delivered Energy (kWh) & 1 \\
\hline - Peak (continuous) Power (kW) & 40 peak for less than a minute, 25 continuous \\
\hline - System ${ }^{1}$ Mass (kg) & 126 \\
\hline - Containment Mass (kg) & 65 \\
\hline - System ${ }^{1}$ Volume (L) & 59 \\
\hline - Specific Energy (Wh/kg) & 7.9 \\
\hline - Specific Power (W/kg) & 317 \\
\hline - Energy Density (Wh/L) & 16.9 \\
\hline - Power Density (W/L) & 678 \\
\hline $\begin{array}{l}\text { - Round-trip Efficiency and } \\
\text { Measurement Method }\end{array}$ & $\begin{array}{l}74 \% \text { up to } 90 \% \text { for special systems, projected from motor/controller } \\
\text { tests and simulations }\end{array}$ \\
\hline - Cost of System ${ }^{1}$ & $\$ 14,000$ each projected for the first several hundred units \\
\hline - Primary Application & Electric vehicle, light duty \\
\hline - Level of Maturity & Two prototypes in manufacture now \\
\hline - Comments & $\begin{array}{l}\text { Two smaller, basically similar, systems tested successfully hundreds } \\
\text { of times in lab and at customer's beta testing }\end{array}$ \\
\hline
\end{tabular}

1 The flywheel system is defined here as including the energy storage rotor, the motor/generator, the bearings, and the containment. Power electronics weight, volume and cost are not considered, in order to allow a more direct comparison with published chemical battery data. 


\section{Synopsis}

Patented bearings and completely mechanical rotordynamics control system, and proprietary safety containment, with measured vibration of only a few tenths of a $g$ running slowly over the entire supercritical speed range, completely benign containment of several rotor failures, and very low losses, coasting over a year with no power in or out.

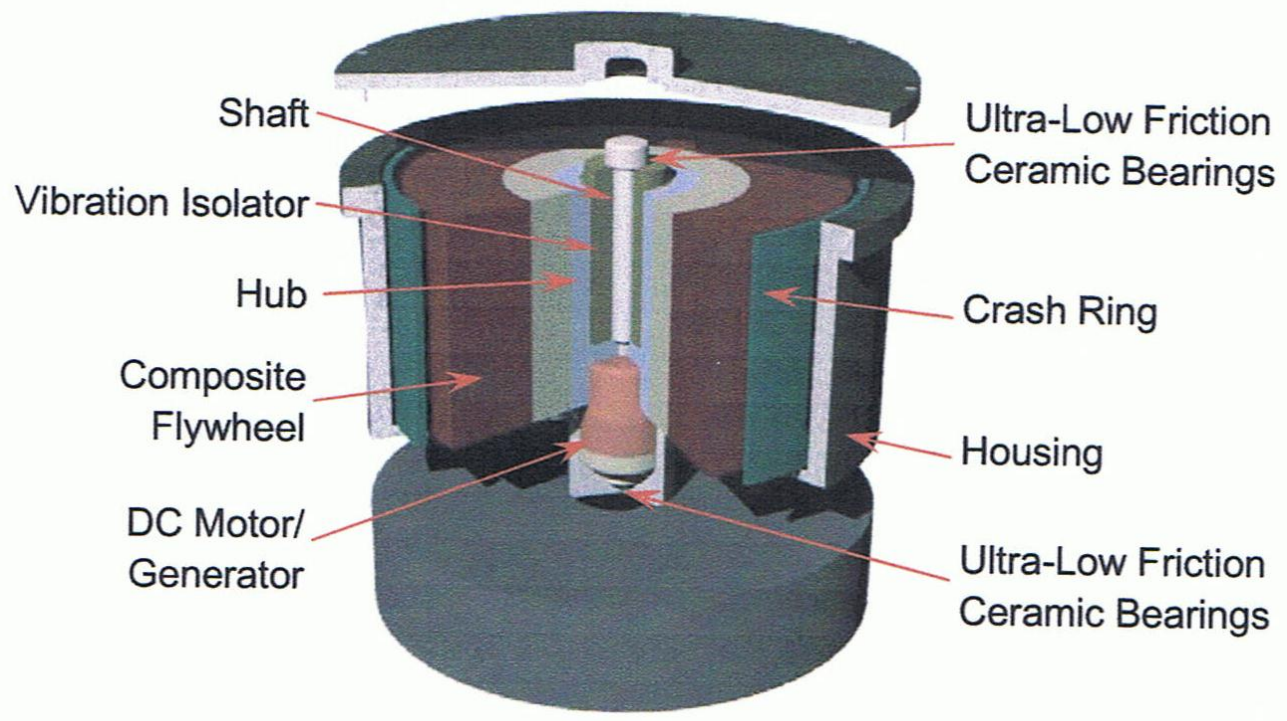

Figure 1. Schematic of complete Flywheel Energy Storage System by Tribology Systems, Inc.

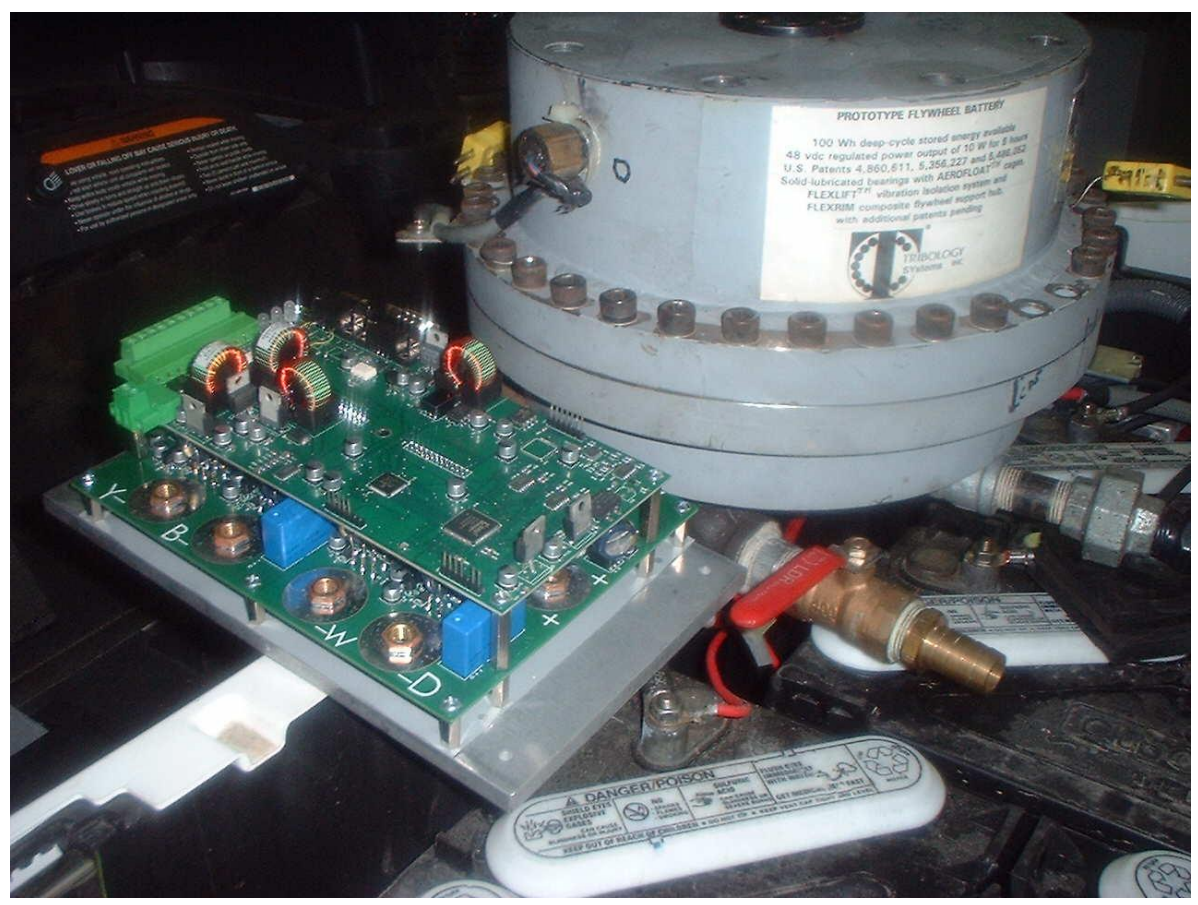

Figure 2. Smaller flywheel energy storage system with controller, replacing the lead-acid batteries in an electric golf car (smaller than flywheel system specified on previous page) 


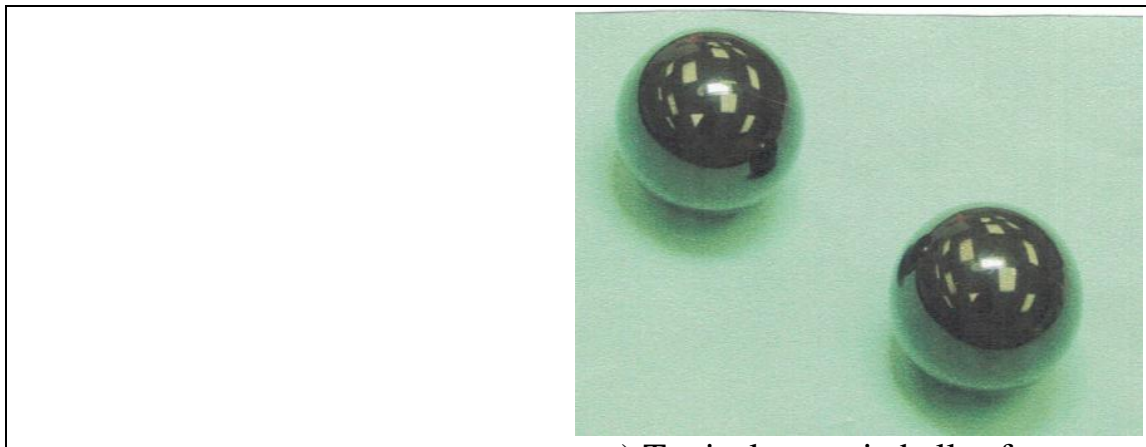

a) Typical ceramic balls after test

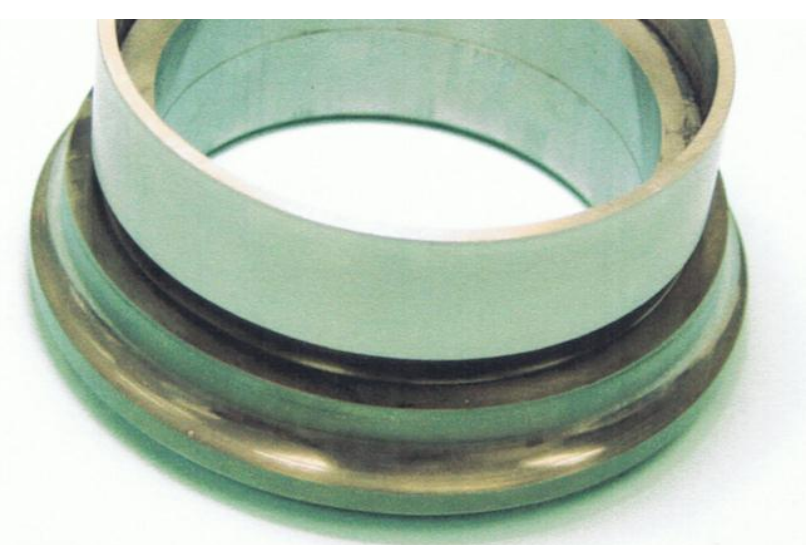

b) Axially-loaded test bearing inner ring after test

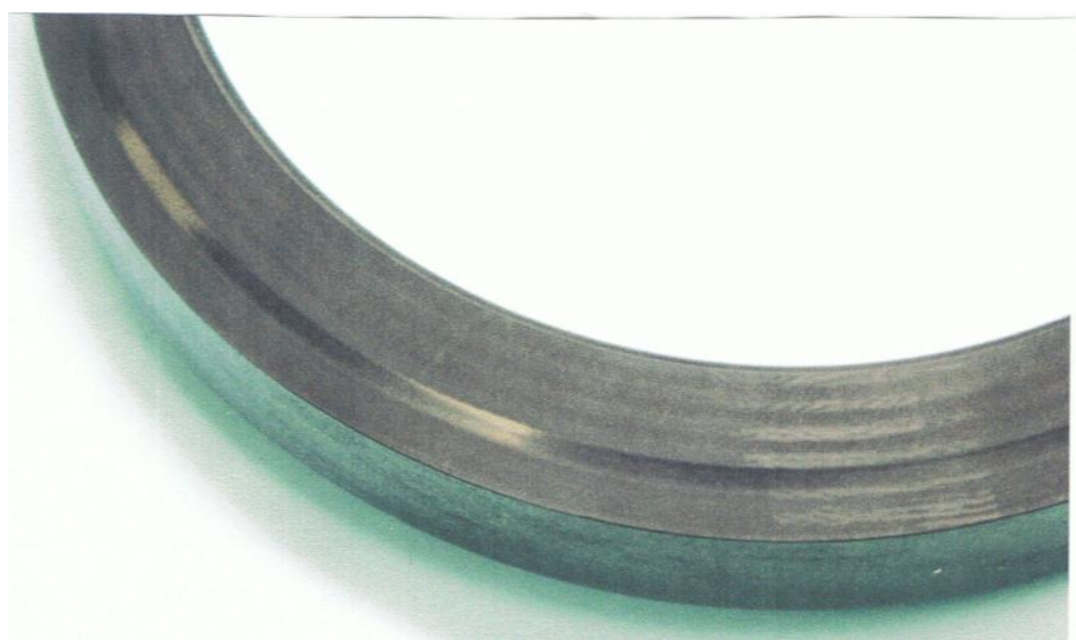

c) Close-up of Ringlube ${ }^{\circledR}$ bottom surface after test

Figure 3. Tested bearing components (Reference 1) on an accelerated bearing test demonstrating ten to twenty years' life with patented solid lubricant

Reference 1. Sibley. Lewis and Nair, Bala R., "Commercial Spool Pump Bearing Performance Testing," Proceedings of WTC2005 World Tribology Congress III, September 2005, Washington, D.C. 
This page intentionally left blank. 
Flywheel Energy Storage System Specifications (Heavy-duty Vehicle)

\begin{tabular}{|c|c|}
\hline $\begin{array}{l}\text { Primary Developer and } \\
\text { Contact Information }\end{array}$ & $\begin{array}{l}\text { University of Texas at Austin, Center for Electromechanics } \\
\text { Contact: R. Hebner, 1University Place \#R7000, Austin, TX } 78712 \\
\text { (512) 232-1628, r.hebner@cem.utexas.edu }\end{array}$ \\
\hline Other Partners & Number of companies and government agencies \\
\hline \multicolumn{2}{|l|}{ Rotor } \\
\hline - Design and Materials & $\begin{array}{l}\text { Carbon composite wheels - both wheels composed of a concentric } \\
\text { series of interference fit rings and of an arbor supporting outer rings } \\
\text { are used }\end{array}$ \\
\hline - Operating Speed Range (rpm) & Limited by tip speed - range from $15,000 \mathrm{rpm}$ to above $60,000 \mathrm{rpm}$ \\
\hline - Maximum Tip Speed (m/s) & Operational: $0.9-1 \mathrm{~km} / \mathrm{s} ;$ Experimental: Near $1.3 \mathrm{~km} / \mathrm{s}$ \\
\hline \multicolumn{2}{|l|}{ Motor/Generator } \\
\hline - Description & $\begin{array}{l}\text { Motors optimized for application considering space, weight, } \\
\text { efficiency, torque and other needs - typically permanent magnet or } \\
\text { induction }\end{array}$ \\
\hline $\begin{array}{l}\text { Voltage, Current, and } \\
\text { Waveform }\end{array}$ & Application specific \\
\hline - Number of Phases (AC) & Application specific \\
\hline - Frequency Range (AC) & Application specific \\
\hline Power Electronics & Pulse width modulation \\
\hline Bearings & Magnetic with mechanical back-up \\
\hline Containment & $\begin{array}{l}\text { Metal vessel with rotatable composite liner - design based on results } \\
\text { of DARPA study, extensive analysis validated by testing }\end{array}$ \\
\hline \multicolumn{2}{|r|}{ 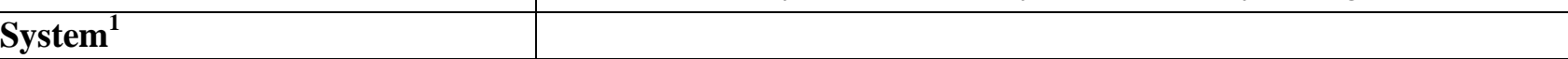 } \\
\hline - Delivered Energy (kWh) & Systems from 0.4 to $130 \mathrm{kWh}$ \\
\hline - Peak (continuous) Power $(\mathrm{kW})$ & Systems from 2 to $2000 \mathrm{~kW}$ \\
\hline - System ${ }^{1}$ Mass (kg) & $390 \mathrm{~kg}$ \\
\hline - Containment Mass (kg) & $90 \mathrm{~kg}$ \\
\hline - System ${ }^{1}$ Volume (L) & $220 \mathrm{~L}$ \\
\hline - Specific Energy (Wh/kg) & Typically about $5 \mathrm{Wh} / \mathrm{kg}$ \\
\hline - Specific Power (W/kg) & Typically about $770 \mathrm{~W} / \mathrm{kg}$ \\
\hline - Energy Density (Wh/L) & Typically about $10 \mathrm{Wh} / \mathrm{L}$ \\
\hline - Power Density (W/L) & Typically about $1400 \mathrm{~W} / \mathrm{L}$ \\
\hline $\begin{array}{l}\text { - Round-trip Efficiency and } \\
\text { Measurement Method }\end{array}$ & $\begin{array}{l}\text { Typically } 90 \% \text { to } 95 \% \text { - determined by design as motor/generators } \\
\text { with efficiencies } 95 \% \text { or above are possible as a trade with size/weight }\end{array}$ \\
\hline - Cost of System ${ }^{1}$ & Estimated $\$ 300$ to $\$ 700$ per $\mathrm{kW}$ for larger units \\
\hline - Primary Application & $\begin{array}{l}\text { Replacement of chemical batteries on mobile platforms, e.g. trucks, } \\
\text { busses, trains, satellites. }\end{array}$ \\
\hline - Level of Maturity & $\begin{array}{l}\text { Extensive laboratory testing, demonstration on a hybrid bus, preparing } \\
\text { for testing on a train. }\end{array}$ \\
\hline - Comments & $\begin{array}{l}\text { Flywheel systems have been tested to } 112,000 \text { charge-discharge cycles } \\
\text { with no degradation in performance. The weight and volume numbers } \\
\text { are for a flywheel system demonstrated on a hybrid bus. The other } \\
\text { numbers cover ranges or are typical for the systems we design, build } \\
\text { and test. }\end{array}$ \\
\hline
\end{tabular}

1 The flywheel system is defined here as including the energy storage rotor, the motor/generator, the bearings, and the containment. Power electronics weight, volume and cost are not considered, in order to allow a more direct comparison with published chemical battery data. 
The University of Texas at Austin is designing, building and testing composite flywheels for battery replacement in mobile and stationary applications. The near term applications appear to be in larger systems, e.g. busses, trucks, and trains, where the power and cost are proportionate to cost. In addition, space applications are promising as battery replacement costs are large.

The key benefits of flywheels for hybrid vehicle applications are very long life even for full charge-discharge cycles, high efficiency, and small size and weight. The long life and small size and weight result from recent advances in composite materials that permit high-speed operation. The efficiency is primarily determined by the efficiency of the motor-generator, which can exceed 95\%. Composite flywheels tend to be less of an environmental hazard than batteries. In addition, the physics of flywheels mean that the designer can separately select the energy to be stored and the power needed. For the bus demonstration, for example, the flywheel was sized to store all of the kinetic energy of the fully loaded bus traveling $60 \mathrm{mph}$, when accelerated from $25 \%$ to $100 \%$ of operating speed, to support regenerative braking. The motor-generator system was sized to transfer all of that energy from the wheel motors to the flywheel as quickly as the bus could be stopped without skidding. Thus, even in a panic stop minimal energy was dissipated. Significant recent developments include containment technology, bearing systems that tolerate road shock and vibration, and gimbal systems to manage gyroscopic forces. The flywheel battery system for a transit bus has been designed, built, and tested. Laboratory tests on a shaker showed the mounting, including magnetic bearings, were adequate for the application. The system was mounted on a bus to operate as the sole energy storage in a hybrid system. On-road tests verified energy recovery operating as designed and a significant improvement in performance was achieved. For example, it was demonstrated that the acceleration time to $50 \mathrm{mph}$ could, if desired, be decreased to as little as a quarter the time it took the bus with an internal combustion engine while reducing emissions and increasing fuel efficiency.

Key benefits of batteries include lower initial (but not life cycle cost), mature technology with established supplier base and revenue base to fund research and development, and lower losses at low or no load.

Drawing of bus flywheel battery:

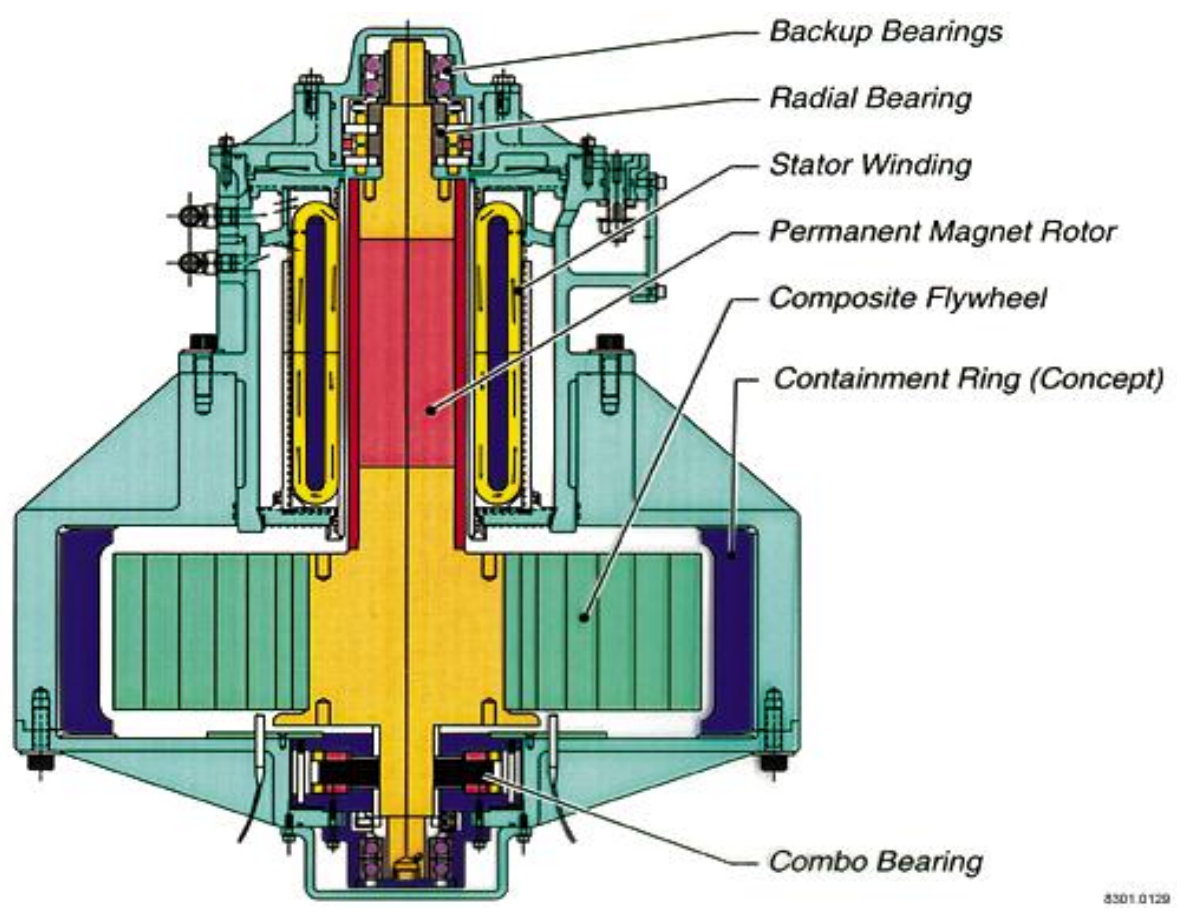


Flywheel Energy Storage System Specification (Light-duty Vehicle)

\begin{tabular}{|c|c|}
\hline $\begin{array}{l}\text { Primary Developer and } \\
\text { Contact Information }\end{array}$ & $\begin{array}{l}\text { Williams Hybrid Power Limited (www.williamshybridpower.com) } \\
\text { Williams F1, Grove, Wantage, OX12 0DQ, United Kingdom } \\
\text { lan Foley, Managing Director, +44 } 7768405001 \\
\text { lan.fole@williamshybridpower.com }\end{array}$ \\
\hline Other Partners & $\mathrm{N} / \mathrm{A}$ \\
\hline \multicolumn{2}{|l|}{ Rotor } \\
\hline - Design and Materials & $\begin{array}{l}\text { Wholly composite rotor design. The rotor uses magnetically loaded } \\
\text { composite (MLC) supported by a carbon fiber outer. The rotor is } \\
\text { magnetized after construction. }\end{array}$ \\
\hline - Operating Speed Range (rpm) & $18,000-36,000 \mathrm{rpm}$ \\
\hline - Maximum Tip Speed (m/s) & $660 \mathrm{~m} \cdot \mathrm{s}^{-1}$ \\
\hline \multicolumn{2}{|l|}{ Motor/Generator } \\
\hline - Description & An integrated inside-out DC motor / generator with liquid-cooled stator \\
\hline $\begin{array}{l}\text { Voltage, Current, and } \\
\text { Waveform }\end{array}$ & $\begin{array}{l}\text { Voltage: } 400 \mathrm{~V} \\
\text { Current: } 800 \mathrm{~A}(\mathrm{Max}) \\
\text { Waveform: six-step }\end{array}$ \\
\hline - Number of Phases (AC) & 3 \\
\hline - Frequency Range (AC) & Maximum switching frequency $4000 \mathrm{~Hz}$ \\
\hline Power Electronics & Water cooled, 600V, IGBT inverter \\
\hline Bearings & Hybrid ceramic ball bearings \\
\hline Containment & Aluminium clamshell design. \\
\hline \multicolumn{2}{|l|}{ System $^{1}$} \\
\hline - Delivered Energy (kWh) & $0.36 \mathrm{kWh}(1.3 \mathrm{MJ})$ \\
\hline - Peak (continuous) Power (kW) & $\begin{array}{l}120 \text { kW peak @ max rpm (110 kW average over operating speed } \\
\text { range) }\end{array}$ \\
\hline - System ${ }^{1}$ Mass (kg) & $55 \mathrm{~kg}$ \\
\hline - Containment Mass (kg) & $15 \mathrm{~kg}$ \\
\hline - System ${ }^{1}$ Volume $(\mathrm{L})$ & $38 \mathrm{~L}$ \\
\hline - Specific Energy (Wh/kg) & $6.55 \mathrm{Wh} / \mathrm{kg}$ \\
\hline - Specific Power (W/kg) & $2180 \mathrm{~W} / \mathrm{kg}$ \\
\hline - Energy Density (Wh/L) & $9.47 \mathrm{Wh} / \mathrm{L}$ \\
\hline - Power Density (W/L) & $3160 \mathrm{~W} / \mathrm{L}$ \\
\hline $\begin{array}{l}\text { - Round-trip Efficiency and } \\
\text { Measurement Method }\end{array}$ & $\begin{array}{l}95 \% \\
\text { Measurement method: Back-to-back flywheel tests. }\end{array}$ \\
\hline - Cost of System ${ }^{1}$ & Projected cost of US $\$ 10,000$ per unit @ 10,000 off \\
\hline - Primary Application & $\begin{array}{l}\text { High power, high cycle-life energy storage for hybrid electric vehicle or } \\
\text { light rail applications. }\end{array}$ \\
\hline - Level of Maturity & $\begin{array}{l}\text { Second season in Porsche GT3R Hybrid motorsport application. } \\
\text { Design validation in progress for series production application. }\end{array}$ \\
\hline - Comments & $\begin{array}{l}\text { WHP have a number of flywheel storage systems in prototype } \\
\text { development. The information above refers to the 'Mk4' product, our } \\
\text { prime design for series production. }\end{array}$ \\
\hline
\end{tabular}

1 The flywheel system is defined here as including the energy storage rotor, the motor/generator, the bearings, and the containment. Power electronics weight, volume and cost are not considered, in order to allow a more direct comparison with published chemical battery data. 


\section{Synopsis}

Williams Hybrid Power Ltd (WHP) is a UK based company that develops and manufactures electromechanical composite flywheel systems. These systems provide a high-power, cost-effective and environmentally friendly solution for mobile or stationary energy recovery and storage.

WHP's flywheel solutions incorporate its novel, patented Magnetically Loaded Composite (MLC) technology which was originally developed by Urenco engineers working on the design of uranium centrifuge machines. The rotor magnets in an MLC system are comprised of tiny particles embedded in the composite matrix. With no other metal in the flywheel rotor eddy current losses and heating are greatly reduced.

The company's first application of the technology was in the highly competitive and extremely harsh environment of Formula One motor racing. Through development of a flywheel for Williams F1's Kinetic Energy Recovery System (KERS), WHP has proved its world-class engineering capabilities in the composite flywheel field as well as radically improving aspects of the technology in the process.

Building on the Formula One project, the company is now making the technology available to meet the highpower energy storage needs in a variety of applications including hybrid passenger vehicles, hybrid buses, electric trains, military applications and renewable energy. WHP currently has prototype projects with leading companies in many of these fields.

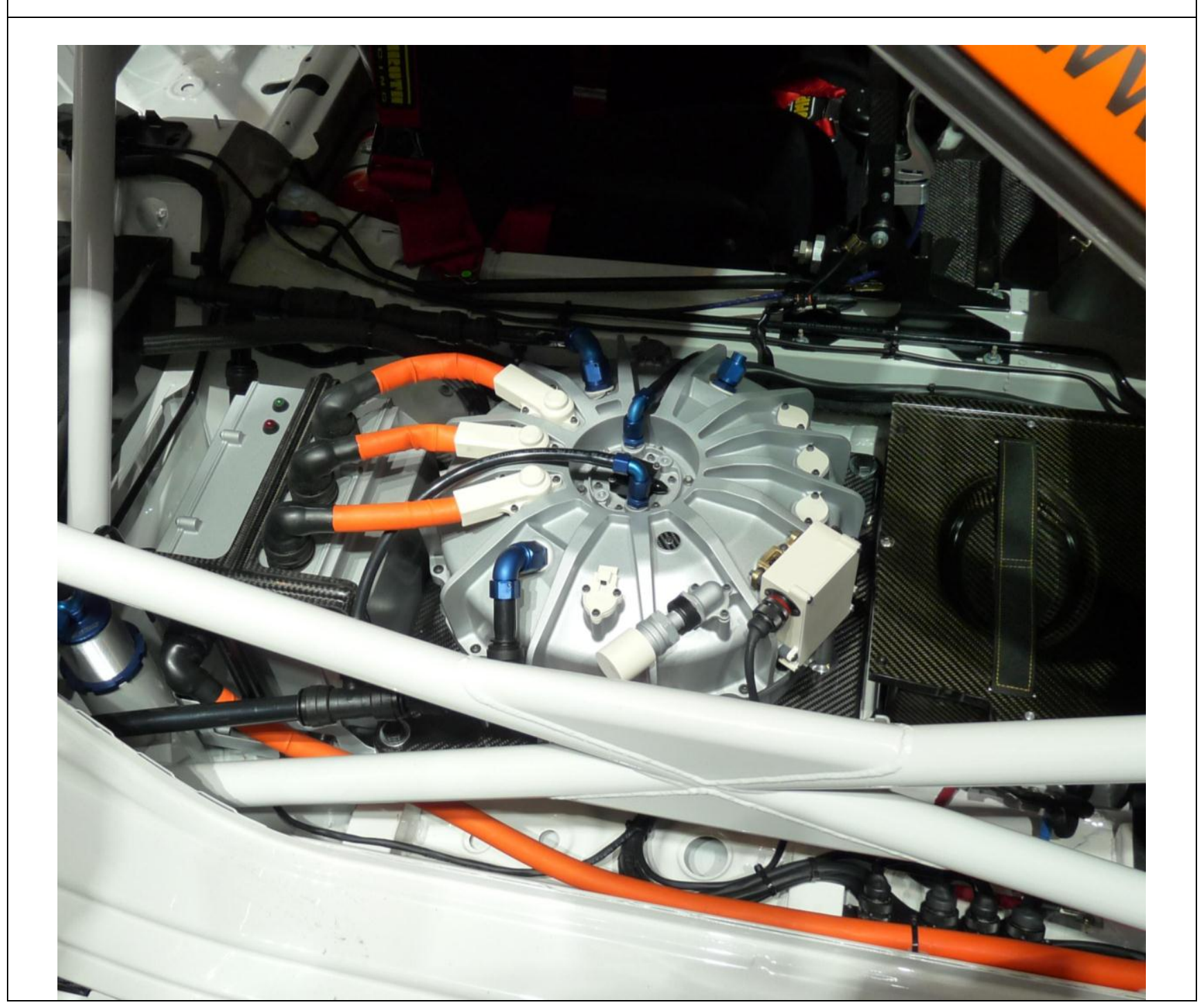


Flywheel Energy Storage System Specifications

\section{INSTRUCTIONS FOR COMPLETING QUESTIONNAIRE ITEMS}

(When completing questionnaire, please fill in the blank form in the electronic file.)

\begin{tabular}{|c|c|}
\hline $\begin{array}{l}\text { Primary Developer \& Contact } \\
\text { Information }\end{array}$ & $\begin{array}{l}\text { Organization name } \\
\text { Principal contact name, phone number, and address (email \&/or postal) }\end{array}$ \\
\hline Other Partners & Key organizations other than reporting organization \\
\hline \multicolumn{2}{|l|}{ Rotor } \\
\hline - Design and Materials & $\begin{array}{l}\text { Design of rotors } \\
\text { Materials in flywheel rim }\end{array}$ \\
\hline - $\quad$ Operating Speed Range (rpm) & Range in rpm \\
\hline - Maximum Tip Speed (m/s) & $\begin{array}{l}\text { Max tangential velocity at outer diameter of rim in } \mathrm{m} / \mathrm{s} \text { when flywheel } \\
\text { rotates at maximum rpm in operating speed range above }\end{array}$ \\
\hline \multicolumn{2}{|l|}{ Motor/Generator } \\
\hline - Description & Basic motor configuration information \\
\hline $\begin{array}{ll}\text { Voltage, Current, and } \\
\text { Waveform }\end{array}$ & Self-explanatory \\
\hline - Number of Phases (AC) & Self-explanatory \\
\hline - $\quad$ Frequency Range (AC) & Self-explanatory \\
\hline Power Electronics & Generic description \\
\hline Bearings & Type and materials of primary and backup (touch-down) bearings \\
\hline Containment & $\begin{array}{l}\text { Generic description } \\
\text { State whether containment system tested or not. }\end{array}$ \\
\hline \multicolumn{2}{|r|}{ 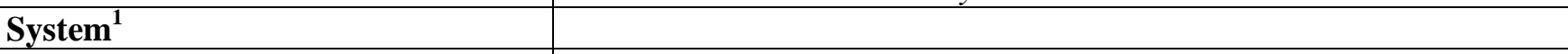 } \\
\hline - $\quad$ Delivered Energy $(\mathrm{kWh})$ & Delivered or net energy, not gross energy \\
\hline - Peak (continuous) Power (kW) & $\begin{array}{l}\text { Please provide peak power as a minimum and continuous power if } \\
\text { available. }\end{array}$ \\
\hline - $\quad$ System $^{1}$ Mass $(\mathrm{kg})$ & System mass excluding mass of power electronics as defined in footnote \\
\hline - Containment Mass (kg) & $\begin{array}{l}\text { Containment mass in system mass above. If some containment mass is } \\
\text { from another source, such as part of vehicle structure or mother earth } \\
\text { for a stationary application, then state such. }\end{array}$ \\
\hline - System $^{1}$ Volume $(\mathrm{L})$ & $\begin{array}{l}\text { System volume excluding volume of power electronics as defined in } \\
\text { footnote }\end{array}$ \\
\hline - Specific Energy (Wh/kg) & Delivered energy/system mass \\
\hline - Specific Power (W/kg) & Peak power/system mass \\
\hline - Energy Density (Wh/L) & Delivered energy/system volume \\
\hline - $\quad$ Power Density (W/L) & Peak power/system volume \\
\hline $\begin{array}{ll}\text { - } & \text { Round-trip Efficiency and } \\
\text { Measurement Method }\end{array}$ & Round-trip efficiency and not one-way \\
\hline - Cost of System ${ }^{1}$ & $\begin{array}{l}\text { State whether actual and/or projected cost, and do not include cost of } \\
\text { power electronics. }\end{array}$ \\
\hline - Primary Application & $\begin{array}{l}\text { Hybrid electric vehicle (load leveling), electric vehicle (powered } \\
\text { exclusively by flywheel), stationary (power quality, UPS, load leveling, } \\
\text { electric rail storage), space, experimental laboratory system, other } \\
\text { (please specify). For hybrid electric vehicle please specify primary } \\
\text { power producer. }\end{array}$ \\
\hline - Level of Maturity & $\begin{array}{l}\text { Commercial product, beta tested, in beta testing, under development, } \\
\text { other (please specify). If your company has a commercial flywheel, you } \\
\text { may want to specify the number of units located in field applications. }\end{array}$ \\
\hline - Comments & Comments on your specifications \\
\hline
\end{tabular}

1 The flywheel system is defined here as including the energy storage rotor, the motor/generator, the bearings, and the containment. Power electronics weight, volume and cost are not considered, in order to allow a more direct comparison with published chemical battery data. 


\begin{tabular}{|l|l|}
\hline Synopsis & $\begin{array}{l}\text { Please provide a two page or shorter synopsis promoting your flywheel systems and/or } \\
\text { technology. Your synopsis will be included in the published assessment. Graphics or } \\
\text { pictures of your system are welcome. One synopsis should be provided to cover both } \\
\text { light-duty and heavy-duty vehicle applications. }\end{array}$ \\
\hline
\end{tabular}




\title{
APPENDIX B - FIA ENVIRONMENTALLY SUSTAINABLE MOTOR SPORT POLICY FIA Commission \\ for Environmentally Sustainable Motor Sport
}

\author{
FIA Environmentally Sustainable Motor Sport Policy
}

Following discussions on a number of issues relating to environmentally sustainable motor sport, the Environmentally Sustoinable Motor Sport Commission (ESMSC) agreed upon a number of policy proposals. These draft proposals were submitted to the World Motor Sport Council (WMSC), where it was agreed that they would serve as a strong framework for further discussions. The ESMSC sought further feedbock to its proposed policies in a plenary meeting bringing together representotives from National Sporting Authorities, Manufactures, and the FlA's Regulatory Commissions. Having now consulted with all parties the ESMSC is submitting its proposals for formal endorsement and odoption by the WMSC.

\section{Efficiency based competition}

Motor sport must move from a power per unit of a combination of one or more of: swept volume/RPM/boost pressure/sonic orifice diameter, as a basis for engine performance regulation, to one of power per unit of energy. This would automatically put the technical emphasis on energy efficiency, and enable all efficiency technologies to be embraced. This approach, combined with appropriate fuels, will also minimise the emissions of $\mathrm{CO}_{2}$. In order to enable the public to easily understand this efficiency concept applied to motor sport, it is also necessary to limit the amount of fuel/energy consumed by a competitor during a race. For reasons of the cost of development, technologies may need to be restricted depending on the nature of a given championship/series.

In order to achieve the goal of increased efficiency, a series of progressive targets for each FIA Championship and International Series are needed in order to measure progress, with the goal of fundamentally changing the technology basis of racing, and contributing to the development of the road car of the future.

Within these changes it is crucial for entertainment to be preserved and even increased, for winners to be determined by the first to cross the finishing line, with new regulations simple enough to be understood by fans and the public.

Energy consumption and $\mathrm{CO}_{2}$ emissions should be regulated on an onboard energy reservoir to wheel basis

2. Fuels

It is not the role of motor sport to determine which chemical molecules will ultimately deliver the energy used in fuels for road transport. Nor is it currently possible to regulate energy consumption or $\mathrm{CO}_{2}$ emissions on a well-to-wheel basis. New alternative fuel sources may be tested and promoted in specific alternative energy series, however other

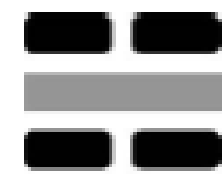

MaKe cars anrry wWw.makecarsareen.com

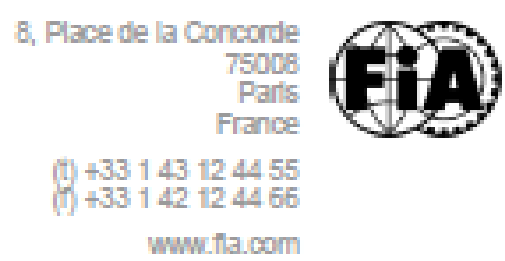


series should follow government/energy industry policy in this respect and promote sustainable fuels that will come into common usage. It should avoid pitting gasoline .v. diesel .v. bio-fuels.v. etc. in the existing, well established championships, as a balancing formula is needed to allow the different fuels and their associated engines to compete equally. This inevitably leads to favouring one fuel over another due to different fundamental characteristics and efficiencies of the engines burning those fuels. Clear and distinct categories are needed if various fuels types compete in a single event.

All fuels permitted and the tendering criteria for the supply of fuels to championships should follow legislation and/or best practice for the production of those fuels, as defined by international organisations e.g. the EU Directive on Low Carbon Fuels and Sustainability Criteria for Biofuels. The use of the highest grade of available production fuels, locally sourced, will help reduce the need for transport of racing fuels globally.

\section{Carbon Neutrality}

It is proposed that the total activity of putting on a motor sport championship or series should be carbon neutral. In line with the polluter pays principle, the FIA should offset its own regulatory presence, and encourage others to offset their own emissions by making offsetting a condition of involvement to a championship or series. The FIA will not regulate carbon assessment or offsetting methods simply require demonstration that both have been undertaken. In order to further assist the FIA will make available a non exhaustive list of recommended auditors and offset providers. Such action in offsetting will gain respect of environmentalists if it is part of a wider long term strategy for emissions reductions.

\section{Technology promotion}

Energy recovery technologies should be promoted through motor sport. The best method of integrating the various levels of hybridisation, ensuring equivalency, and promoting their qualities, is in an efficiency-based formula as described in point one. Although many automobile manufacturers are developing hybrids, there is a strong opinion that they do not represent a cost effective means of reducing fuel consumption and $\mathrm{CO}_{2}$ emissions, but are increasingly demanded by the market place. Energy Recovery Systems technology, however, is fundamental to the future of the automobile, including these hybrids. Motor sport can make a useful contribution to development and marketing. Technology such as fly wheels reducing dependence on batteries and concentrating on ICE load shift proves to be the most promising way forward.

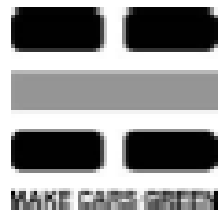

ww.malvecarsoreen.com
8, Place de la Concorde

75008

Parts

France

(1) +33143124455

(f) +33142124466

wow. fla.com

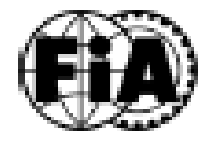

B-2 


\section{Best practice}

Best environmentally sustainable practice in the holding of motor sport events, both circuit-based and rallies, and including energy use, carbon offsetting, noise control, waste disposal, water protection, spectator traffic management, and physical damage to the local enwironment, should be established in consultation with ASNs and circuit operators. Existing best practices should be pooled and commonly established, and best practice guidelines should be published.

\section{Polluter pays}

In line with polluter pays principle motor sport should not offset spectators or their travel, effectively subsidising others parties personal emissions. Initiatives to aid offsetting of third parties should be supported.

\section{Communication}

Motor Sport is symbolic of the entire motor industry. Communications should be prepared to show how motor sport is moving to becoming sustainable itself and how it is catalysing sustainability across the entire sector. In addition communications should aim to protect motor sport from external critics, while also focusing on educating internal audiences to help motor sport champion its sustainability credentials. Focus should be on: motor sport's carbon neutrality and lowering GHG emissions, as well as motor sport's technological contribution to the wider automotive reductions of fuel consumption. The irrelevance of direct comparison between road vehicles and motor sport vehicles on issues such as driving cycles should also be clearly communicated.

8. Safety

The responsibility for the safety of a vehicle remains with the competitor. New fuels and new high voltage electric power technologies bring new safety issues to Motor Sport:

Factory/workshop/Labs: Must abide by Health and Safety Regulations Pits, Pit lane: Vehicle: Must abide by Health and Safety Regulations Must not degrade existing motor sport safety standards. Minimum standard is relevant Road Vehicle Standard.

Rescue: Medical: New Motor Sport standards and training to be developed Appropriate standards and training to be developed.

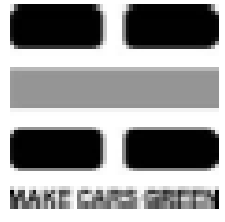

www.makecarsoreen.com
8, Place de la Concorde

75006

France

(t) +33143124455 (f) +33142124466 wow. fla.com

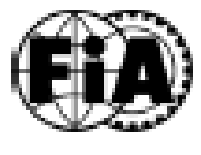

$$
\text { m }
$$


Safety concerns should be dealt with on a case by case basis by the appropriate existing FIA body.

9. Driver Aids

Electric power trains and efficiency based performance regulation introduces the possibility for two classes of Driver Aids, both highly relevant to road vehicles:

Traction control, ABS, ESC: Should not be allowed unless existing Sporting/Technical Regulations permit it.

Efficiency: Each class of racing should decide whether it wishes to encourage efficient driving skills, or permit software for optimum use of energy.

Each championship/series should consider which driver aids should be banned or permitted. 


\section{APPENDIX C - HOOP STRESS IN A THIN ROTATING RING}

An expression for the hoop stress in an idealized thin ring will be developed.

A free body diagram of a sector of the spinning ring with swept infinitesimal angle, $d \theta$, exaggerated is shown in Figure $\mathrm{C}-1$.

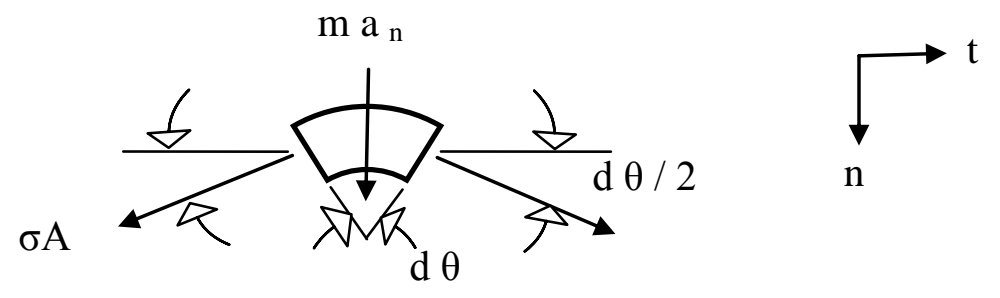

\section{Figure C-1. Free body diagram of segment of spinning ring}

Applying Newton's second law

$$
\Sigma \mathrm{F}_{\mathrm{n}}=\mathrm{ma}_{\mathrm{n}}
$$

The normal forces are projections of the hoop force, $\sigma \mathrm{A}$,

$$
\Sigma F_{n}=2 \sigma A \sin d \theta / 2
$$

where: $\mathrm{A}$ is the cross-sectional area of the ring

Since for small angles $\sin \theta \sim \theta$

$$
\Sigma \mathrm{F}_{\mathrm{n}}=\sigma \mathrm{Ad} \theta
$$

The normal acceleration equals $r \omega^{2}$ so

$$
\mathrm{ma}_{\mathrm{n}}=\mathrm{mr} \omega^{2}
$$

The mass of the infinitesimal sector in the free body diagram equates to the density times the volume of the sector expressed as the arc length, $\mathrm{r} d \theta$, times the cross-sectional area

$$
\mathrm{m}=\rho \mathrm{V}=\rho \mathrm{rd} \theta \mathrm{A}
$$

Substituting terms into Newton's law

$$
\sigma \mathrm{A} d \theta=\rho \mathrm{rd} \theta \mathrm{Ar} \omega^{2}
$$

Simplifying

$$
\sigma=\rho r^{2} \omega^{2}
$$


This page intentionally left blank. 


\section{APPENDIX D - THICK RIGHT CIRCULAR CYLINDER RIMS AND ROTORS WITH VARIABLE THICKNESS}

For a thick rim the shape of a right circular cylinder, the stress field in the rim is quite complex. For that case the radial and hoop stress components at a distance $r$ from the axis of rotation are given in the textbook by Ugural (Reference 33) as:

$$
\begin{aligned}
& \sigma_{r}=\frac{3+v}{8}\left(r_{i}^{2}+r_{o}^{2}-r^{2}-\frac{r_{i}^{2} r_{o}^{2}}{r^{2}}\right) \rho \omega^{2} \\
& \sigma_{\theta}=\frac{3+v}{8}\left(r_{i}^{2}+r_{o}^{2}-\frac{1+3 v}{3+v} r^{2}+\frac{r_{i}^{2} r_{o}^{2}}{r^{2}}\right) \rho \omega^{2}
\end{aligned}
$$

$$
\text { where: } \quad \begin{aligned}
v & =\text { Poisson's ratio } \\
& r_{i}=\text { inner radius of disk } \\
r_{o} & =\text { outer radius of disk }
\end{aligned}
$$

The radial stress is maximum in the interior of the disk and zero at the inner and outer radii, while the hoop stress is maximum at the inner radius and minimum at the outer radius.

Computer codes are best used to solve for the stresses in this 2-dimensional rim and in the more involved 3-dimensional analysis.

For rotors with a variable thickness, the detailed analysis is usually carried out using finite element analysis. However, a simplified expression for the specific kinetic energy can be expressed as

$$
\mathrm{E}_{\max } / \mathrm{m}=\mathrm{K} \sigma_{\max } / \rho
$$

where: $\mathrm{K}$ is a shape factor that depends on the rotor cross-section.

Nine different cross-section geometries are given by Bolund (Reference 34) along with their associated shape factors. The cross-section with the highest specific kinetic energy has a $\mathrm{K}$ value that is twice that of a thin ring, however, the practicality of manufacture and mass production of rotors with the complex cross-section required is highly suspect. In addition Ugural (Reference 33) gives the radial and hoop stress as a function of radius for two special cases:

1. Rotating disk with a uniform internal stress, so that $\sigma_{\mathrm{r}}=\sigma_{\theta}=$ constant everywhere in the disk

2. Rotating disk with a hyperbolic cross-section 
This page intentionally left blank. 


\section{APPENDIX E - EVALUATION OF THE ENERGY STORAGE REQUIREMENT FOR A LIGHT DUTY VEHICLE}

The DOE suggested energy and power requirements for flywheels in Table 2-1 that were based on USABC goals should be reconsidered. Based on input from flywheel developers, it is reasonable to revise the specifications such that the target delivered energy level for a flywheel for a light duty vehicle is somewhat less than the $0.3-0.5 \mathrm{kWh}$. For a typical family car, the value might be as low as about $0.2 \mathrm{kWh}$. Consider the following example:

Assume a vehicle weight of $1800 \mathrm{~kg}$ (typical for family sedan).

A reasonable design basis for the bounding case maximum required acceleration event might be accelerating up an interstate ramp (6 meters elevation change) from $0 \mathrm{mph}$ to a merge speed of $70 \mathrm{mph}$.

The kinetic energy from $0 \mathrm{mph}$ to $70 \mathrm{mph}$ is $881 \mathrm{~kJ}$ ( $245 \mathrm{Wh})$. The potential energy due to $6 \mathrm{~m}$ elevation change is $106 \mathrm{~kJ}(29 \mathrm{Wh})$. Therefore the total delivered energy requirement is $987 \mathrm{~kJ}(274 \mathrm{Wh})$ (not accounting for losses due to aerodynamics and rolling resistance; therefore the true required energy is slightly more). If the energy transfer out of the flywheel is $86 \%$ efficient, then $987 / 0.86=1148 \mathrm{~kJ}(319 \mathrm{Wh})$ would need to be available for delivery from the flywheel rotor.

This calculation assumes that all of the energy for acceleration comes from the flywheel. It is more likely that the prime power source in the vehicle will be providing a significant portion of the energy needed for acceleration.

A reasonable design basis for the bounding case maximum required deceleration event might be decelerating down an interstate ramp (6 meters elevation change) from $70 \mathrm{mph}$ to $0 \mathrm{mph}$.

The kinetic energy from $70 \mathrm{mph}$ to $0 \mathrm{mph}$ is $881 \mathrm{~kJ}$ (245 Wh).

The potential energy due to $6 \mathrm{~m}$ elevation change is $106 \mathrm{~kJ}(29 \mathrm{Wh})$.

The total delta energy is $987 \mathrm{~kJ}(274 \mathrm{Wh}$ ) (not accounting for losses due to aerodynamics and rolling resistance; therefore the available energy is slightly less).

If the energy transfer into the flywheel is $86 \%$ efficient, then $987 \mathrm{X} 0.86=849 \mathrm{~kJ}(236 \mathrm{Wh})$ would be added to the energy stored in the flywheel rotor.

This calculation assumes that all of the energy from deceleration goes to the flywheel. As far as reasonably achievable, we want to capture as much of the braking energy as possible.

Therefore, the flywheel developer has a choice to size the flywheel based on bounding case acceleration or bounding case deceleration. Even though the acceleration energy (1148 kJ or 319 $\mathrm{Wh}$ ) is higher than the deceleration energy ( $849 \mathrm{~kJ}$ or $236 \mathrm{Wh})$, it is logical to use the deceleration energy to determine the energy storage requirement for the flywheel, because the prime power source can provide part of the required energy during acceleration. Therefore, for a flywheel capable of a full 100\% energy recovery during the assumed maximum deceleration event with an $1800 \mathrm{~kg}$ vehicle, the designer will design a flywheel capable of delivering no more than $849 \mathrm{~kJ}(236 \mathrm{Wh})$.

In normal daily driving, most of the deceleration/acceleration cycles will require much less energy than the assumed maximum deceleration event. The overall optimum efficiency will be 
achieved with a flywheel which is sized to handle somewhat less than the maximum deceleration event; perhaps at the $70 \%$ or $80 \%$ level. The result will be a lighter flywheel and the increase in fuel economy will be higher than for the case where the flywheel can handle $100 \%$. If the flywheel is designed for $100 \%$ energy recovery during the maximum deceleration event, then extra weight is being carried and it is seldom used. With the slightly smaller flywheel, it would be necessary to use friction braking to dissipate some of the energy during the maximum deceleration event. If the flywheel is designed for about $75 \%$ of the assumed maximum deceleration event, then the flywheel would be capable of delivering no more than $637 \mathrm{~kJ}(177$ Wh).

The control system for the flywheel storage unit must be able to control the state of charge so that when acceleration is desired, the flywheel rotor is near full speed and ready to deliver the required amount of energy. Similarly, during deceleration, when the flywheel must absorb the required amount of energy, it is essential that the flywheel rotor be near the minimum normal operating speed so that the flywheel can absorb the energy from braking. Maintaining this state of preparedness will require the velocity of the flywheel rotor to be varied approximately inversely proportional to the velocity of the vehicle. Consider the case where the vehicle is cruising at an intermediate speed of $40 \mathrm{mph}$. The flywheel unit needs to be at an intermediate speed, ready to deliver energy if acceleration is requested or to absorb energy if braking is requested.

The example above assumed an $1800 \mathrm{~kg}$ family sedan. In designing a flywheel for a different vehicle, the kinetic energy and the potential energy both vary with the mass of the vehicle; therefore, the flywheel deliverable energy would need to be scaled by the vehicle mass. Table E1 shows a variety of potential vehicle applications and the energy storage requirement for each vehicle.

Table E-1. Energy Storage Requirement for Different Vehicles

\begin{tabular}{|c|c|c|c|}
\hline Vehicle Class & $\begin{array}{c}\text { Vehicle Weight } \\
(\mathrm{kg})\end{array}$ & $\begin{array}{c}\text { Flywheel Design } \\
100 \% \text { recovery* }\end{array}$ & $\begin{array}{c}\text { Flywheel Design } \\
75 \% \text { recovery* }\end{array}$ \\
\hline Compact & 1500 & $708 \mathrm{~kJ}(197 \mathrm{Wh})$ & $531 \mathrm{~kJ}(148 \mathrm{Wh})$ \\
\hline Midsize Sedan & 1585 & $748 \mathrm{~kJ}(208 \mathrm{Wh})$ & $561 \mathrm{~kJ}(156 \mathrm{Wh})$ \\
\hline Family Sedan & 1800 & $849 \mathrm{~kJ}(236 \mathrm{Wh})$ & $637 \mathrm{~kJ}(177 \mathrm{Wh})$ \\
\hline Midsize SUV & 1935 & $913 \mathrm{~kJ}(254 \mathrm{Wh})$ & $685 \mathrm{~kJ}(514 \mathrm{Wh})$ \\
\hline Large SUV & 2320 & $1094 \mathrm{~kJ}(304 \mathrm{Wh})$ & $821 \mathrm{~kJ}(228 \mathrm{Wh})$ \\
\hline
\end{tabular}

* \% of energy recovered from a bounding case deceleration event, which is assumed to be deceleration down an interstate ramp (6 meters elevation change) from $70 \mathrm{mph}$ to $0 \mathrm{mph}$.

Based on this reconsideration of the required energy storage specification, it appears that the range of interest for light duty vehicles is about 531-821 kJ (148-228 Wh), based on the 75\% recovery target. This is slightly less than one-half of the energy storage level of 1080-1800 kJ (300-500 Wh) per USABC as stated in Table 4-5 "Flywheels compared with USABC Power Assist HEV Battery Goals," which was the basis for the flywheel energy storage requirement in Table 2-1 for light-duty vehicles. 
Reconsideration of the specifications for flywheel energy storage was prompted by excellent input from Jon Hilton of Flybrid Systems. He is using an even less aggressive bounding case deceleration event. He suggests the maximum recovery for the $1800 \mathrm{~kg}$ family vehicle should be based on deceleration from $50 \mathrm{mph}$, therefore his $100 \%$ recovery energy is only $450 \mathrm{~kJ} X 0.86=$ $387 \mathrm{~kJ}(108 \mathrm{Wh})$. He also suggests using something lower than $100 \%$ recovery, which makes the value even smaller. The energy values suggested by Hilton are about one-half of the values shown in our calculation above in Table E-1. (The kinetic energy at $50 \mathrm{mph}$ is only about half of the kinetic energy at $70 \mathrm{mph}$.)

Postlude:

Reconsideration of the specifications for flywheel energy storage is in line with new USABC goals for the high power, Lower Energy- Energy Storage System (LEESS) for Power Assist Hybrid Electric Vehicle (PAHEV) applications. The new LEESS goals call for a smaller and lighter, lower-cost battery cell with lower energy storage, higher regenerative power capability and improved cold-crank capability. USABC LEESS requirements in Table E-2 were included as Appendix A of a USABC request for proposal information (Reference 35).

Table E-2. USABC Requirements at End of Life for LEESS PAHEV

\begin{tabular}{|c|c|c|}
\hline End of Life Characteristics & Unit & PA (Lower Energy) \\
\hline 2s / 10s Discharge Pulse Power & $\mathrm{kW}$ & \begin{tabular}{l|l}
55 & 20 \\
\end{tabular} \\
\hline 2s / 10s Regen Pulse Power & $\mathrm{kW}$ & 40 \\
\hline Discharge Requirement Energy & $\mathrm{Wh}$ & 56 \\
\hline Regen Requirement Energy & Wh & 83 \\
\hline Maximum current & $\mathrm{A}$ & 300 \\
\hline Energy over which both requirements are met & Wh & 26 \\
\hline Energy window for vehicle use & Wh & 165 \\
\hline Energy Efficiency & $\%$ & 95 \\
\hline Cycle-life & Cycles & $300,000(\mathrm{HEV})$ \\
\hline $\begin{array}{l}\text { Cold-Cranking Power at }-30^{\circ} \mathrm{C} \text { (after } 30 \text { day } \\
\text { stand at } 30^{\circ} \mathrm{C} \text { ) }\end{array}$ & $\mathrm{kW}$ & 5 \\
\hline Calendar Life & Years & 15 \\
\hline Maximum System Weight & $\mathrm{kg}$ & 20 \\
\hline Maximum System Volume & Liter & 16 \\
\hline Maximum Operating Voltage & $\mathrm{Vdc}$ & $\leq 400$ \\
\hline Minimum Operating Voltage & $\mathrm{Vdc}$ & $\geq 0.55 \mathrm{~V}_{\max }$ \\
\hline Unassisted Operating Temperature Range & ${ }^{\circ} \mathrm{C}$ & -30 to +52 \\
\hline $30^{\circ}-52^{\circ}$ & $\%$ & 100 \\
\hline $0^{\circ}$ & $\%$ & 50 \\
\hline$-10^{\circ}$ & $\%$ & 30 \\
\hline$-20^{\circ}$ & $\%$ & 15 \\
\hline$-30^{\circ}$ & $\%$ & 10 \\
\hline Survival Temperature Range & ${ }^{\circ} \mathrm{C}$ & -46 to +66 \\
\hline Selling Price/System @ 100k/yr) & $\$$ & 400 \\
\hline
\end{tabular}


Note that the discharge and regen requirement energies are 56 and $83 \mathrm{Wh}$, which are somewhat less than the 108 Wh suggested by Jon Hilton of Flybrid Systems, as previously discussed. USABC initiated contracts in 2011 based on the requirements in Table E-2. 


\section{INTERNAL DISTRIBUTION}

1. W. J. Allington

2. G. P. Andrews

3. P. J. Blau

4. R. G. Boeman

5. E. N. Coffey

6. B. Damiano

7. C. Daniel

8. C. C. Eberle

9. B. J. Frame

10. R. L. Graves

11. J. G. Hansen

12. T. J. King, Jr.

13. G. M. Ludtka

14. C. R. Luttrell

15. J. M. Miller

16. R. E. Norris, Jr.

17. M. Olszewski

18. F. L. Paulauskas

19. D. E. Smith

20. T. M. Smith

21. J. M. Starbuck

22. M. R. Starke

23. B. W. Van Hoy

24. R. M. Wagner

25. C. D. Warren

26. D. E. Welch

27. B. H. West

28. K. D. Yarborough

\section{EXTERNAL DISTRIBUTION}

29. T. Q. Duong, U.S. Department of Energy, EE-2A/L'Enfant Plaza Building, 1000 Independence Ave., S.W., Washington, DC 20585-1615

30. D. Gardner, NREL

31. R. Hawsey, NREL

32. D. Howell, U.S. Department of Energy, EE-2G/Forrestal Building, 1000 Independence Ave., S.W., Washington, DC 20585

33. D. U. O'Kain, Oak Ridge Turnpike, Oak Ridge, TN 37830

34. L. A. Slezak, U.S. Department of Energy, EE-2G/Forrestal Building, 1000 Independence Ave., S.W., Washington, DC 20585 